\title{
EVALUATING THE EFFECTIVENESS OF A HYBRID GEOSYNTHETIC REINFORCEMENT SYSTEM TO MITIGATE DIFFERENTIAL HEAVE ON FLEXIBLE PAVEMENT DUE TO EXPANSIVE SUBGRADES
}

\section{by}

Mir Md. Tamim

\author{
A thesis \\ submitted in partial fulfillment \\ of the requirements for the degree of \\ Master of Science in Civil Engineering at \\ Boise State University
}

December 2017 
(C) 2017

Mir Md. Tamim

ALL RIGHTS RESERVED 


\section{BOISE STATE UNIVERSITY GRADUATE COLLEGE}

\section{DEFENSE COMMITTEE AND FINAL READING APPROVALS}

of the thesis submitted by

Mir Md. Tamim

Thesis Title: Evaluating the Effectiveness of a Hybrid Geosynthetic Reinforcement System to Mitigate Differential Heave on Flexible Pavement due to Expansive Subgrades

Date of Final Oral Examination: 8 November 2017

The following individuals read and discussed the thesis submitted by student Mir Md. Tamim and they evaluated his presentation and response to questions during the final oral examination. They found that the student passed the final oral examination.

Bhaskar Chittoori, Ph.D., P.E. Chair, Supervisory Committee

Debakanta Mishra, Ph.D., P.E. Co-Chair, Supervisory Committee

Arvin Farid, Ph.D., P.E. Member, Supervisory Committee

Jairo Hernandez, Ph.D., P.E. Member, Supervisory Committee

The final reading approval of the thesis was granted by Bhaskar Chittoori, Ph.D., P.E., Chair of the Supervisory Committee. The thesis was approved by the Graduate College. 


\section{DEDICATION}

This thesis work is dedicated to my parents. 


\section{ACKNOWLEDGEMENTS}

First of all, I would like to extend my sincere gratitude to my advisor, Dr. Bhaskar Chittoori, for his tireless support and guidance throughout all phases of this research study. As a mentor, he has not only guided me but also walked with me along the path to reach my goal. His limitless dedication, determination and keen knowledge toward any problem always gave me the motivation to complete my work. He is always a good listener to figure out the problem in a precise and elegant manner. His door was always open to me when I needed help, no matter the circumstance. It is my pleasure and honor to have a supervisor like Dr. Chittoori.

I am also grateful to my co-advisor Dr. Debakanta Mishra for his guidance and patience in helping me to learn new concepts during the course of my research work. His keen knowledge and continuous feedback provided me better understanding of my research study. I would like to express my sincere gratitude to my committee members, Dr. Arvin Farid and Dr. Jairo Hernandez for their valuable advice and suggestions.

I would like to acknowledge Mr. Keith Nottingham of Idaho Transportation Department, Mr. Mark Sikkema of Tencate and Mr. Andy Clark of Contech Engineered Solutions for their help to get the materials for this research. I also would like to extend my special thanks to my friends Kazi Moinul Islam, Md. Touhidul Islam, Md Jibon, and Haider Malik for their help during the laboratory and modeling works. I am also thankful to Rhonda Magill of Boise State University who took care of all the administrative processing during the course of this research.

I want to express my deepest gratitude and appreciation to my parents, mother-inlaw, Tahsin, Tousif and Parom for their enormous patience, comprehension, support and 
love all through my life. I am also thankful to all my friends for their constant support and encouragement.

Finally, I would like to acknowledge my better half Karishmae Kadrager for waiting up many late nights for my arrival after working late. Her encouragement, support, patience and unparalleled love are undoubtedly the most precious gifts of my life. 


\begin{abstract}
Transportation agencies encounter substantial challenges with respect to ride quality and serviceability when they deal with expansive soils underneath roadway structures. These soils exhibit swell-shrink behavior with moisture variations, which cause surficial heaving on the pavement structure and cost billions of dollars for the maintenance of pavements. For the past four decades, a particular stretch of US-95 (Oregon line to Elephant Butte) exhibited recurrent swelling distresses due to the underlying expansive soils. Despite remedial measures that exhibited satisfactory results for most of the sections, recurrent damage still continued in few sections. Further research indicated that the problematic soils were located at a depth below $1.8 \mathrm{~m}$. Conventional chemical remediation methods typically performed at a depth no greater than 0.9 to $1.2 \mathrm{~m}$. To be able to address the adverse effects of this swell-shrink behavior of soil at a deeper depth, hybrid geosynthetic systems were proposed. Hybrid geosynthetic systems were successfully used to mitigate expansive soil swelling in railroad applications. Hence, this research study explored this idea of using hybrid geosynthetic reinforcement systems (geocell-geogrid combination) to mitigate differential pavement heaving resulting from underlying expansive soils.

To evaluate the use of hybrid geosynthetic systems to reduce differential heaving from expansive subgrades, a large-scale box test was developed to simulate a pavement section with a base course and expansive subgrade (asphalt layer was ignored). The surficial heave on the base course reinforced with geocell, geogrid and Hybrid
\end{abstract}


Geosynthetic Reinforcement System (HGRS) were measured over time and compared with the unreinforced case. The large-scale box test results showed that the geosynthetic systems significantly reduced the maximum surficial heave along with the differential swelling on the pavement section. The pavement section comprising HGRS exhibited better performance compared to those comprising only geocells or geogrids.

Numerical analysis using the finite element approach was conducted to study the response of other soil types not tested in the box. The numerical model was first calibrated using the box test results and the calibrated model was used to change soil properties for two other soil types with different swelling characteristics. In the numerical model, swelling behavior of expansive soils was simulated using material models that incorporate volumetric swelling and suction as a function of moisture content. The modulus of the unreinforced base was determined using laboratory tests while the modulus that for the reinforced sections were calibrated using large scale test data. The calibration of control model was performed by controlling the moisture percolation through subgrade. The improvements of the reinforced models were reflected by higher modulus of reinforced base. These calibrated models were used to conduct a parametric study by varying the subgrade swell characteristics and the modulus of reinforced base. The parametric study revealed that the expansive soils with higher suction and swelling characteristics exhibited higher swelling than the expansive soils with lower suction and swelling characteristics. It was observed that the reinforcing effect was higher for soils with lower swelling characteristics. Additionally, parametric study with varying modulus of reinforced base showed that the reinforced base system with higher modulus showed better performance than a reinforced base system with lower modulus. 


\section{TABLE OF CONTENTS}

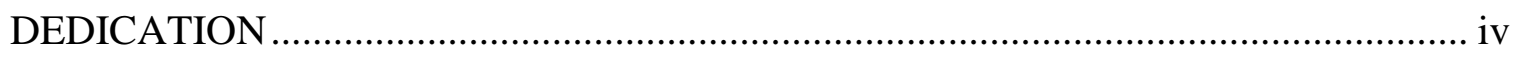

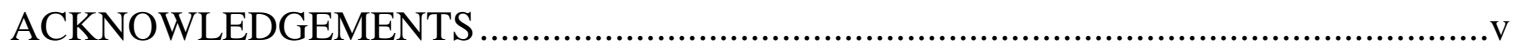

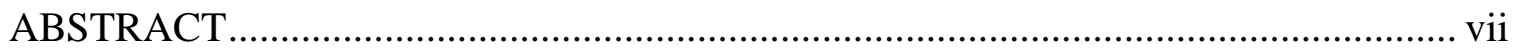

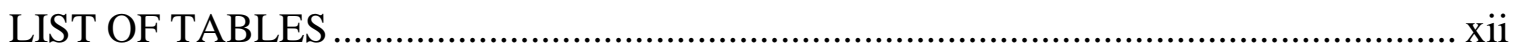

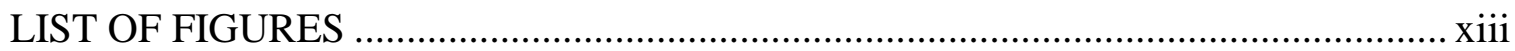

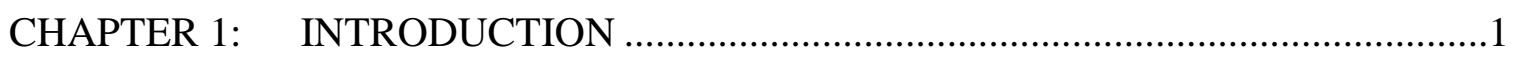

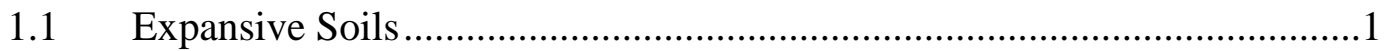

1.2 Expansive Soil Problems in South West Idaho..............................................

1.3 Other Heave Mitigation Alternatives ......................................................6

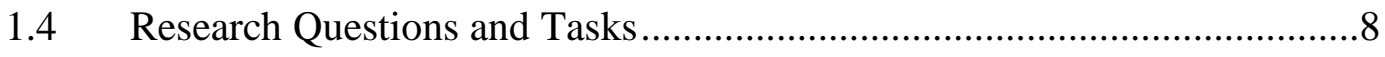

1.5 Outline of the Thesis Document …………….....................................10

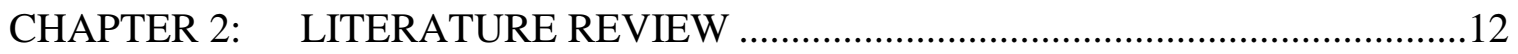

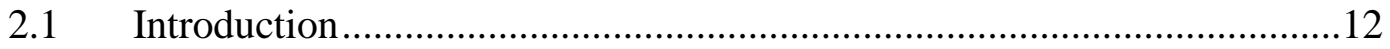

2.2 Expansive Soils and Problems Associated with Them ..............................12

2.3 Prediction Methods to Measure Volumetric Movement of Expansive Soils 17

2.3.1 Analytical Methods to Predict Expansive Swelling .......................18

2.3.2 Numerical Methods to Predict Expansive Swelling........................21

2.4 Current Methods to Mitigate Expansive Soil Issues...................................23

2.5 Limitations of Current Mitigation Methods...............................................26

2.6 Potential of Geosynthetics to Stabilize Expansive Soils in Flexible

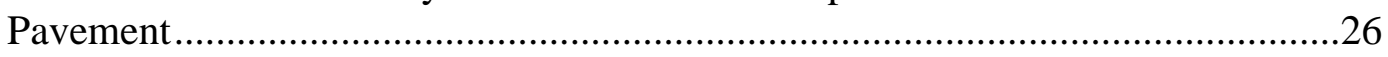

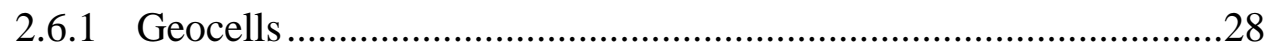


2.6.3 Hybrid Geosynthetic Reinforcement System-HGRS (Geocell-

Geogrid Combination) ..................................................................40

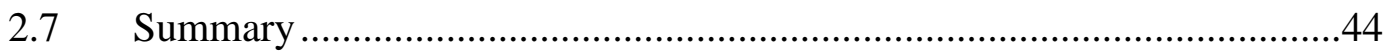

CHAPTER 3: $\quad$ LARGE-SCALE BOX SYSTEM ....................................................45

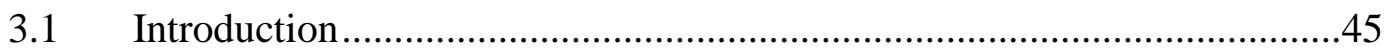

3.2 Development of Large-Scale Test Setup .........................................45

3.3 Materials used for the Large-Scale Box System..................................49

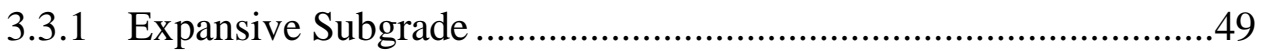

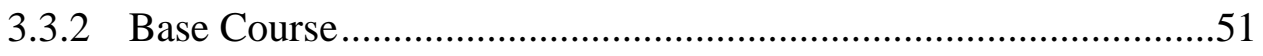

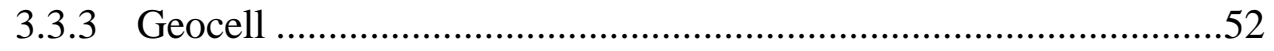

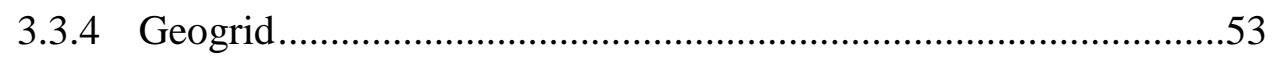

3.4 Large-Scale Box Test Configurations................................................54

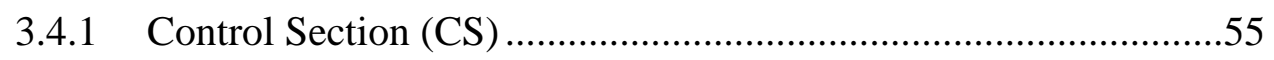

3.4.2 Geocell Reinforcement (GC) ..........................................57

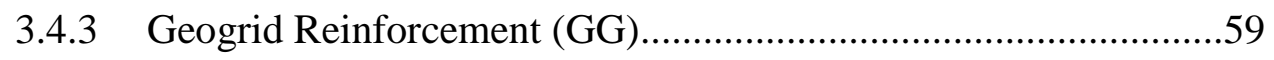

3.4.4 Hybrid Geosynthetic Reinforcement System (HGRS) ...............60

3.5 Large-Scale Box Test Results .......................................................61

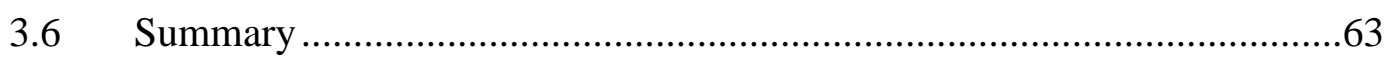

CHAPTER 4: NUMERICAL ANALYSIS OF LARGE-SCALE BOX TEST............64

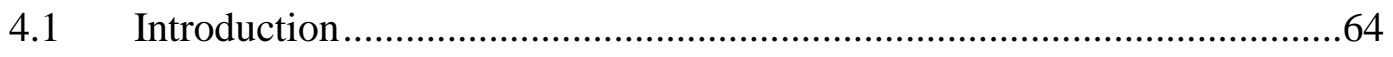

4.2 Finite Element Model Development ...............................................64

4.4.1 Control Section Model (CSM) .........................................65

4.4.2 Model with Geocell Reinforcement (MGC) ............................77 
4.4.3 Model with Geogrid Reinforcement (MGG)

4.4.4 Model with Hybrid Geosynthetic Reinforcement System (MHGRS)

4.4 Calibration Approach and Numerical Analysis Results .92

4.5 Parametric Study to Evaluate HGRS Performance.....................................94

4.5.1 Varying Subgrade Swell Characteristics ........................................94

4.5.2 Varying Reinforced Base Elastic Modulus ....................................98

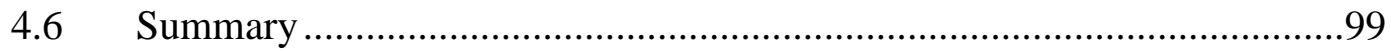

CHAPTER 5: $\quad$ SUMMARY, CONCLUSIONS, AND RECOMMENDATIONS.......101

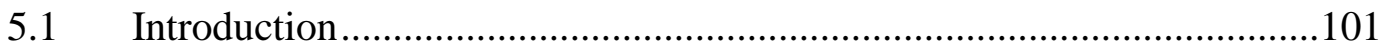

$5.2 \quad$ Summary and Conclusions …………………....................................101

5.3 Recommendations for Future Research ................................................102

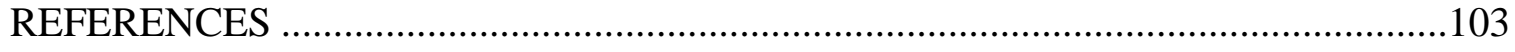

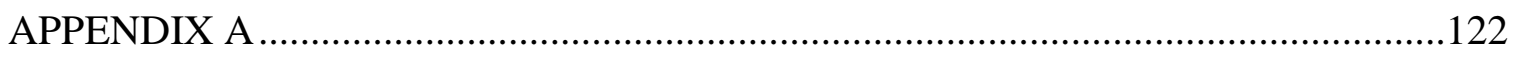

Large-Scale Box Test Materials Characterization ..............................................122 


\section{LIST OF TABLES}

Table 2.1 Primary functions of Geosynthetics (Han 2015) ................................. 27

Table $3.1 \quad$ Results of Atterberg Limit Tests........................................................ 50

Table 3.2 Results of Moisture Density Relationship ........................................ 51

Table $3.3 \quad$ Gradation Analysis Results ........................................................... 51

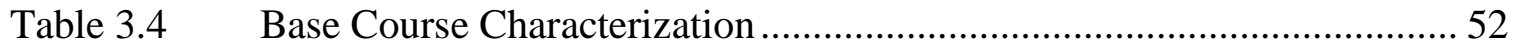

Table $3.5 \quad$ Geocell Material Characteristics.......................................................... 52

Table 3.6 Geogrid Material Characteristics (TenCate 2017) ................................. 53

Table 4.1 Engineering Properties of Pavement Materials used in the CSM............ 67

Table $4.2 \quad$ Element Type and Numbers in CSM ............................................... 76

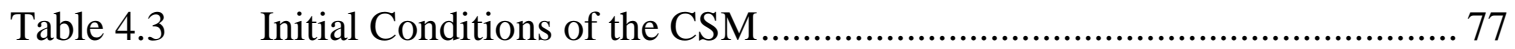

Table 4.4 Engineering Properties of Pavement Materials used in the MGC ........... 79

Table 4.5 Element Type and Element Numbers in MGC .................................... 81

Table 4.6 Engineering Properties of Pavement Materials Used in the MGG .......... 84

Table 4.7 Element Type and Element Numbers in MGG .................................... 85

Table 4.8 Engineering Properties of Pavement Materials used in the MHGRS ....... 88

Table $4.9 \quad$ Element Type and Element Numbers in MHGRS ................................. 91

Table 4.10 Properties of the ES-2 and ES-3 Soil Samples ..................................... 95

Table 4.11 Engineering Properties of ES-2 and ES-3 as Input for Numerical Models 


\section{LIST OF FIGURES}

Figure 1.1 Swelling clay map of the conterminous United States (Olive et al. 1989). 2

Figure 1.2 Annual cost of damage to structures underneath expansive soils in the USA since 1973 (modified from Adem and Vanapalli 2016) .................... 2

Figure 1.3 Pavement Distresses on US 95 pavement section (MP 16.7 to MP 18.5) due to expansive subgrade ...................................................................... 5

Figure 1.4 Flow Chart showing the Research Approach of the Thesis Work............ 10

Figure 2.1 Illustration of Montmorillonite Structure (Heyer 2012) .......................... 14

Figure 2.2 Crack Types Associated with Expansive Soils (Dafalla and Shamrani

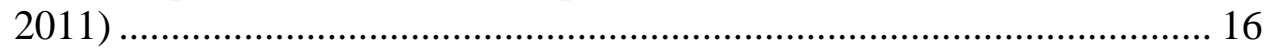

Figure 2.3 Mechanisms involved in Crack Relocation (Zornberg et al. 2012) .......... 17

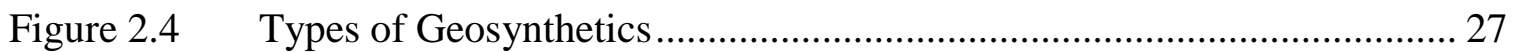

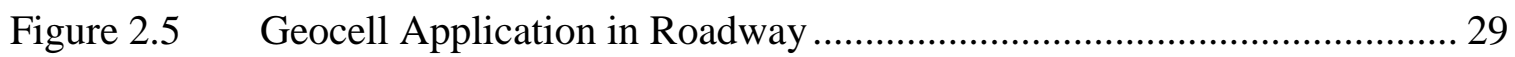

Figure 2.6 Reinforcing Mechanism of Geocells (Tsorani 2008)............................... 30

Figure 2.7 Types of Geogrid (Das 2010) ……………........................................... 35

Figure 2.8 Reinforcing effect of Geogrid (a) Lateral resistance; (b) Increased bearing capacity; and (c) Membrane effect (Holtz et al. 1998) .............................. 36

Figure 2.9 Geocell-Geotextile Hybrid System ......................................................... 40

Figure 2.10 Reinforcing Mechanism of HGRS ………............................................ 41

Figure 2.11 Proposed foundation scheme to support embankment using GeocellGeogrid Combination (Sitharam and Hedge, 2013) ................................ 42

Figure 2.12 Cross Section of Hybrid Geosynthetic Solution (Kief 2015) ................... 43

Figure 3.1 Detail Schematic of Large-Scale Box System ........................................... 46

Figure $3.2 \quad$ Transparent Box ........................................................................... 46

Figure 3.3 Moisture Percolation in the Box ………………................................... 46 
Figure 3.4 Soaker System Arrangement........................................................... 47

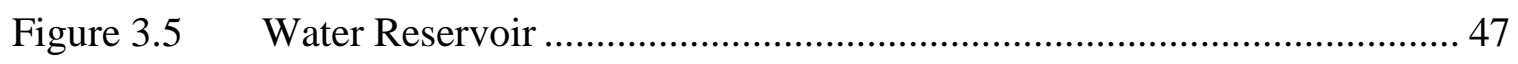

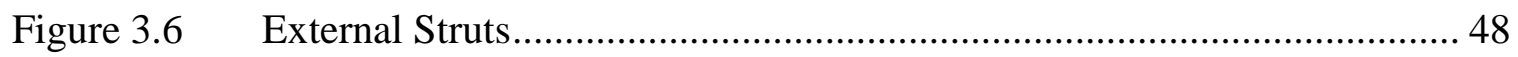

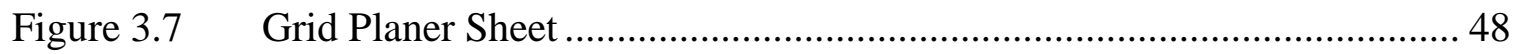

Figure $3.8 \quad$ Laser Distance Measuring Tool .................................................... 48

Figure 3.9 Complete Set-up of the Large-Scale Box System................................. 49

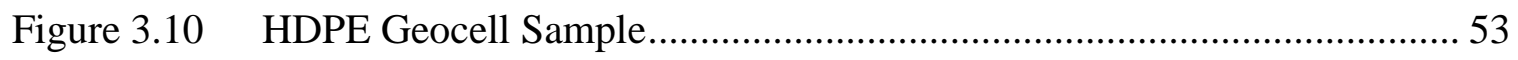

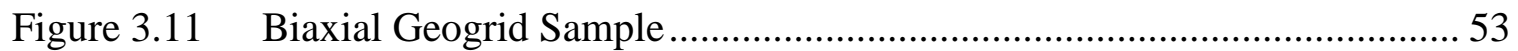

Figure 3.12 Schematics of Test Configurations ................................................... 54

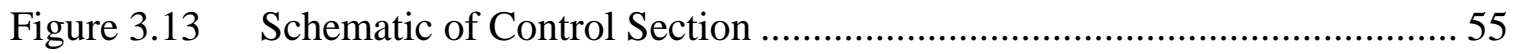

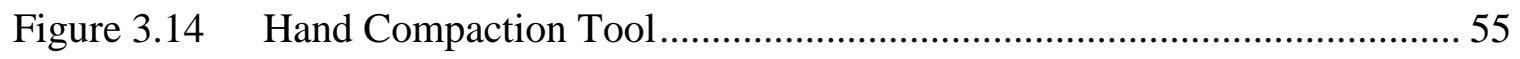

Figure 3.15 Placement of Soaker System at the Top Half of Subgrade ..................... 57

Figure 3.16 Control Section after Compaction ….............................................. 57

Figure 3.17 Moisture Supply through Water Reservoir ........................................ 57

Figure 3.18 Measurement of Vertical Swelling .................................................... 57

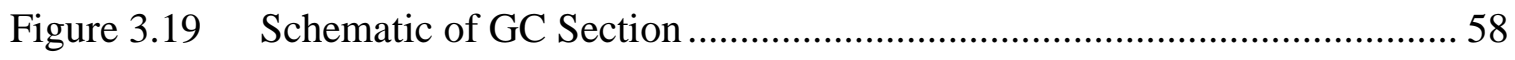

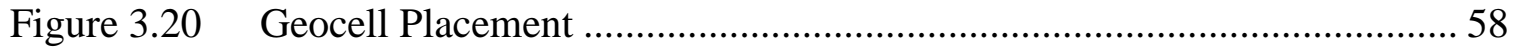

Figure 3.21 GC Section after Compaction ........................................................ 58

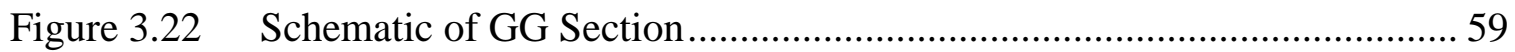

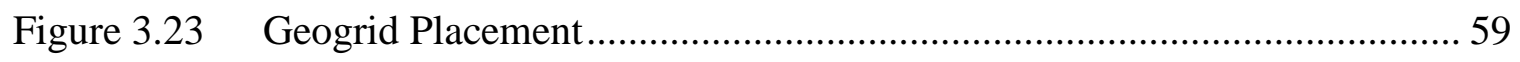

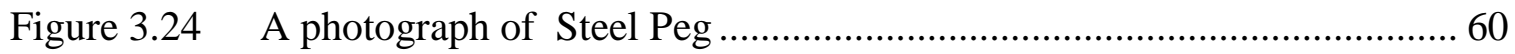

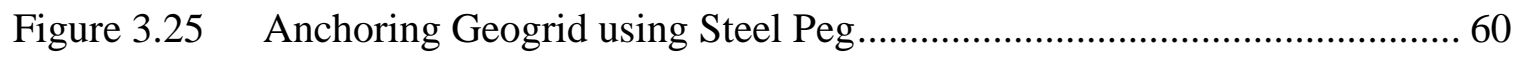

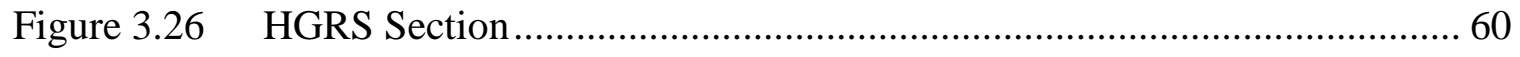


Figure 3.27 Geogrid Installation in HGRS Section.................................................. 61

Figure 3.28 Geocell Installation in HGRS Section ................................................... 61

Figure 3.29 Maximum Heaving Plot over Time …………………………….......... 62

Figure 3.30 Comparisons of Percent Swell Reductions for the Three Reinforced Test

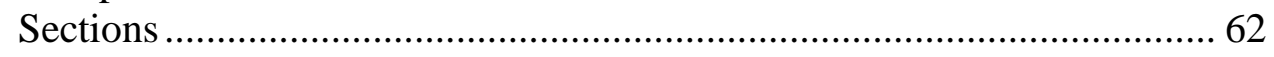

Figure 4.1 Geometry of the Control Section Model (CSM)....................................... 66

Figure 4.2 Typical Absorption and Exsorption Behavior of Porous Medium (Dassault

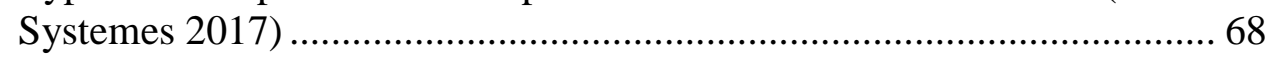

Figure 4.3 Soil Specimen Prepared for Matric Suction Measurement........................ 69

Figure 4.4 Soil Specimen Prepared for Total Suction Measurement.......................... 69

Figure 4.5 Input data for Sorption Behavior of ES-1 Soil....................................... 70

Figure 4.6 Typical Volumetric Swelling vs Saturation Curve of Porous Medium (Dassault Systemes 2017) ........................................................................ 71

Figure 4.7 Inundation of Soil Sample in Water Bath ............................................. 72

Figure 4.8 Measurement of Radial Swell using Pi-Tape.......................................... 72

Figure 4.9 Input data for Moisture Swelling Model.............................................. 73

Figure 4.10 Boundary Conditions in CSM.............................................................. 74

Figure 4.11 Convergence Study to Optimize Mesh Size .............................................. 75

Figure 4.12 Meshing of the CSM Model Section ……............................................. 75

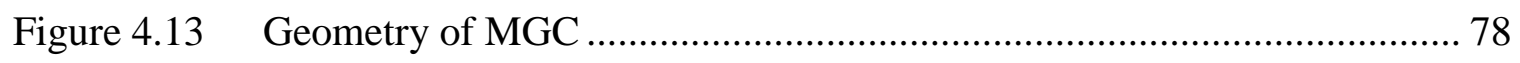

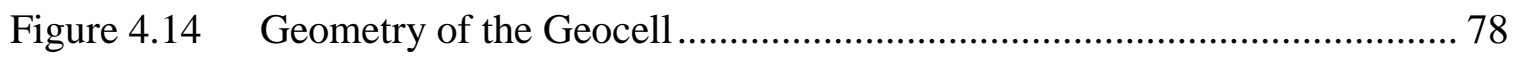

Figure 4.15 Boundary Conditions of MGC .............................................................. 80

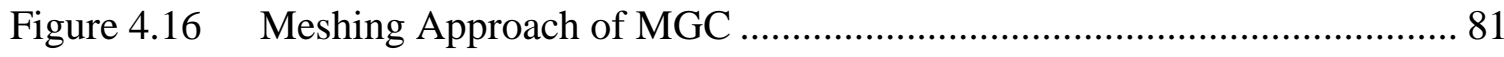

Figure 4.17 Meshing Approach of Geocell ............................................................. 81

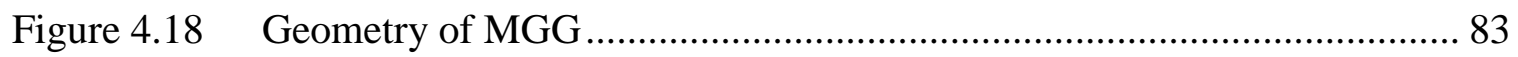




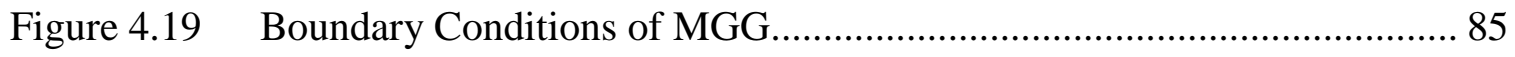

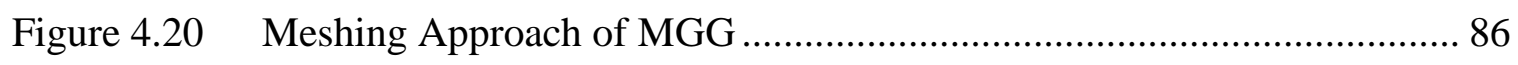

Figure 4.21 Meshing Approach of Geogrid Sheet ................................................. 86

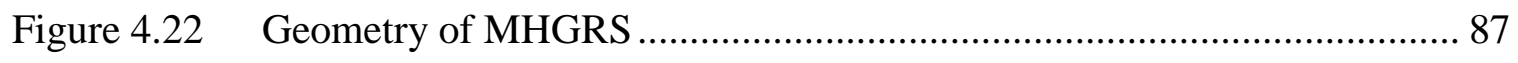

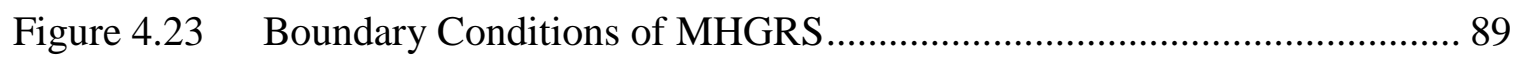

Figure 4.24 Meshing Approach of MHGRS …................................................. 90

Figure 4.25 Calibration Results from the Numerical Analysis ............................... 92

Figure 4.26 Displacement Contours for the Numerical Models ............................... 93

Figure 4.27 Comparison of Experimental and numerical results ............................. 94

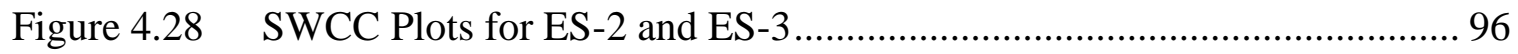

Figure 4.29 Volumetric Swell Test Results for ES-2 and ES-3 ............................. 96

Figure 4.30 Vertical Deformation Contour of HGRS for ES-2 .............................. 97

Figure 4.31 Vertical Deformation Contour of HGRS ES-3 .................................. 97

Figure 4.32 Percent Reduction of Maximum Heave for Different soils .................... 98

Figure 4.33 Percent Reduction of Differential Heave for Different soils .................. 98

Figure 4.34 \% Reduction of Maximum Heave for Reinforced Base Layer with varying

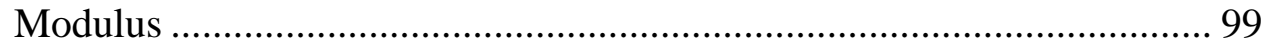

Figure 4.35 \% Reduction of Differential Heave for Reinforced Base Layer with varying Modulus ............................................................................ 99 


\section{CHAPTER 1: INTRODUCTION}

\subsection{Expansive Soils}

Expansive soils have adverse effects on lightly loaded structures such as pavements and residential buildings as they are susceptible to volumetric increase or decrease due to the variation in water content (Nelson and Miller 1992; Chen 1988). These natural high plasticity soils typically contain clay mineral montmorillonite that exhibits high swelling with the increase of water content (Chen 1988). These types of soils are mostly found in arid and semi-arid climatic regions (Hussein 2001). The United States is one of the major sources of expansive soils and they occur in all 48 states of the conterminous United States (Chen 1988). Olive et al. (1989) developed a map to visualize the extent of swelling soils in the USA as shown in Figure 1.1. This map represents the geologic units that contain the soils with varying swelling potentials. Purple and blue indicate high swelling potential, whereas orange, green and brown indicate moderate to very little swelling potential. Yellow indicates insufficient information to predict swelling potential which is mostly located in the north-west parts of United States. The map shows that expansive soils are distributed all over the United States especially in western and midwestern parts. Therefore, it is almost impossible to alter highway routes to avoid these problematic soils due to their wide distribution in USA (Johnson et al. 1975). Each year, these soils cause greater damage and financial losses to structures than natural disasters (Jones and Holtz, 1973). 


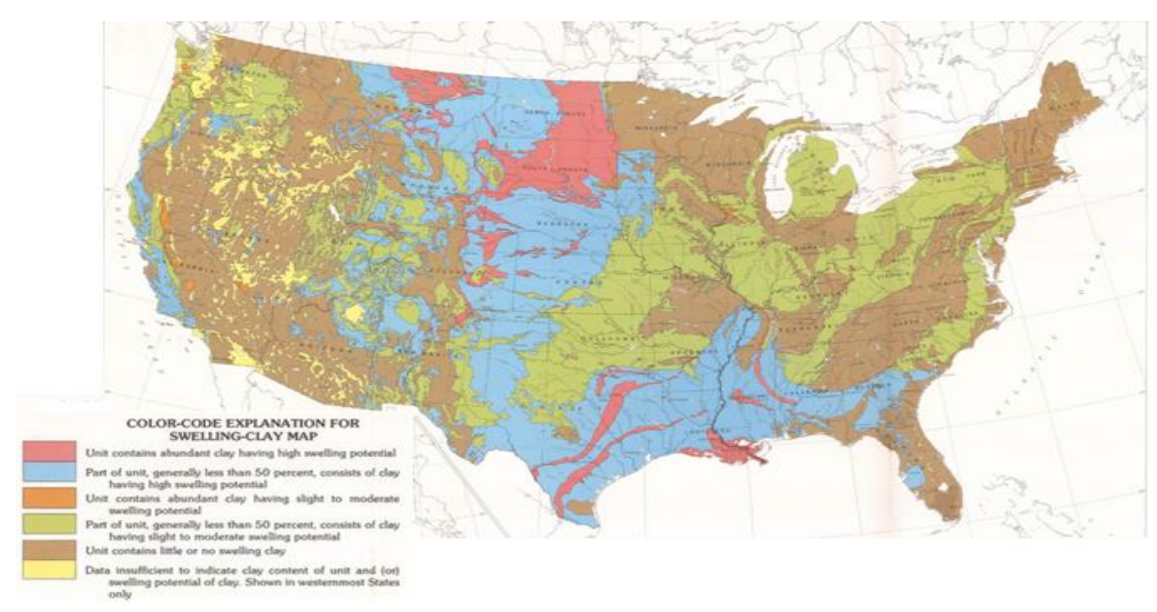

Figure 1.1 Swelling clay map of the conterminous United States (Olive et al. 1989)

Although these soils do not cause loss of life as natural calamities such as earthquakes or hurricanes, the property damage caused by these soils is in the order of billions of dollars (Coduto 2015). Figure 1.2 presents the annual damage cost of structures due to the swell-shrink behavior of soils in the USA since 1973. It is clearly shown that the cost of damage is increasing day by day and it is almost impossible to avoid problematic soils because of the widespread distribution of problematic soils in the USA. So, this kind of problems will occur as long as the structural construction is going on.

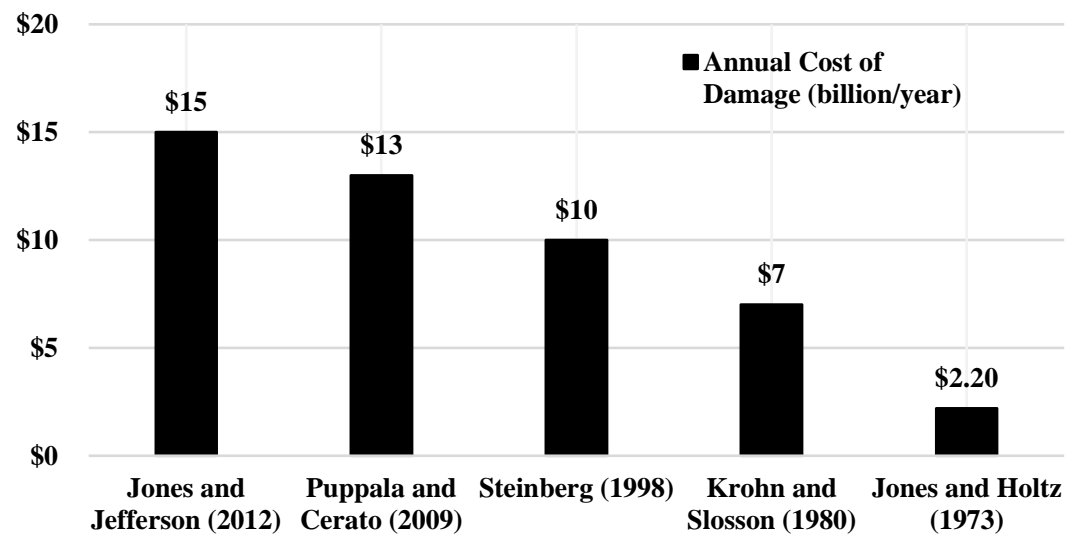

Figure 1.2 Annual cost of damage to structures underneath expansive soils in the USA since 1973 (modified from Adem and Vanapalli 2016) 
Flexible pavements constructed on expansive soils are subjected to uplift pressures due to the heaving nature of these soils. These uplift pressures cause pavement cracking and heaving, there by causing riding discomforts to travelers (Kassiff et al. 1969; Djellali et al. 2012). Consequently, pavement authorities are forced to spend on rehabilitation of the distressed pavements (Al-Qadi et al. 2009).

\subsection{Expansive Soil Problems in South West Idaho}

U.S. Route 95 (US 95) highway continues north-south near the western boundary of Idaho and runs over 865.8 kilometers from Oregon to British Columbia (US 95 2016). A segment of US 95 highway from Oregon Line to Elephant Butte (milepost 0 to 18.5) in Owyhee County has gone through several reconstructions over last four decades (Hardcastle 2003; Chittoori et al. 2016) due to underlying expansive soils. Several rehabilitation attempts were made for this pavement section to mitigate the distresses caused by expansive soils (Hardcastle 2003; Chittoori et al. 2016). During that period, compaction and lime stabilization were dominant as remedial measures. Nottingham (1988) reported an exhaustive study to define the soils and associated distresses within the study area and suggested lime stabilization as a remedial measure to mitigate the pavement distresses.

A more comprehensive investigation on the US 95, Owyhee County soils was conducted by Hardcastle (2003). The prime observations of Harcastle's study were that soils of the existing alignment of US 95 were not entirely expansive and not all the distresses were related to swelling soils. Heave related distresses mainly found at the transitions between cut and fill sections (grade points) and near natural soil surfaces in comparatively plain areas with colluvial materials. The explanation behind the distresses 
at those locations was that regardless of the requirements to use non-expansive borrow material for the fill, there might be a high possibility that potentially expansive soil adjacent to the cut sections were used to construct the fill sections at grade points. Due to the higher initial suction of the compacted expansive soil and increased exposure to surface water at these locations, substantial pavement distresses were observed. Additionally, compaction of soils near natural soil surfaces in comparatively plain areas with colluvial materials. Figure 1.3 represents the surficial distresses in the US 95 pavement section.

As a remedial measure to this problematic soil, several alternatives were proposed for existing and new pavements. For the existing pavements, two alternatives were suggested to minimize future heaving. One of the alternatives was to provide a continuous horizontal membrane from the surface of the pavement to the bottom of the existing ditch by utilizing shoulder and ditch paving in cut sections. Exposure of the subgrade to infiltration of surface water could be reduced by shoulder and ditch paving during and shortly after precipitation events and also prevented ponding of surface water. Deep vertical moisture barrier could be installed at the outside edges of the pavement as an alternative to paving the ditches. In case of pavement renovation, backfilling with nonexpansive soils could be an option to mitigate surficial heave. Lime stabilization could also be a remedial measure exposed soils in existing pavements. 

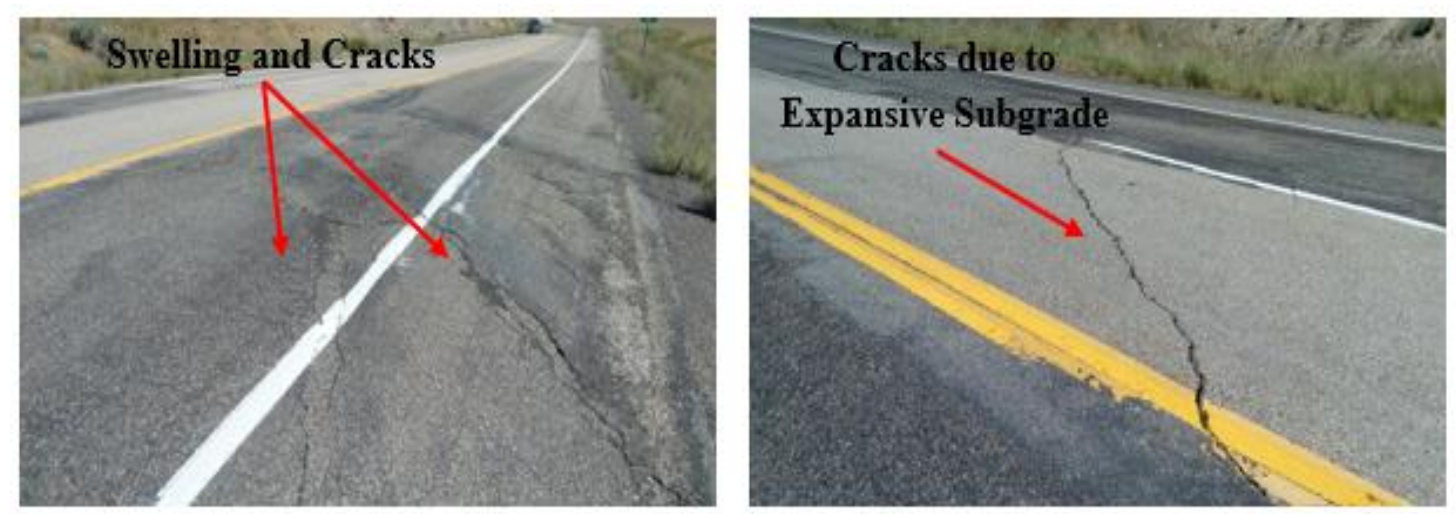

\section{Figure 1.3 Pavement Distresses on US 95 pavement section (MP 16.7 to MP 18.5) due to expansive subgrade}

For new construction, well-graded ballast materials with non-plastic fines with low permeability were recommended for the base. It can create an impermeable non-expansive layer which will prevent the movement of surficial water onto the surface of underlying soils. In case of unavailability of such base materials, conventional free-draining base materials with impervious asphalt or geosynthetic membrane on the surface of subgrade could be another option. Alternatively, lime stabilization was also proposed at a level of as high as nine percent with non-swelling backfill materials.

Hardcastle's recommendations were implemented in the field and most of the sections performed acceptably after lime stabilization. However, some of the sections (MP 16.7 to MP 18.5; MP - mile post) still exhibited surficial heaving on the pavement surface (Chittoori et al. 2016). To reveal this heaving phenomenon, Islam (2017) conducted an in-depth investigation into the subsurface characterization of the soils along US 95 between MP 16.7 to MP 18.5. The most significant finding of this study was the location of expansive soils. It was found that expansive soils were at a depth of about $1.83 \mathrm{~m}$. and below. Hence, shallow stabilizations with lime/cement are not appropriate, the depth of treatment is typically limited to less than $0.9 \mathrm{~m}$. Additionally, soluble sulfate 
test results exhibited high sulfate contents (>2000 ppm) in some of these soils. The presence of sulfates might lead to the formation of swelling minerals like ettringite when treated with calcium-based stabilizers, which can cause more damage than natural expansive soils (Puppala et al. 2012). Based on the above study, it was found that lime stabilization was not a long-term solution for swelling distresses.

\subsection{Other Heave Mitigation Alternatives}

Geosynthetic materials have been used to reduce pavement distresses for the past three decades (Fannin and Sigurdsson 1996; Perkins and Ismeik 1997; Perkins et al. 2004; Zornberg and Gupta 2009; Al-Qadi et al. 2011). Koerner (2012) reported that the total expenses of geosynthetic application were about $\$ 5$ billion all over the world in 2010. Geosynthetics offer varieties of function (i.e. separation, reinforcement, filtration) to increase the durability, design life and decrease the cost of construction.

Geosynthetics inclusion can play a significant role to reduce the swelling phenomenon in flexible pavements (Zornberg et al. 2008; Gupta 2009; Khodaii et al. 2009; Zornberg and Gupta 2010; Koerner 2012). Zornberg et al. (2008) reported that geosynthetics offered to reinforce against cracking of the pavement underneath expansive soils which indicate their potential to reduce the distress due to heave. Additionally, Geosynthetics can increase the modulus of confined granular materials (Yuu et al. 2008; Keif and Rajagopal 2008; Yang 2010; Pokharel 2010). The improvement of the reinforced layer is dependent on the material of infill, the stiffness of geosynthetics, subgrade and relative position of the confined layer (Kief et al. 2015). This reinforced confined layer has the potential to provide additional strength and offer resistance against the swelling pressure of expansive soils. 
Hybrid geosynthetic reinforced systems are a recent extension of the geosynthetic applications. Saride et al. (2011) studied the performance of basal geogrids to reduce the rutting effect of geocell reinforced weak subgrades. Sitharam and Hedge (2013) investigated the performance of geocell-geogrid combination over the soft settled red mud in embankments. Kief (2015) introduced a hybrid geosynthetic system to mitigate swelling distresses in railroad tracks. This solution comprised of geogrid and geocells which created a unique composite behavior that surpassed the sum of its individual components. This composite layer formed a semi-rigid platform that reduced the differential swelling distresses.

However, there were no research studies that studied the application of hybrid geosynthetics in pavement infrastructure built over expansive soils. Based on earlier studies presented here, it could be hypothesized that hybrid geosynthetic systems can be used to mitigate swelling distresses in flexible pavements. However, such hypothesis needs to be carefully studied before hybrid geosynthetic reinforcement systems can be used in pavement applications. It is important to demonstrate the swell reduction capabilities of HGRS in case of pavements built of the expansive subgrade. The mechanisms responsible for these mitigations should be properly understood. Additionally, the effect of soils swell potential on the effectiveness of HGRS should also be studied to establish threshold swell potentials beyond which these systems may not be applicable.

In an attempt to find a long-term solution for the US-95 section described in the previous section, and also to test the hypothesis that HGRS can mitigate swelling distresses, this research studied the application of HGRS to mitigate the swelling 
distresses reported in the US-95 section between MP 16.0 to 18.0. Pavement sections built on expansive soil from US-95 were replicated in a large-scale box and the effectiveness of geocells, geogrids, and combination of geocell and geogrid (HGRS) in mitigating surficial pavement heaving was tested. This data was later used to calibrate a finite element model that was developed to study the effect of different swell potentials.

\subsection{Research Questions and Tasks}

The primary research goal of this MS thesis is to evaluate the application of hybrid geosynthetic reinforcement systems (HGRS) to mitigate swelling distresses in the flexible pavements constructed on expansive soils. In order to achieve this research goal, the following key research questions needed to be answered:

$>$ Can the HGRS mitigate differential swelling on the flexible pavement surface due to expansive soil?

$>$ Is the HGRS performance better than its components (geocells and geogrids) alone?

$>$ Does the swelling characteristics of expansive soil have an impact on the effectiveness of HGRS?

What is the effect of the stiffness of reinforced base layer on the performance of HGRS?

The following research tasks were undertaken to answer the above research questions:

1. Perform large-scale box tests to study surficial heaving distresses of the pavement systems with and without geosynthetic reinforcement due to the expansive soil. 
2. Develop finite element models replicating the different combinations of largescale box tests.

3. Calibrate the finite element model using the results from task\#1.

4. Investigate the impact of swell characteristics of expansive soils and stiffness of reinforced base using the calibrated models.

5. Analyze all test results and comment on the applicability of HGRS to mitigate expansive soil swelling.

A flow chart is shown in Figure 1.4 to illustrate the overall research approach of this thesis work. 

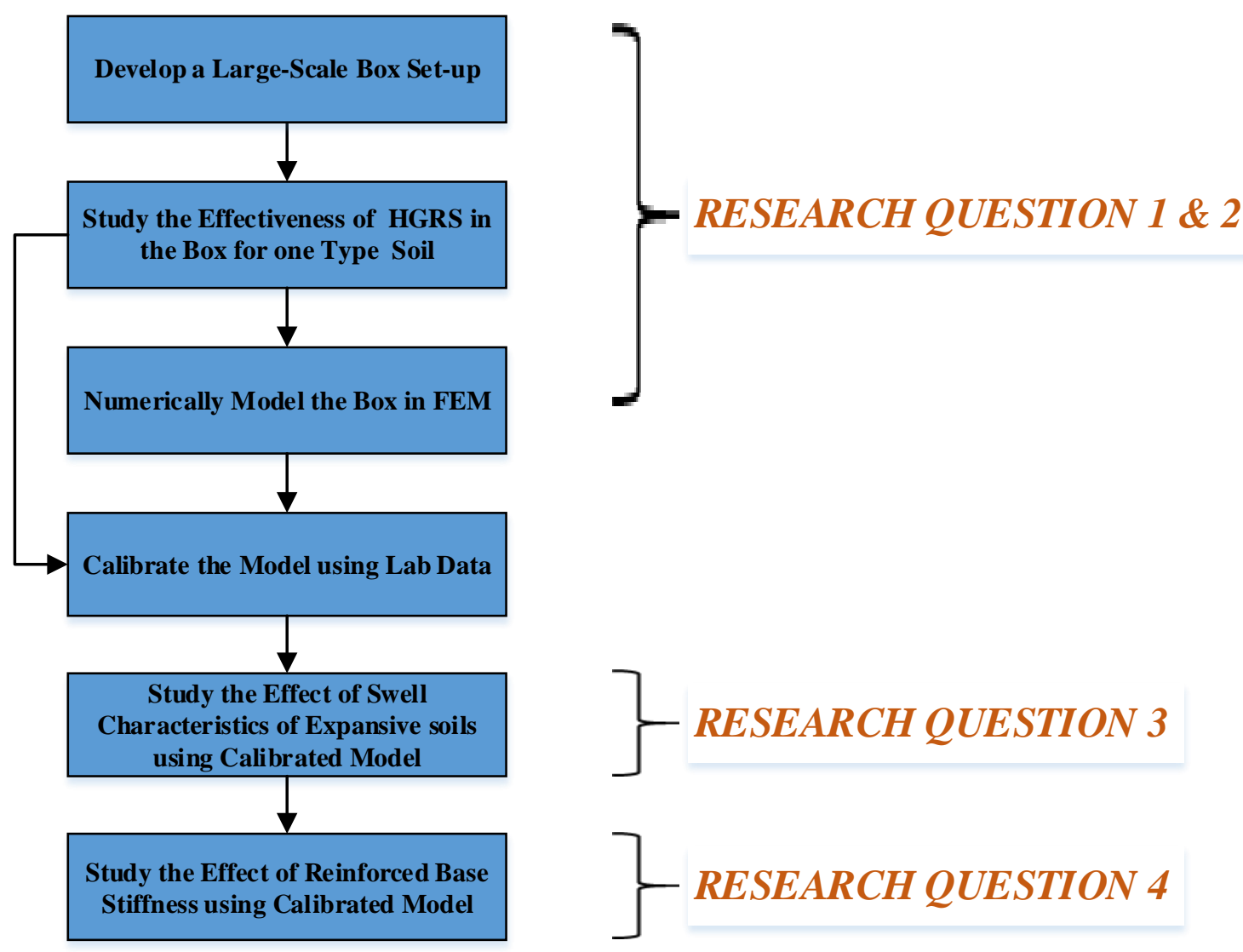

\section{Figure 1.4 Flow Chart showing the Research Approach of the Thesis Work}

\subsection{Outline of the Thesis Document}

The final document of the Master's thesis was organized into six chapters including this chapter 1 which introduces the overall thesis document.

Chapter 2 illustrates a review of published literature on the swell behavior and prediction models of expansive soils along with literature on hybrid geosynthetic reinforcement systems (HGRS) applications.

Chapter 3 discusses the design and development of the large-scale box test to evaluate the effectiveness of HGRS to mitigate the surficial heaving on the pavement 
surface. The performance of individual geocell, individual geogrid and HGRS was evaluated in the box set-up and compared in this chapter.

Chapter 4 presents the details of the numerical modeling effort undertaken during this research effort. This chapter also describes the laboratory test matrix developed to establish material properties of the soil and base materials that were later used as inputs in the numerical model. Calibration approach of the numerical models using the largescale box test data was also discussed in this chapter along with the parametric study. The parametric study was conducted by varying expansive soils and stiffness of reinforced base to evaluate the performance of HGRS. Finally, inferences was drawn based on the numerical analysis and parametric features regarding the effectiveness of HGRS as potential rehabilitation approach for pavements under expansive subgrades.

Lastly, Chapter 5 summarizes the overall thesis work and presents major findings and conclusions highlighting the significance of the results from experimental and numerical efforts, along with recommendations for future research. 


\section{CHAPTER 2: $\quad$ LITERATURE REVIEW}

\subsection{Introduction}

Expansive soil related problems have been known to the geotechnical engineers since 1938 (Chen 2012). Every year, these soils cause severe damage to the transportation industries due to their volumetric movements with moisture variation (Jones and Jefferson 2012). Over time, researchers have developed different remedial measures to mitigate the swelling distresses on pavement structures (Nelson and Miller 1992). However, these methods may be insufficient in some cases due to the formation and location of the problematic soils, complexity and economic viability of the projects. This chapter presents a summary of the published literature on expansive soils and associated problems along with the current remedial approaches and their limitations to mitigate these problems. Researchers showed that application of a flexible mechanical system like geosynthetics can be a remedial measure when conventional stabilization methods fall short due to the formation and location of problematic soils at a deep depth (Chittoori et al. 2016; Islam 2017). This research effort explored this idea of swell mitigation approach in the flexible pavement and focused on the application of geosynthetic reinforcement systems while searching for published literature. A brief discussion on the potential of geosynthetic systems (experimentally and numerically) have been presented to reduce the surficial distresses on pavements due to the volume change behavior of underlying expansive subgrades.

\subsection{Expansive Soils and Problems Associated with Them}

Nelson and Miller (1992) define expansive soils as - "the soil or rock material that has a potential for shrinking or swelling under changing moisture conditions." In 
1938, expansive soil related problems were first encountered in Oregon, where the swelling behavior revealed under the foundation for steel siphon. (Holtz and Gibbs 1956). Since then engineers recognized the significance of this phenomenon to the structural damages. Arid and semi-arid regions are the prime sources of expansive soils. Their distribution is dependent on geological features, climatic conditions, hydrology, geomorphology, and vegetation. This kind of problem arises when the swelling related deformations significantly surpass the elastic deformation of the soils and this swelling behavior cannot be explained by the classical elastic and plastic theory (Jones and Jefferson 2012).

The sources of expansive soils are directly related to the clay mineral formations through different compound processes and situations (Chen 2012). The composition of the clay minerals triggers the swelling behavior with the presence of water. Hydrous aluminum silicates are the primary components of most of the clay minerals. Typically, highly expansive soils contain montmorillonite clay mineral which comprises of 2:1 layer silicate minerals. This 2:1 silicate layer contains two silica tetrahedrons surrounding by an aluminum octahedron. Tetrahedral and octahedral structures are used to define the crystalline lattice orientation of the clay particles (Heyer 2012). Tetrahedrons are commonly filled with silica, while octahedrons are commonly filled with aluminum. The basic structural unit of montmorillonite mineral is consisting of two inward-pointing tetrahedral sheets with a central alumina octahedral sheet. The structure of montmorillonite clay is illustrated in Figure 2.1. 


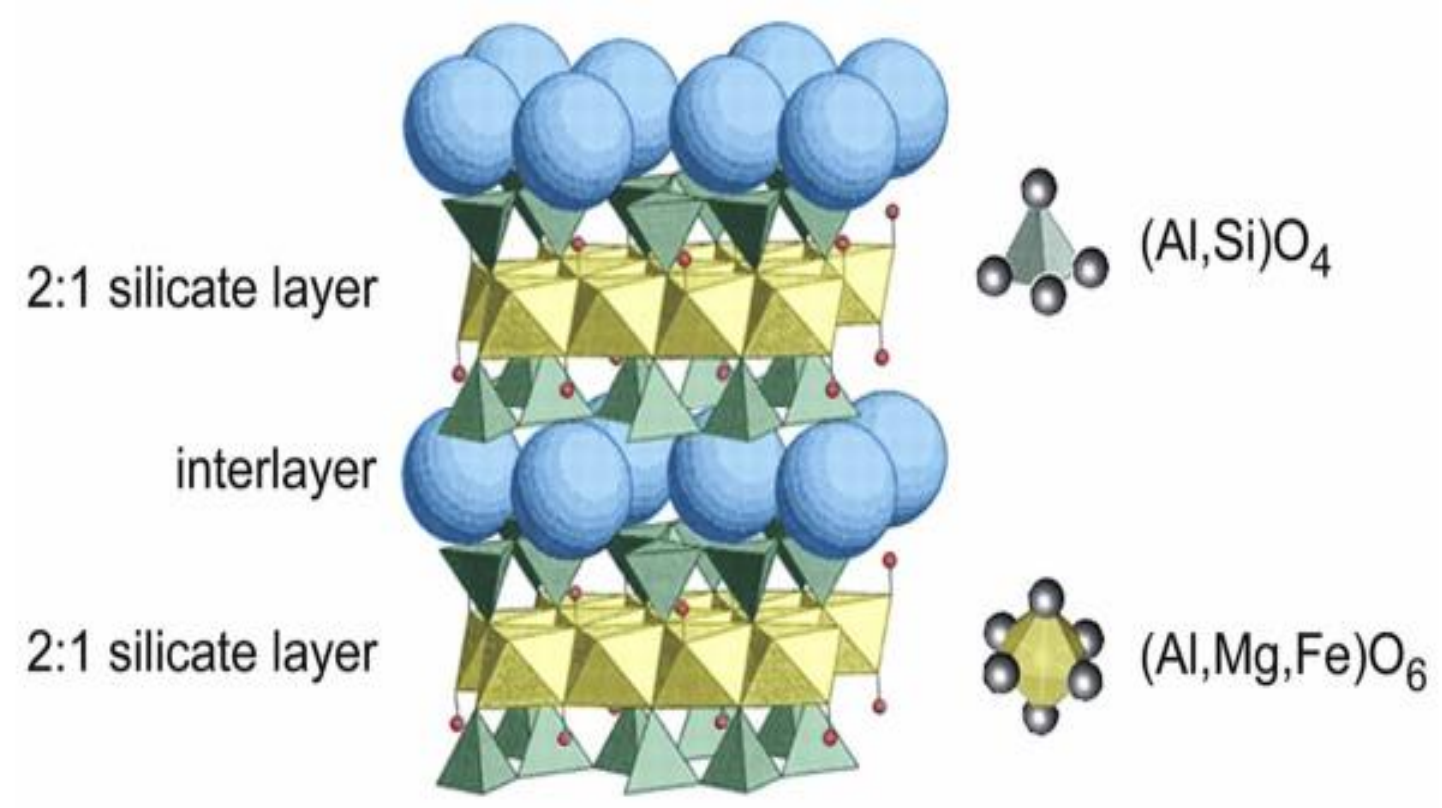

Figure 2.1 Illustration of Montmorillonite Structure (Heyer 2012)

The net negative charge of montmorillonite is balanced by exchangeable cations which collect around the negative surface of the clay particle (Bohn et al. 1985). As a result, an electrostatic force is developed between the negative surface and thoFse exchangeable cations. When a dry clay particle has a chance to contact with water, these exchangeable cations around the surface of clay particle would try to diffuse away from the surface and tries to neutralize throughout pore water. As a result, a diffusive double layer is developed at the interface between the clay surface and the soil solution. The size and charge of cations present in the diffuse double layer control the limits of expansion. This swelling phenomenon can cause severe damage to the overlying lightly loaded structures like pavements and residential houses.

Pavements over expansive subgrades exhibit surficial distresses due to the swellshrink behavior of the problematic soils which lead to cracks and allow moisture percolation through the cracks at a deeper depth in the pavement structure. In addition, 
recurrent traffic movement coupled with wetting and drying cycle exacerbate the condition of the pavement layer (Kassiff et al. 1969). Kassiff et al. (1969) identified the swelling distresses as unevenness of the pavement surface, cracks on longitudinal and lateral directions, and localized failures with the disintegration of the road surface. Dafalla and Shamrani (2011) classified the cracks as six different forms that were attributed to expansive soils which are shown in Figure 2.2.

Longitudinal cracks grow along the joints of the construction lanes or parallel to the edge of the roadway over expansive soils. When the volume change behavior of expansive soils is beyond the resistance capacity of asphalt layer, cracks form in the transverse direction which are defined as transverse cracks. They are found at the top of mound or bottom of depression features along the roadway. These cracks are often associated with transverse subsurface moisture variation. Block cracks form as the result of volume change of expansive subgrade due to moisture variation under roadway patches. Yield cracks are the result of frequent, heavy vehicular movement coupled with the vertical movement of the subgrade due to wetting and drying cycle. They are found in the wheel path of the pavement. Spot ridge cracks are found at the localized failure zones created by pockets of expansive soil beneath the pavement structure. Lastly, green zone cracks are found near the landscaping and green zones as a result of rapid moisture movement through the soil created by root networks. 


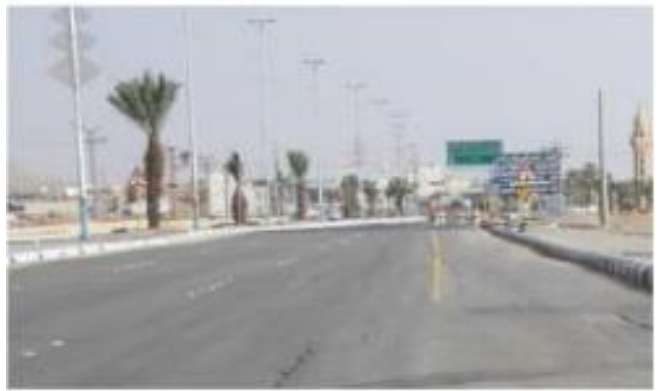

Longitudinal Crack

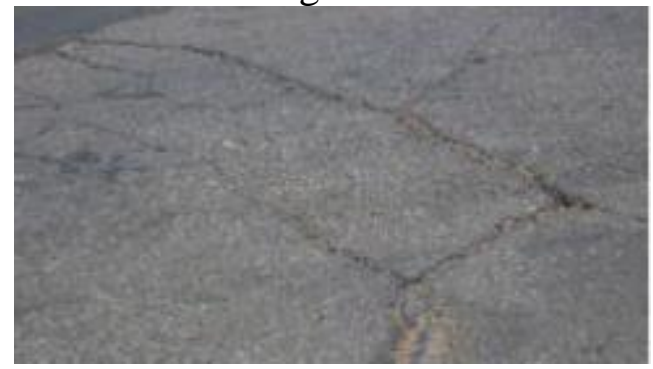

Block Crack

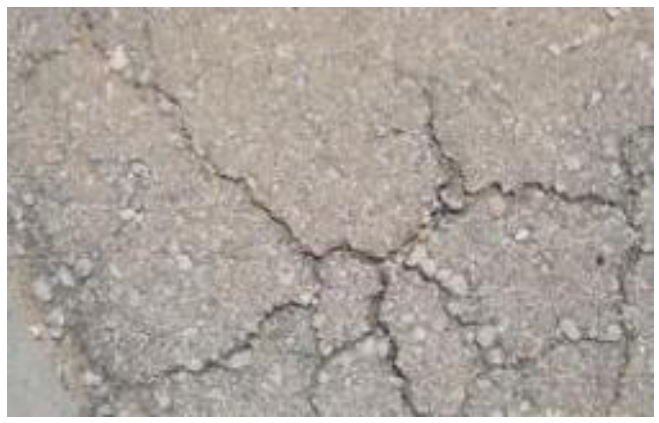

Spot Ridge Crack

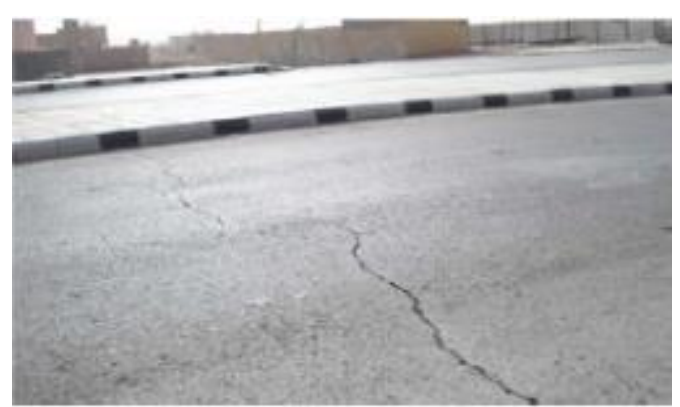

Transverse Crack
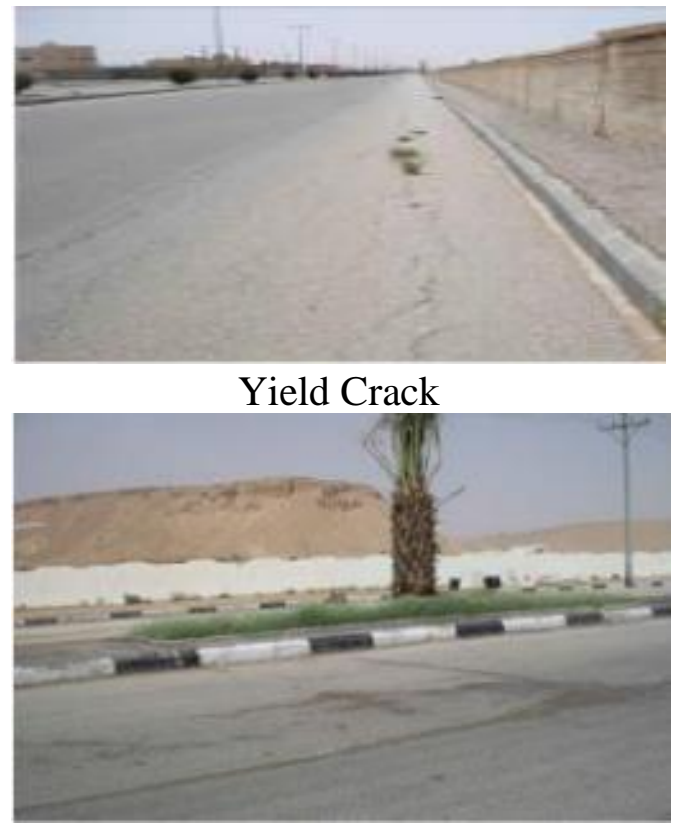

Green Zone Crack

\section{Figure 2.2 Crack Types Associated with Expansive Soils (Dafalla and Shamrani}

\section{1)}

Zornberg et al. (2012) illustrated the mechanism of crack formation due to expansive soils. They identified the points of maximum differential strain, and thus the most probable location for cracking failures in the roadway profile, caused by volumetric movement of the expansive subgrade. Figure 2.3 presents the mechanism involved in crack relocation. 


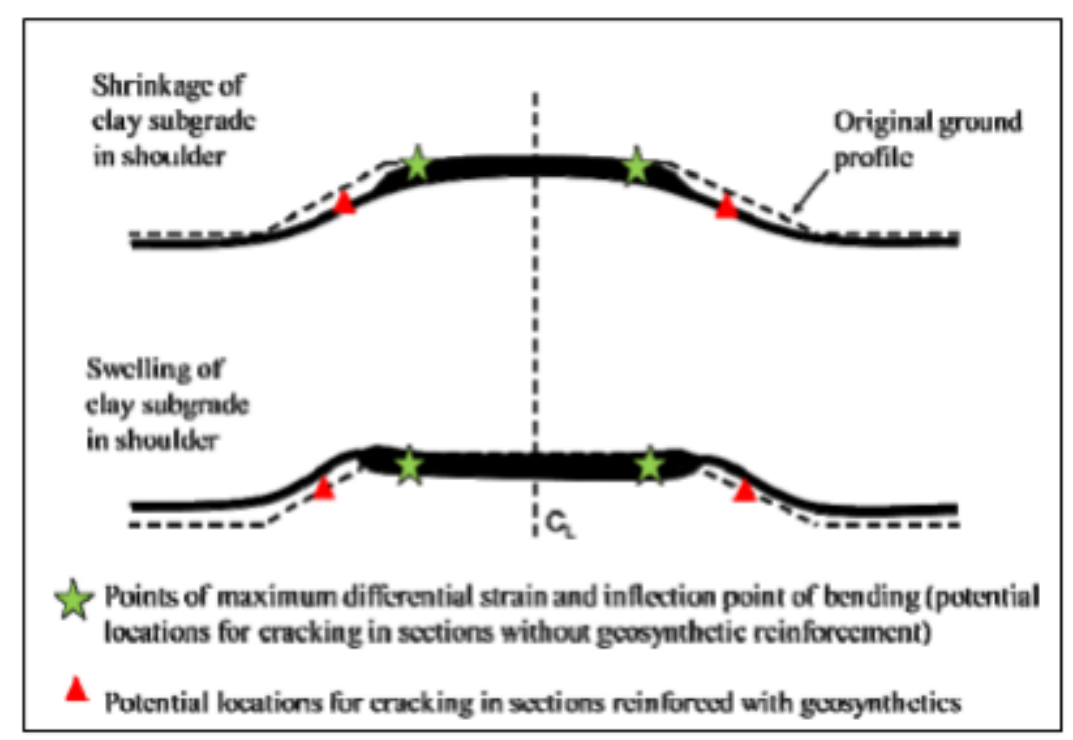

Figure 2.3 Mechanisms involved in Crack Relocation (Zornberg et al. 2012)

\subsection{Prediction Methods to Measure Volumetric Movement of Expansive Soils}

The behavior of expansive soils is sensitive to both moisture variation and suction. Several researchers tried to predict the volumetric movement of expansive soils analytically (Alonso et al. 1999; Briaud et al. 2003; Vu and Fredlund 2004; Wray et al. 2005; Overton et al. 2006; Adem and Vanapalli 2013) and numerically (Vu and Fredlund 2006; Rajeev and Kodikara 2011; Puppala et al. 2013; Chittoori et al. 2017). Analytical methods of swell prediction are based on moisture/suction variation and constitutive laws that link the soil state variables (Briaud et al. 2003). Nowadays, numerical methods have been used to simulate complex problems like swelling behavior of expansive soils. These methods are widely accepted because of their accuracy in predicting practical conditions more realistically than theoretical or analytical solutions based on the infinite slab and other idealized assumptions (Kuo and Huang 2006). A brief discussion of both analytical and numerical methods are given in the subsections. 


\subsubsection{Analytical Methods to Predict Expansive Swelling}

Several analytical methods have been suggested by the researchers to estimate the volume change behavior of expansive soils over time (Alonso et al. 1999; Briaud et al. 2003; Vu and Fredlund 2004; Wray et al. 2005; Overton et al. 2006; Vu and Fredlund 2006; Adem and Vanapalli 2013). To evaluate the volume change behavior, moisture or suction variation ranges over time and constitutive laws that linked with soil behaviors must be defined (Briaud et al. 2003). In an attempt to state the methods for volume change movement, Adem and Vanapalli (2015) categorized three approaches based on the variables that influence the swell-shrink behavior of soil. They are-

1. Approaches based on Consolidation Theory

2. Approaches based on Moisture Variation

3. Approaches based on Soil Suction

Volumetric movement of unsaturated soil is illustrated by the volume change of soil structure as well as moisture variation with time (Adem and Vanapalli 2015). Coupled consolidation based approach can connect this two phenomenon to explain the volumetric movement of unsaturated soil. To develop the consolidation-based approach, stress equilibrium equations and water continuity equation are required (Lloret and Alonso 1980; Fredlund and Rahardjo 1993; Wong et al. 1998; Vu and Fredlund 2002). The constitutive relationship for solids (i.e. soil) and flow relationship for fluids (i.e. water and air) are needed to form these equations. Based on the elastic and plastic characteristic of the soil, volumetric constitutive relations can be grouped as elastic 
constitutive model-based methods and elastoplastic constitutive model based methods (Adem and Vanapalli 2015). Elastic approaches correlate the volumetric movement with net stress and matric suction (Fredlund and Morgenstern 1978; Vu and Fredlund 2004; Zhang 2005; Vu and Fredlund 2006). On the other hand, elastoplastic approaches reveal the collapse behavior of unsaturated soil upon wetting (Lloret and Alonso 1980; Alonso et al. 1990; Gens and Alonso 1992; Wheeler et al. 2003; Thu et al. 2007; Sheng et al. 2008).

Marr et al. (2004) reported that moisture content could be a reliable and more efficient way than suction to evaluate the volume change of soils. Some approaches are used to determine the soil movement using water content methods (e.g. Briaud et al. 2003; Overton et al. 2006). Briaud et al. (2003) suggested an approach that can predict vertical distresses of ground surface with moisture variation over time. The governing parameter of this model is moisture content. This method can evaluate the swelling as well as shrinking behavior of soil. This method is simple and reliable; however, moisture content variation is only considered in this method. Overton et al. (2006) evaluated the free field heave over time using volumetric water content. The free field heave, which will occur at the ground surface if no stress is applied, is a fundamental parameter in this approach. It can be predicted using the oedometer method (Nelson and Miller 1992). This method is applicable for homogenous soil profiles with minimal macroscale fracturing or cracking and can predict the time rate of the migration of the wetting front and the resulting time rate of soil heave realistically (Adem and Vanapalli 2015). However, this method is time-consuming and no indication of shrinkage effect. 
Suction-based methods are the most extensive methods to evaluate the soil movement of unsaturated soils (Richards 1965; Lytton and Kher 1970; Fredlund 1997; Fredlund and Hung 2001; Wray et al. 2005; Adem and Vanapalli 2013). Soil suction is more efficient than water-based method because of its low sensitivity to soil material variables and convenient relation with soil parameters (Richards 1974). Basic formation of these methods is a proportionate relationship of volume change with suction variation within field condition. Wray et al. (2005) used two models to predict the movement of expansive soils. One is moisture flow model to estimate the water flow (Mitchell 1979) and the other model is volume change model to define vertical soil movement incorporated with suction over time (Wray 1997). The moisture flow model was used to determine the suction with time. Then the suction model was formulated to determine the vertical soil movement of each node using the suction values over time. Summation of all the node deformations gave the total vertical movement. Adem and Vanapalli (2013) suggested a method based on the modulus of elasticity. This method was developed based on the assumption that the soil is isotropic, linear elastic material, and the influence of the mechanical stress on the volume change of expansive soil underlying lightly loaded structures is insignificant and neglected. They simplified the Fredlund and Morgenstern (1976) soil structure constitutive relationship for 1-D problems and correlated matric suction and modulus of elasticity with swelling behavior of expansive soil. Matric suction variations in the active zone depth and the associated modulus of elasticity are the key parameters to calculate the vertical soil movements (heave/shrink) over time in this model. This method is a relatively simple and promising method that can be used in 
engineering practice for predicting the long-term vertical movements of unsaturated expansive soils considering all the environmental factors.

\subsubsection{Numerical Methods to Predict Expansive Swelling}

Volume change behavior in expansive clay is complex and cannot be described accurately by simple models. This volume change behavior is a 3-D problem in which changes in stress, deformation, and moisture or suction value throughout the region including the boundary conditions need to be considered. So, this swelling phenomenon can be described only as interactive processes, each of which is hard to describe separately, mainly because of the non-linear behavior of expansive soils. Numerical analysis can be a strong method to simulate this kind of complex problems realistically, especially when the expansive soils are in unsaturated/partially saturated condition. Several researchers successfully modeled expansive soil and predicted the swelling behavior of the soils (Vu and Fredlund 2006; Abed 2007; Rajeev and Kodikara 2011; Puppala et al. 2013; Chittoori et al. 2017).

Abed (2007) studied the numerical simulation of a trail wall on expansive soils in Sudan. He used PLAXFLOW-Plaxis, finite element tool, to simulate the mechanical behavior of unsaturated expansive soils. Soil water characteristic curve was developed to define suction variation with water content. Unsaturated groundwater flow and suction variation with time were simulated in the model using PLAXFLOW. The Barcelona Basic Model was applied in PLAXIS to calculate the deformation. This method successfully predicted the heave of expansive soils from the field measurements.

Ranjeev and Kodikara (2011) conducted a three-dimensional finite difference continuum approach to simulate the response of a pipe buried in expansive 
soils. Pipe material was modeled as linear elastic and expansive soil was modeled as nonlinear elastoplastic material. FLAC ${ }^{3 \mathrm{D}}$ computer program was used for the simulation. Swelling-induced stresses were computed in terms of moisture variation. Soil moisture changes were computed using the capillary rise. The modeling approach gave reasonable values of vertical deflection of pipe in expansive soils when compared to the results obtained from the laboratory experiment.

Abaqus Unified FEA offers a more accurate simulation of expansive soil behavior using built-in material models (Puppala el al. 2013, Chittoori et al. 2017). These model can handle volumetric movement and the suction relationship of expansive soils with moisture variation. Using the material models, Puppala et al. (2013) simulated the swell-related soil movement involving partially saturated soils. In the numerical analysis, they used moisture swelling and sorption models to characterize the heaving nature of the soils. Moisture swelling model illustrates the saturation-driven volumetric swelling of the soils during partially saturated flow condition and requires volumetric movement relationship with water content. The sorption model illustrates the suction relationship with moisture content. The soil element, when subjected to swelling, undergoes volumetric changes caused by absorbing water, and this element is not expected to either fail or yield during the swelling period. Thus, the linear elastic property was used to simulate expansive soils. Numerical analysis results exhibited similar kind of trends for swell movement as those observed in the field.

Chittoori et al. (2017) evaluated the ability of swell prediction models to predict the swelling behavior of highly expansive soils. For this purpose, four existing analytical prediction models that use combinations of above-mentioned properties were selected 
and used to predict the one-dimensional and three-dimensional swelling strains on three high swelling soils. These predictions were verified by conducting one-dimensional and three-dimensional swell tests on the three soil types. In addition, finite element modeling was performed to simulate one-dimensional and three-dimensional swell tests by using material models that use volumetric and suction changes with moisture contents to simulate expansive soil behavior within the finite element model. The results indicated that while the analytical prediction models gave reasonable results the finite element analysis predicted results were closest to the laboratory measure soils in case both 1-D and 3-D analyses.

\subsection{Current Methods to Mitigate Expansive Soil Issues}

Soil stabilization is defined as the modification of soil material to enhance the physical properties to prevent structural deterioration (Ingles and Metcalf 1972).

Stabilization can increase the shear strength of a soil and/or control the shrink-swell properties of a soil, thus improving the bearing resistance of a subgrade to support pavements and foundations. (Makusa, 2012). The effective application of soil stabilization procedure requires considerable experience and judgment regarding local geology, limitations of the stabilization methods and correct implementation processes (Nelson and Miller 1992). Additionally, social, economic and environmental impacts along with strength improvements of the soil need to be considered (Puppala et al., 2013). The following sections briefly describe some of the commonly used remediation methods to mitigate swelling distresses.

Compaction is one of the popular methods to increase the bearing capacity as well as the improvement of subgrade soil and reduce swelling potential (West 1995). Inter 
particle repulsive force can be minimized under compaction at less than optimum moisture content (Das 2006). Moreover, the degree of compaction is important for the improvement of the subgrade. For the same degree of compaction, lower compaction with moisture slightly greater than optimum moisture content (OMC) and higher compaction with moisture slightly below OMC is required. Nevertheless, moisture content should be kept 3-5\% above OMC during the construction (Petry and Little 2002).

The prewetting method can stabilize the expansive subgrade to mitigate heave (Petry and Little 2002). The main goal of pre-wetting is to reach equilibrium and reduce susceptibility to water. Ponding water on a foundation can reduce the future swell potential, often controlled by moisture barrier installation (McKinney et al. 1974; Steinberg 1977; Poor 1978). Generally, the best time to apply ponding is during the dry season when the natural cracks and fissures are open due to desiccation (Snethen 1979). Das (2004) stated the benefit of ponding over of inducing heave. Water injection is yet another method of achieving moisture stabilization of foundations/subgrades. A moistened soil can be immediately covered with a plastic barrier to keep moist or constructed upon immediately (Petry and Little 2002).

Chemical stabilization is the widespread stabilization technique over other methods due to their wide range of applicability and availability (Chittoori et al. 2016). Cement and lime stabilization have been widely used to improve the strength of the expansive soils. They are also cost-effective over other stabilization techniques. Lime shows the greatest improvement to compressibility, CBR and swelling over other chemical stabilizers (Chen 1988). It can also increase the coefficient of permeability and the bearing capacity of clay (Khattab et al. 2007). Sebesta (2002) suggested that lime can 
be a good stabilizer for roads with low traffic but not good for high traffic roads. The stabilizing behavior of cement is very similar to lime due to their chemical formation (Estabragh et al. 2013). Chittoori et al. (2011) illustrated the process of cement stabilization as cation exchange, flocculation, carbonation, and pozzolanic action. Change in soil properties is significantly contributed by pozzolanic action. These materials form moisture resistant materials with fine-grained soils and resistant to leaching in long-term as well as increase the shear strength of the soil (Chittoori et al. 2011). Additionally, Fly ash can be used as a stabilizer to reduce the expansive nature the soil. Malhotra \& Naval (2013) showed that the right proportion of fly ash and lime could reduce the swelling and shrinkage characteristics of expansive soils.

Moisture variation is one of the prime factors for swelling of expansive soils. Uneven change in moisture content and/or soil properties can occur non-uniform heave (Jones and Jefferson 2012). Therefore, the swelling potential can be reduced, if water content variation can be controlled. Additionally, slowing down or uniformity in water distributions can also reduce the differential heave. Moisture barriers are able to minimize the seasonal water variation and lengthening the migration time for water content changes (Nelson and Miller 1992). Depending on the application, two types of techniques have been developed for moisture control method. One type of method is horizontal barriers (Woodward et al. 1968; Hammitt and Ahlvin 1973) and another type is vertical barriers (Goode 1982; Hamberg 1985; Poor 1979). Black and Holtz (1999) conducted research into the performance of geotextile separators five years after installation on soft silty subgrades with pavements having a history of rutting and fatigue. 


\subsection{Limitations of Current Mitigation Methods}

Not all the mitigation approaches are applicable to the same field conditions. Every method has some limitations over other methods considering the field situations. Compaction method needs frequent testing to determine the optimum density and water content which may increase the project cost. On the other hand, prewetting is a very timeconsuming method to stabilize the expansive soils. Chemical stabilization is a very popular method to stabilize heaving soils. However, their application is limited to a shallow depth (0.9-1.22 m). Additionally, calcium-based additive can produce ettringite mineral if the sulfate is present in the soils. This ettringite exacerbates the swelling distresses on the pavement section. Moisture barriers are also economic when the expansive soils are at a shallow depth. Extra care is also required during construction. If the expansive soils at a deeper depth, conventional method fall short to stabilize the soils. A flexible mechanical system can be a possible solution that can reduce the expansion coming from the underlying clay layers and protects pavement structure. One such alternative is to use a geosynthetic system to support the pavement structure as well as to mitigate the surficial heaving due to expansive soils.

\subsection{Potential of Geosynthetics to Stabilize Expansive Soils in Flexible Pavement}

Geosynthetics is controlled factory-manufactured polymeric materials, which offer widespread scope with various application in pavement industry (Koerner 2012). Geosynthetics are mainly categorized as geotextile, geogrid, geonet, geomembrane, geocell, geofoam, 

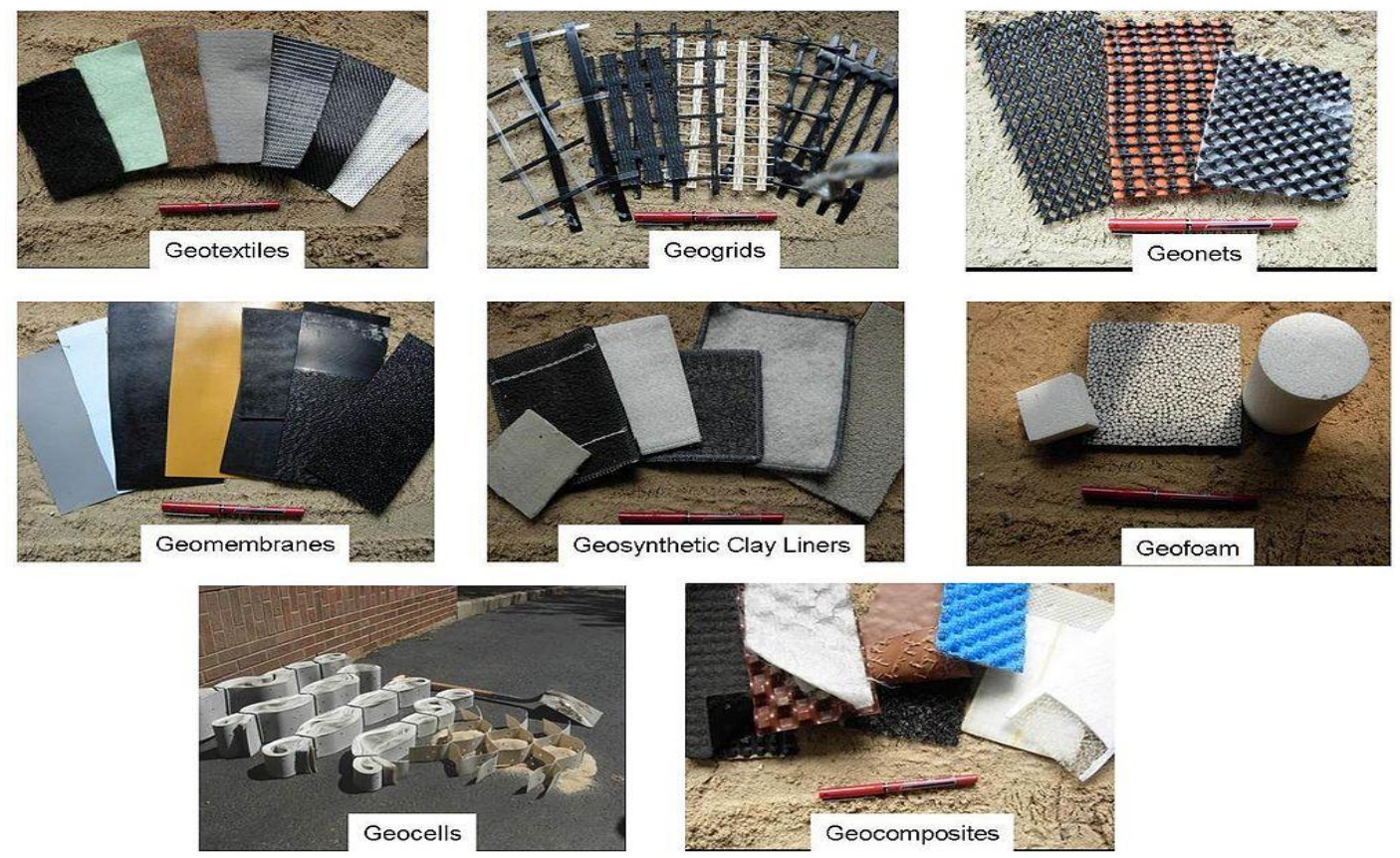

Figure 2.4 Types of Geosynthetics

(https://en.wikipedia.org/wiki/Geosynthetics\#/media/File:Geo2.jpg)

geocomposite and geosynthetic clay liner (Han 2015). Figure 2.4 illustrates different types of geosynthetic materials. Typically, geosynthetics are two-dimensional planer materials except for geocell and geofoam. The shape of geocell and geofoam are 3-D honeycomb and cubic block respectively. They have been used in the pavement with the functions of separation, filtration, drainage, sealing and reinforcement (Zornberg 2011).

Table 2.1 presents the primary function of the different type of geosynthetics.

Table 2.1 Primary functions of Geosynthetics (Han 2015)

\begin{tabular}{|c|c|c|c|c|c|c|}
\hline Type & Separation & Reinforcement & Filtration & Drainage & $\begin{array}{c}\text { Erosion } \\
\text { Protection }\end{array}$ & Barrier \\
\hline Geotextile & $\mathrm{X}$ & $\mathrm{X}$ & $\mathrm{X}$ & $\mathrm{X}$ & $\mathrm{X}$ & $\mathrm{X}$ \\
\hline Geogrid & & $\mathrm{X}$ & & & & \\
\hline Geonet & & & & $\mathrm{X}$ & & \\
\hline Geomembrane & $\mathrm{X}$ & & & & $\mathrm{X}$ & $\mathrm{X}$ \\
\hline $\begin{array}{c}\text { Geosynthetic } \\
\text { Clay Liner }\end{array}$ & $\mathrm{X}$ & & & & $\mathrm{X}$ & $\mathrm{X}$ \\
\hline Geocell & & $\mathrm{X}$ & & & $\mathrm{X}$ & \\
\hline Geocomposite & $\mathrm{X}$ & $\mathrm{X}$ & $\mathrm{X}$ & $\mathrm{X}$ & $\mathrm{X}$ & $\mathrm{X}$ \\
\hline
\end{tabular}


Geosynthetics have extensive functions to stabilize the problematic soils (Vessely and $\mathrm{Wu} 2002)$. Vessel and $\mathrm{Wu}$ (2002) conducted a feasibility study to define the potential of geosynthetics over expansive soils. They found that inclusion of geosynthetics was able to reduce the swelling. Zornberg et al. (2012) studied 32 low-volume road test sections in Texas including control (unreinforced), lime-treated sub-base, geosynthetic reinforced (without lime stabilization) and geosynthetic reinforced (with lime stabilization) test sections. They used geogrids and geotextiles in their study. The study revealed that geosynthetic reinforced section prevented the development of longitudinal cracks over expansive clays while unreinforced sections over similar clays have shown significant cracking. Another finding from their study was the percentage of cracking in the reinforced sections, which was by far less than the cracking in the control sections and lime-treated sections. In addition to this, they also reported that lime treatment sections might have a very limited contribution in terms of the improvement of the performance of the sections in longitudinal cracking. Steinberg (1998) stated the potentials of geomembranes to mitigate the swelling phenomenon. Based on the research scope, potentials of geocell, geogrid and hybrid system over swelling distresses are addressed below-

\section{$\underline{2.6 .1 \quad \text { Geocells }}$}

\subsubsection{Definition}

Geocells are the latest edition of the geosynthetic group. Geocells are known as cellular confinement systems with 3-D honeycombed structure. United States Army Corps of Engineers initially developed this concept of lateral confinement in 1970 to 
enhance the strength of low bearing soils (Webster 1981). Typically, geocells can be made of paper, cardboard, bodkin bars, aluminum, high-density polyethylene (HDPE) or novel polymeric alloy (NPA) (Kief et al. 2015). Geocells can be manufactured into different sizes and shapes based on their applications. A typical application geocells is shown in Figure 2.5.

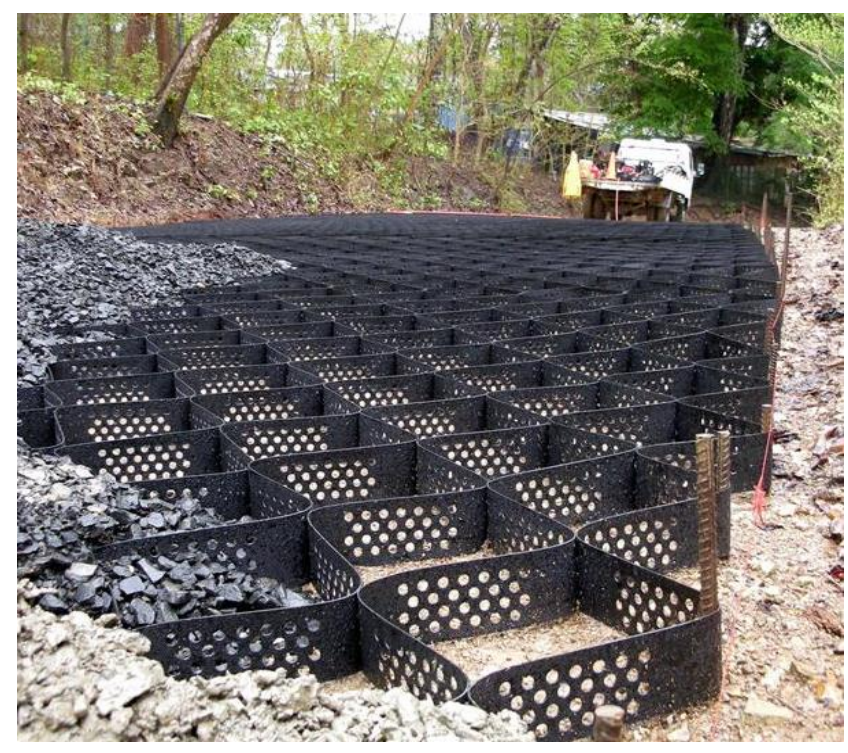

\section{Figure 2.5 Geocell Application in Roadway}

(http://www.conteches.com/DesktopModules/Bring2mind/DMX/Addons/NewGal lery/GetImage. ashx?img=14406\&w=800\&h=600\&c=false)

\subsubsection{Reinforcing Mechanism of Geocells}

When the cells are filled with the granular materials, a composite system is developed due to the interaction between the cell wall and confined granular materials (Webster 1981). This composite system significantly increases the strength parameters of the granular materials. Primary functions of geocells are confinement (lateral and vertical), beam effect and load distribution (Zhou and Wen 2008; Pokharel et al. 2009; Yang 2010; Han et al. 2011; Leshchinsky and Ling 2012). Tsorani (2008) explained the strengthening mechanism of geocells and the confined materials that enhance the 
stiffness of infill materials within the cells. Vertical loading on confined materials in the cells results in high lateral resistance on the geocell walls, which reduce the punching effect along with an increase in bearing capacity. Vertical loads induce lateral stresses on the cell walls that enhance the shearing resistance and stiffness of the infill soils. Hoop Stresses also generate along the cell walls due to the confinement which restricts the lateral movement of infill soils. Neighboring cells around a confined cell can provide additional resistance to lateral deformation. Moreover, the cell walls can also provide frictional resistance against deformation due to loading. Figure 2.6 illustrates the reinforcing mechanism of geocells.

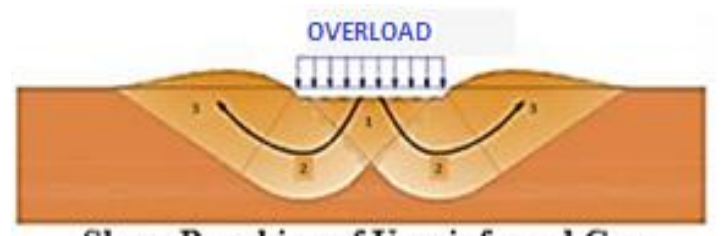

Shear Punching of Unreinforced Case

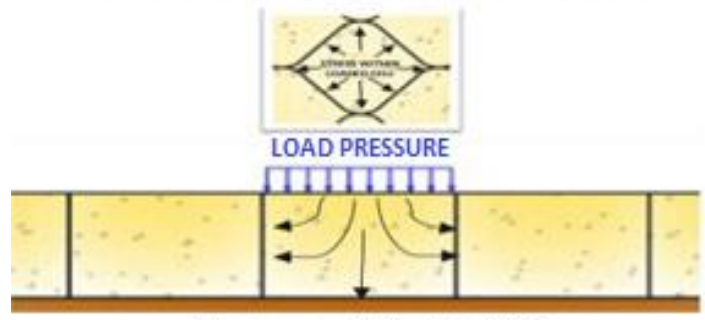

Stresses within the Cell

LOAD PRESSURE

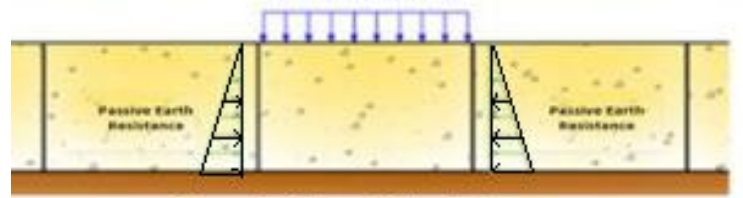

Passive Earth Resistance

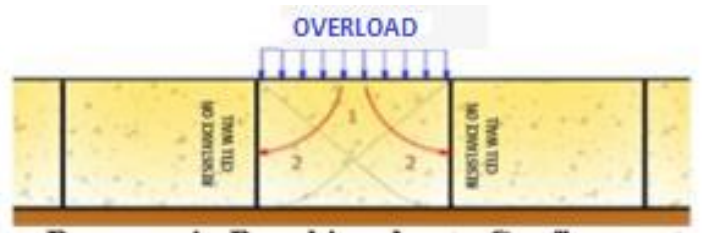

Decrease in Punching due to Confinement
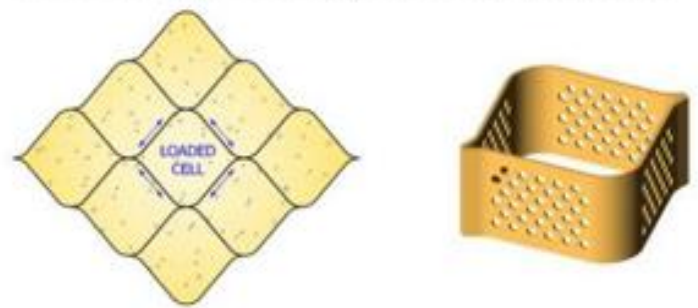

3-D Hoop Stress LOAD PRESSURE

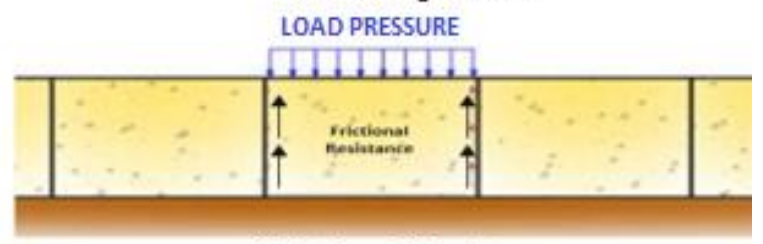

Frictional Resistance

Figure 2.6 Reinforcing Mechanism of Geocells (Tsorani 2008)

\subsubsection{Previous Studies on Geocells:}

Since 1970, geocells are very widespread materials for soil stabilization in transportation industries. Initially, research attempts were concentrated on the viability of 
geocell confinement (Webster and Watkins 1977; Webster and Alford 1978; Webster 1981; Bathurst and Jarrett 1988; Dash et al. 2003) Later the attempts were more focused on the influencing factors of cell confinements and design methods (Latha and Murthy 2007; Chang et al. 2007; Yuu et al. 2008; Yang 2010; Leshchinsky 2011; Kief et al. 2015). Several lab-based and numerical methods are found to evaluate the effectiveness of geocell reinforcement. A brief discussion on both the methods was given below-

\subsection{Experimental Studies}

Recent years, geocells have been used to reinforce base in pavement construction (Yang 2010). The reinforcing mechanism of geocell mainly comprises of stresses within cells, passive resistance in the adjacent cells, and hoop stresses around cell walls (Tsorani 2008). The geocell-reinforced base layer acts as a stiff composite layer with mattressing effect to distribute the vertical traffic load over a wider area of the subgrade. As a result, the vertical stresses applied on the subgrade are reduced and the bearing capacity is increased. Most of the experimental studies demonstrated the beneficial use of geocells. Dash et al. (2003) found that the bearing capacity of geocell reinforced sand could be up to seven times more than the unreinforced case.

A laboratory model test was conducted by Latha et al. (2006) to evaluate the efficacy of geocell confinement on the performance of earth embankments constructed over weak foundation soil. In their study, the performance behavior of embankment was studied based on different influencing factors of geocell reinforcement such as- geocell stiffness, height, and length, cell size, and type of fill material. Geocell reinforcement was found to be beneficial in increasing the bearing capacity and reducing the deformation of the embankment. 
Singh et al. (2007) found that the ultimate bearing capacity of a square footing was appreciably increased by geocell confinement under the axial load as well as under the eccentrically inclined load. It was observed that the confinement of soil under the footing resisted the lateral displacement of the infilled material leading to a significant decrease in the settlement and an increase of the ultimate bearing capacity.

Yuu et al. (2008) summarized 26 technical papers on geocell confinement effect in base courses. They found that geocell system reduces the stress applied to the subgrade due to bending stiffness and also the deformation. They also illustrated the contributing factors that can enhance geocell performance which are- geometric variables of geocells, quality of infill soil, subgrade types, loading condition and location of geocells.

Pokharel et al. (2009) conducted an experimental study to evaluate the behavior of geocell-reinforced bases under static and repeated loading. Two base course materials, Kansas River sand, and quarry waste were used as the infill materials. The test results showed that geocell confinement increased the bearing capacity and stiffness of the Kansas River sand by improvement factors of 1.75 and 1.5 respectively, under static loading.

Advancement of polymer materials for geosynthetics along with the research on confining mechanism directed the application of geocells on all categories of roads including those without weak soils (Kief et al. 2015). They introduced novel plyometric alloys (NPA) which are more stiff, strong and durable than conventional HDPE geocells. Increased in modulus of reinforced bases using NPA geocells were verified by numerical analysis and introduced a new term, Modulus Improvement Factor (MIF) to define the increased modulus (Pokharel 2010; Kief et al. 2015). MIF is the ratio of the modulus of 
the reinforced base and the modulus of the unreinforced base. Results showed that MIF can be 1.5 to 5.0 for reinforced bases using NPA geocells depending on the stiffness of geocells, infill materials, subgrade and position of confining layers.

\subsection{Numerical Studies}

Several researchers tried to model geocells using finite element analysis to see the confining effect in pavements, railroads, and foundations (Sitharam et al. 2005; Yang 2010; Leshchinsky 2011). Most of the researchers used Duncan-Chang model for the stress dependency behavior of the infill soils. Additionally, they frequently used geocellreinforced soil as a composite layer in their analysis to replicate the 3-D problem in 2-D analysis. However, these composite layers cannot illustrate the interaction behavior of the geocell-infill soils. First 3-D model was developed by Han et al. (2008) that can illustrate soil and geocell separately in the model. They found that the modulus of infill material inside the geocell increased significantly.

Sitharam et al. (2005) conducted a numerical study using FLAC3D to evaluate the influence of geocell confinement on the bearing capacity of a circular footing supported on a 14 sand bed subjected to vertical loading. The numerical analysis demonstrated that the footing pressure was well distributed within the geocell mattress and was transferred to a wider area of the subsoil when compared to the unreinforced sand bed.

A comprehensive full-scale study was conducted by Yang (2010) to evaluate the performance of geocell reinforcement under static and repeated loading using box test, numerical analysis and field trials. Laboratory results showed that the effect of geocell reinforcement was related to the geocell modulus. Geocell modulus had a proportionate relation with bearing capacity and stiffness of reinforced base. Numerical analysis by 
Yang (2010) was also predicted the experimental results quite accurately. Numerical results showed that increased geocell stiffness increases the stiffness (up to $43 \%$ ) of the soil and pavement layers. The parametric studies revealed that geocell confinement had a less effect on the bearing capacity on the firm subgrade. A full scale field test showed that geocells reduced the rut depth and vertical stresses transferred to the subgrade by distributing the load over a wider area approximately half of that in the unreinforced section.

Leshchinsky (2011) conducted experimental studies on geocell confinement for railroad applications. He found that geocells greatly restricted vertical deformation by 40 $72 \%$ and lateral displacement by 50-67\% under controlled cyclic loading. Leshchinsky and Ling (2013) conducted numerical analysis to evaluate the effect of geocell confinement over ballasted layer. They modeled ballast layer as non-associative elasticplastic material, obeying 3D Drucker Prager yield criterion. The deformation and strength properties were obtained from triaxial compression tests (Leshchinsky, 2011). The geocell was modeled as an elastic material with the rhomboidal shape. Confinement effectively reduces the vertical displacement as well as lateral spreading. Mattressing effect increased the bearing capacity of the soil, however, the effect is less over stiffer ballast layers.

However, geocells are not an established method to mitigate the swelling distresses in the flexible pavements. Not enough research was found to define the effectiveness of geocell for swelling distress mitigation. In swelling distresses, the loading effect is not conventional. Typically, the loads are applied from the top in the pavement, but in pavement over expansive soils, the loads are coming from the bottom 
due to the swelling pressure. Though the mattressing effect of geocell can increase the bearing capacity of soil and reduce the displacement over soft subgrades (Zhou and Wen 2008; Leshchinsky and Ling 2013), there is not enough proof of geocell effectiveness over expansive soil related distresses.

\section{$\underline{2.6 .2 \text { Geogrids }}$}

\subsubsection{Definition}

Koerner (2012) defined geogrid as a geosynthetic material consisting of tensile ribs with large apertures for the interlocking mechanism. Geogrids are typically composed of polypropylene, polyethylene, polyester, or coated polyester polymers. McGown et al. (2005) classified geogrid into two categories: - uniaxial geogrid and biaxial geogrid. In uniaxial geogrid, tensile stiffness is developed in one direction. When tensile stiffness is generated in two orthogonal directions, it is referred to biaxial geogrid. Nowadays woven, welded and tri-axial geogrid are also commercially available for reinforcement application (Das 2010). Figure 2.7 shows different types of geogrid.

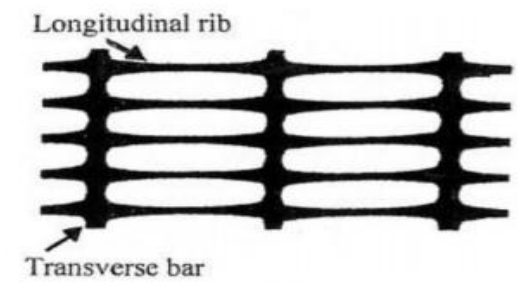

(a) Uniaxial geogrid

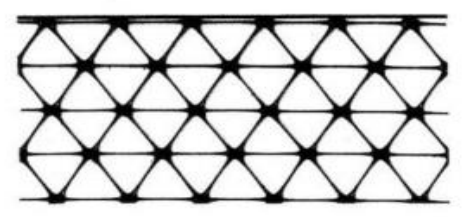

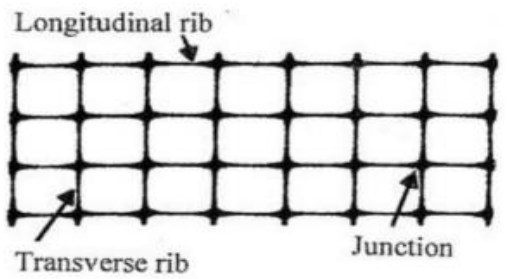

(b) Biaxial geogrid

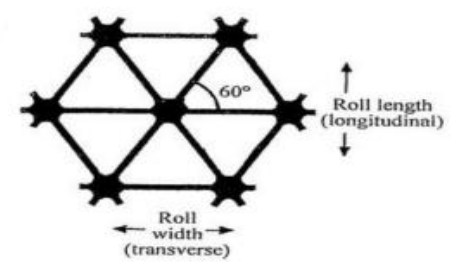

(c) Triaxial geogrid

Figure 2.7 Types of Geogrid (Das 2010) 


\subsubsection{Reinforcing Mechanism of Geogrids}

Geogrids are popular for their reinforcing mechanism (Perkins and Ismeik 1997). Geogrids have a uniformly distributed array of apertures between longitudinal and transverse tension-bearing elements. The apertures allow direct contact between particles on either side of the installed sheet, which serves to increase the interaction between the geogrid and the backfill soil. Three main mechanisms were attributed to geogrid reinforcement. They are- 1) lateral resistance due to friction, 2) improvement of bearing capacity and 3) membrane effect (Giroud and Noiray 1981; Giroud et al. 1984; Perkins and Ismeik 1997; Holtz et al. 1997). Frictional and interlocking characteristics at the interface between the soil and the geosynthetic contribute to lateral resistance mechanism. The inclusion of geogrid can reduce the shear stresses transmitted to the subgrade and offer vertical confinement at the interface. These phenomena led to increase in bearing capacity. Geogrids can also be acted as tensioned membrane, which can support the vertical loads and resist vertical deformations. However, significant deformation is necessary to realize the effect (Barksdale et al. 1989). Figure 2.8 illustrates the reinforcing mechanism of geogrid.

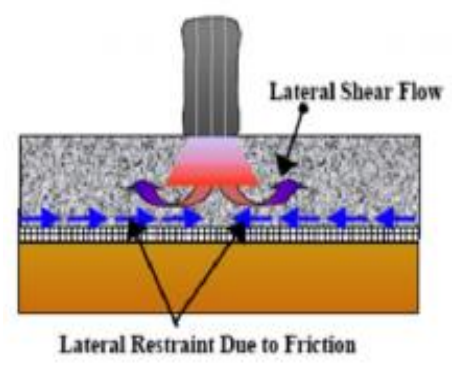

(a)

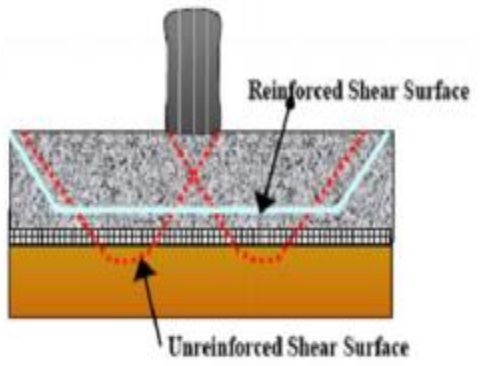

(b)

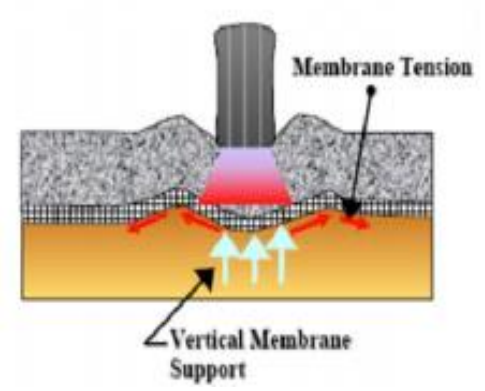

(c)

Figure 2.8 Reinforcing effect of Geogrid (a) Lateral resistance; (b) Increased bearing capacity; and (c) Membrane effect (Holtz et al. 1998) 


\subsubsection{Previous Research on Geogrid}

Geogrids have been used in numerous applications in pavement industries (Zornberg 2011). Geogrids have been successfully used to provide a construction platform over weak subgrades (Cancelli et al. 1996, Haas et al. 1988, Halliday and Potter 1984). Researchers qualified and quantified the effectiveness of geogrids in pavements (Al-Qadi et al.1997; Perkins and Ismeik 1997; Berg et al. 2000).

\subsection{Experimental Studies}

Geogrid reinforcement offers lateral stiffness of base materials against swelling (Dessouky 2015). He conducted a comprehensive study of pavement rehabilitation performance over expansive soils in three projects. Each site was evaluated using visual survey, field and laboratory testing, surface condition/ride data and structural design calculations. Based on the field performance, it was found that geogrids were effective with the combination of subgrade stabilization. The offer lateral stiffness to base materials along with vertical stiffness of itself.

Zornberg and Gupta (2009) illustrated case studies on basal reinforcement in pavements to mitigate the development of longitudinal cracks due to swelling clays. They conducted their case studies on low volume roads in central Texas. The cracks were governed due to the volumetric movements of expansive soils with seasonal moisture variations. Based on their field survey results regarding the impact of expansive soils showed that $86 \%$ of their projects were reported with pavement cracking due to heaving nature subgrade. The finding of these surveys illustrated the potential benefits of geogrid reinforcement to mitigate the longitudinal cracks due to expansive soils. In one of the 
projects (FM 1915), a particular stretch of pavement section in Milam County, Texas was reconstructed due to severe longitudinal cracks. The pavement segment was divided into three sections. In two sections, geogrids were placed at the interface of base and subgrade whereas no reinforcement was placed in the middle section. Field results exhibited significant cracks on unreinforced section while no longitudinal cracks were shown on the reinforced sections. Several other projects also provided enough evidence of potential benefits of geogrids by stabilizing pavement over expansive clays with high plasticity.

Though the field results revealed the benefit of geogrid application, there is no indepth study available to evaluate geogrid performance on flexible pavement over expansive subgrade. Further investigation is needed to identify the governing mechanism behind the performance benefit.

\subsection{Numerical Studies}

Several studies that employ numerical analysis to analyze geogrid-reinforced pavement structures have been reported in the literature (Barksdale et al. 1989, Dondi 1994, Kwon et al. 2005, Nazzal et al. 2010, Hussein and Meguid 2016). Most of the cases, researchers tried axisymmetric analysis to observe the effect of geogrid reinforcement. Numerical analysis results of both Barksdale et al. (1989) Miura et al. (1990) showed that bearing capacity of base course increased with reinforcement and reduction of surficial displacement. However, the difference in numerical and actual results of surficial displacement is large due to linear elastic analysis (Miura et al. 1990).

Using three-dimensional finite element analysis by Abaqus, Dondi (1994) studied the performance of geosynthetics in the pavements. He found that geosynthetics improved the bearing capacity of the subgrade as well as reduced rutting up to $15-20 \%$. 
Perkin's (2001) 3-D model can quantify the reinforcing mechanism of geogrid using finite element analysis. He found that there was a reduction of lateral strain along with an increase in mean stress confinement of base layer adjacent to geogrid layer. Reinforcement also increased the stress distribution in subgrade and reduced vertical displacement at the surface.

Leng and Gabr (2005) reported that the modulus ratio of the aggregate layer to subgrade decreased with the enhancement of reinforcement of unpaved pavement sections. They also found that higher stiffness of geogrid increased reinforcement performance significantly. Kwon et al. (2005) and Nazzal et al. (2010) also followed the similar reinforcing effect of Leng and Gabr (2005).

Numerical analysis of $\mathrm{Gu}$ (2011) showed that geogrid placement within a base layer can reduce lateral stain as well as a vertical strain in base and subgrade layer. However, the performance is dominant for weak subgrade compared with moderate or stiff subgrade. Additionally, he found that the reinforcing benefits have an inverse relationship with base thickness.

Hussein and Meguid (2016) illustrated the reinforcing mechanism pf geogrid reinforcement and geogrid-soil interaction in the 3-D analysis. They tried to quantify the geogrid-soil interlocking mechanism within their analysis. The results showed that the model can illustrate the essential interlocking and friction behaviors of the system and the performance of geogrid. They also found that increase in geogrid layer can increase the bearing capacity.

Current numerical approaches do not provide clear understanding of geogrid performance in expansive soil. Interlocking mechanism of geogrid can reduce the uplift 
pressure of expansive soil (Zornberg et al. 2008). So, numerical study is needed to enlighten the reinforcing mechanism of geogrid in expansive soil.

\subsubsection{Hybrid Geosynthetic Reinforcement System-HGRS (Geocell-Geogrid}

\section{$\underline{\text { Combination) }}$}

\subsubsection{Definition}

The hybrid geosynthetic reinforcement system is an emerging term to mitigate expansive soils. The basic idea of this hybrid term is to combine the top features of different materials and to enhance better performance than their individual materials. Hybrid geosynthetics can be the combination of geocell-geogrid, geotextile-geonet, geomembrane-geogrid, geotextile- geogrid; geocell-geotextile etc. based on their specific application (Koerner 2012). HGRS is defined as geocell-geogrid reinforcement combination which can surpass the individual benefits of geocells or geogrids. Figure 2.9 presents an application of geocell-geotextile hybrid system in railroads.

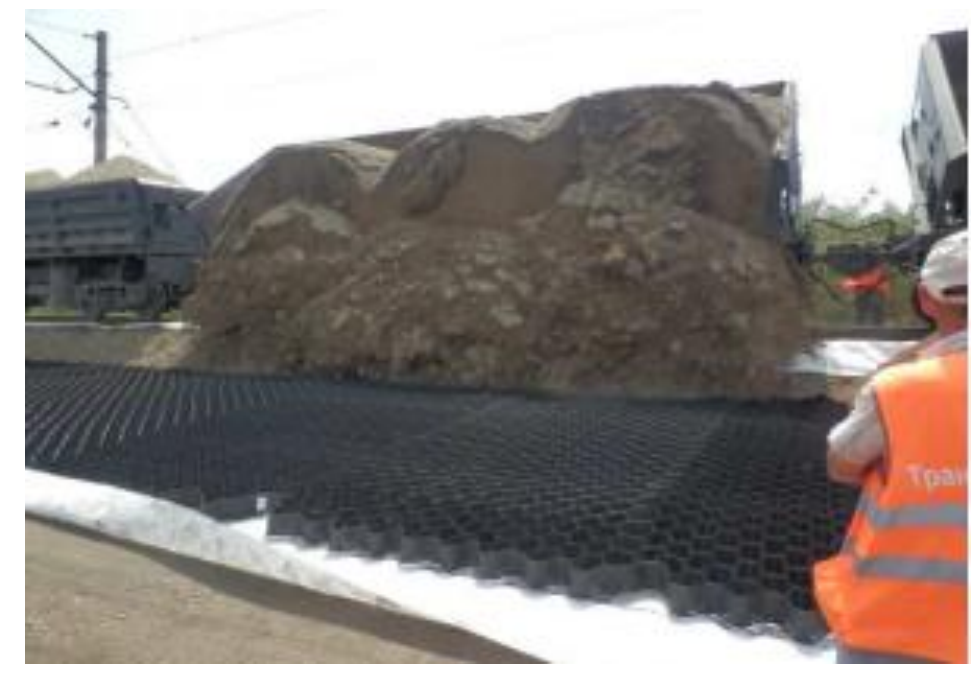

Figure 2.9 Geocell-Geotextile Hybrid System (http://geosynsummit.in/Presentation/Miki-Granski.pdf) 


\subsubsection{Reinforcing Mechanism of HGRS}

The philosophy behind HGRS is to combine their reinforcing mechanism and add additional supports to their individual members. Geocells have confinement, hoop stress, and horizontal frictional resistance benefits whereas geogrids have lateral frictional resistance and membrane effect. When both of these materials are placed in a combined system, a collective reinforcing effect is generated which have not only confinement and hoop stress but also lateral resistance and tension effect. Figure 2.10 illustrates the combined effect of HGRS. In the figure, orange, purple, blue, red and sky-blue arrows represent the confinement within the cell, frictional resistance within the cell wall, passive earth resistance due to adjacent cells, membrane effect and lateral resistance respectively.

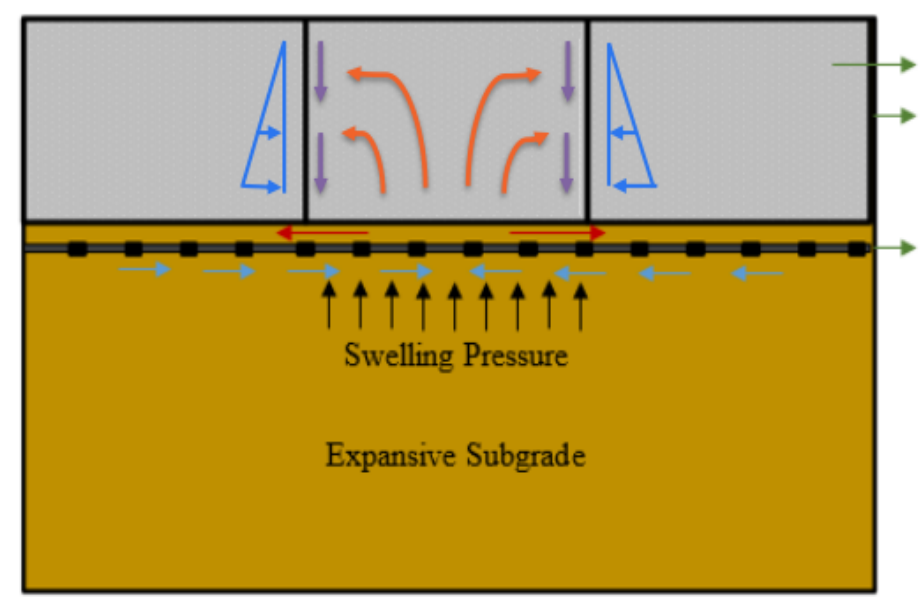

\section{Infill Materials}

Geocell

Geogrid

$\longrightarrow$ Confinement within the cell

$\longrightarrow$ Frictional resistance within the cell

$\longrightarrow$ Passive Earth Resistance

$\longrightarrow$ Membrane effect

$\longrightarrow$ Lateral resistance

Figure 2.10 Reinforcing Mechanism of HGRS

2.6.3.3 Previous Research on HGRS

HGRS is not an established stabilization method in transportation industries. Very few studies have been found for railroads and embankments which can fortify the 
combined benefit of the geocell-geogrid hybrid system (Sitharam and Hedge 2013; Kief 2015).

Sitharam and Hedge (2013) investigated the performance of geocell-geogrid combination over the soft settled red mud in embankments shown in Figure 2.11. It was found from the study that the performance of combined effect of the geosynthetic system increased the bearing capacity 4-5 times compared with the unreinforced case. The interconnected cells formed a panel mattress and transferred the load to a larger area, leading to a better performance. Moreover, geocell confinement also decreases the settlement and the surface heaving. Hence, geocell can be preferred alternative for the stabilization of soft soil. Results suggested that the combination of the geocell and geogrid can be more beneficial than geocell alone. The inclusion of geogrid can be mobilized the extra support in clay bed as well as resisted the settlement of the footing. Based on their experimental study, they proposed a foundation scheme to support an embankment.

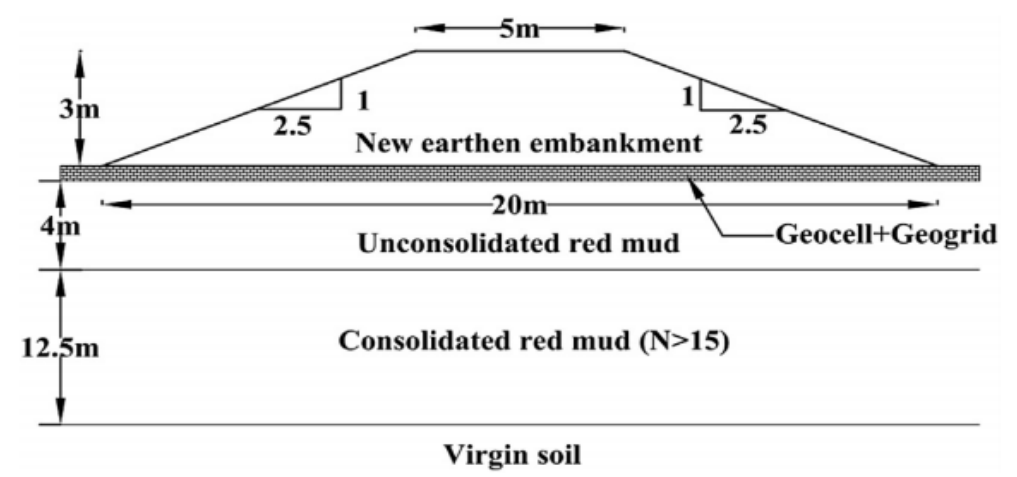

\section{Figure 2.11 Proposed foundation scheme to support embankment using Geocell- Geogrid Combination (Sitharam and Hedge, 2013)}

Kief (2015) introduced a newly developed hybrid geosynthetic system combining a stiff biaxial geogrid located at the subgrade/pavement interface with a stiff geocell layer 
embedded in the unbound granular layer in railroad engineering. The stiff geogrid provides a working platform for the stiff geocell layers, which act like an 'I' shaped structure. This combined shape created a unique composite which surpassed the sum of individual effects. They tried to address the low bearing capacity and volumetric changes (due to swelling of expansive soils) problems underneath the rail tracks. This semi-rigid composite mattress acted as a foundation which separated the weaker subgrade from the upper rail track structure and mitigated the surficial heave. Stiff geocells over weak soil act as a stable working platform and provide resistance to swelling distresses. Geogrid will provide an interlocking mechanism on the smoothed subgrade surface. More than one geocell layer will offer higher modulus and more confined layers. The performance of this hybrid system was verified by track monitoring measurements which showed negligible surficial distresses compared with the unreinforced section. These results exhibited the effectiveness hybrid geosynthetic system for other rail and road soil stabilization. Figure 2.12 presents a cross-section of hybrid geosynthetic solution proposed by Kief (2015)

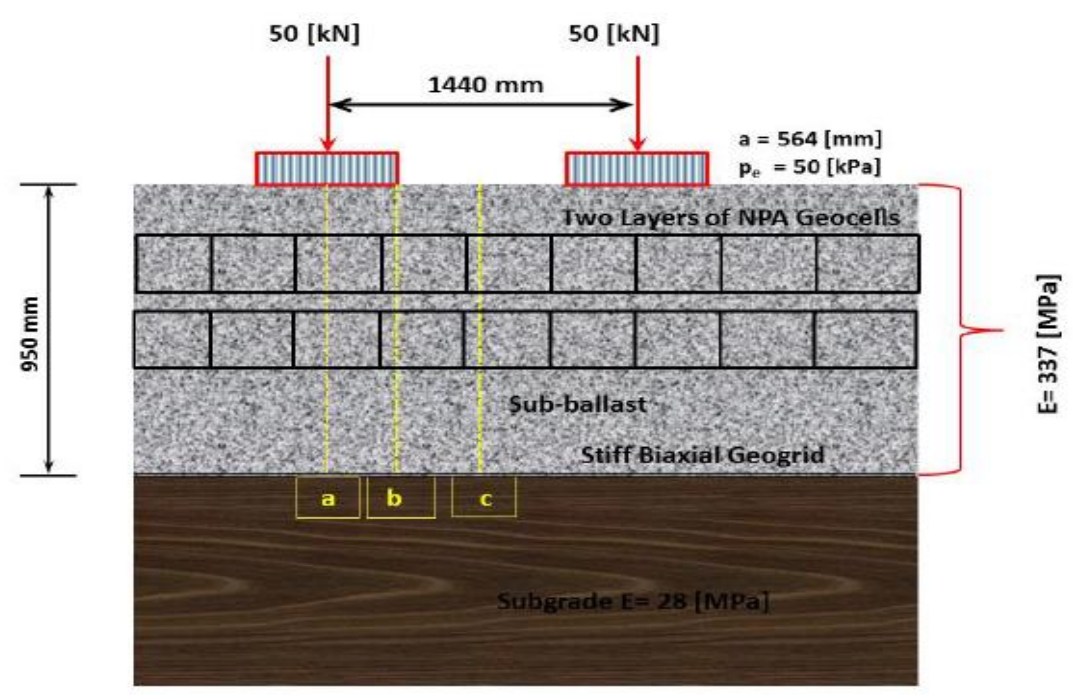

Figure 2.12 Cross Section of Hybrid Geosynthetic Solution (Kief 2015) 
Not enough literature is found for HGRS system using numerical analysis. There is enough potential of the hybrid geosynthetic reinforced system to reinforce the base layer and improve swell mitigation method on pavement surfaces. The research effort also explored the idea of the numerical study of the hybrid geosynthetic system and evaluate the efficacy over swelling related distresses.

\subsection{Summary}

Findings from an extensive review of published literature were reported in this chapter. Initially, an elaborate discussion on expansive soils and associate problems in the pavement were presented, followed by an overview of expansive swell prediction methods along with the mitigation methods. Focusing on the limitation of current mitigation methods, the potential of geosynthetic materials to stabilize expansive soils were discussed in this chapter. 


\section{CHAPTER 3: LARGE-SCALE BOX SYSTEM}

\subsection{Introduction}

This chapter presents the development of a large-scale box set-up to evaluate the effectiveness of HGRS to mitigate the swelling distresses on pavement due to expansive subgrade. This is followed by a discussion of test matrix and procedures to conduct the tests. Important outcomes from the large-scale box testing effort are presented, and inferences are drawn concerning the mitigation effort of swelling distresses on the pavement surface. The size of the box was chosen in such way that it could maintain all the practical aspects in a pavement section reliably without any boundary effect.

\subsection{Development of Large-Scale Test Setup}

Large-scale box system is aimed to measure the surficial distresses of a pavement section with and without geosynthetic systems due to expansive nature of the subgrade. The large-scale box set up is comprised of six components. They are-

1. Transparent Box

2. Soaker System

3. External Strut

4. Grid Planner Sheet

5. Displacement Measuring Tool

6. Water Reservoir

Figure 3.1 illustrates the schematic of large-scale box system. 


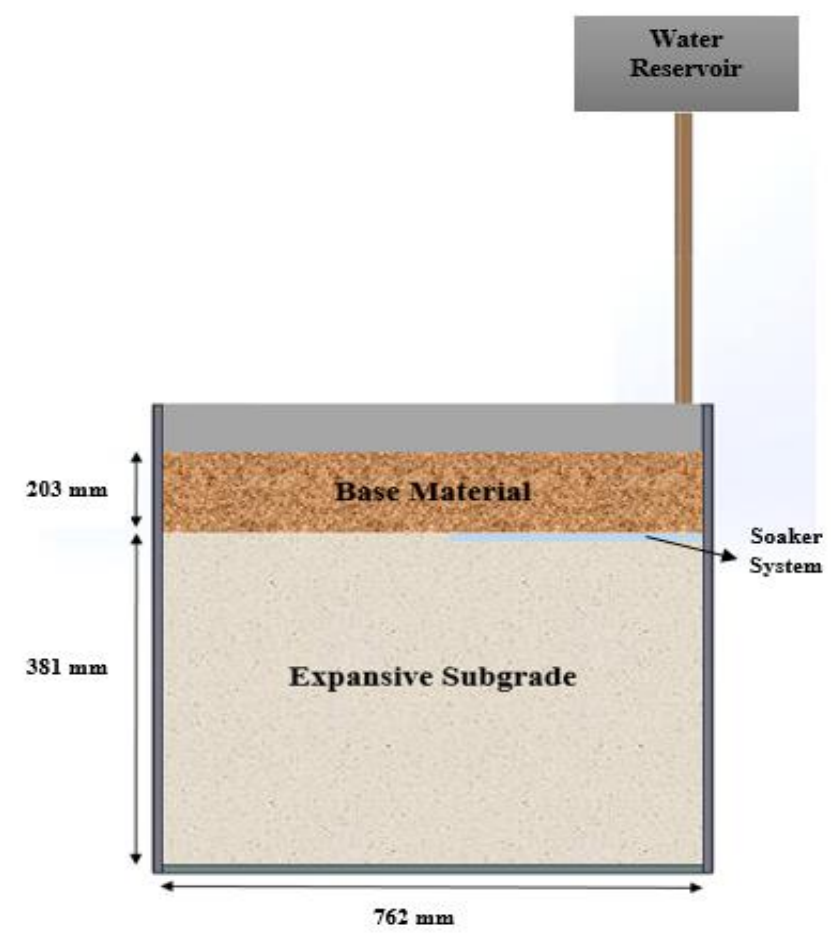

\section{Figure 3.1 Detail Schematic of Large-Scale Box System}

A transparent box with inner dimensions of $762 \mathrm{~mm}$ (length) $\times 762 \mathrm{~mm}$ (width) $\times$ $762 \mathrm{~mm}$ (height) was used for the large-scale test setup (see Figure 3.2). The box is made out of acrylic and the wall thickness was $12 \mathrm{~mm}$. The transparency of the box allows for the visual observation of moisture percolation through the soils as shown in Figure 3.3.

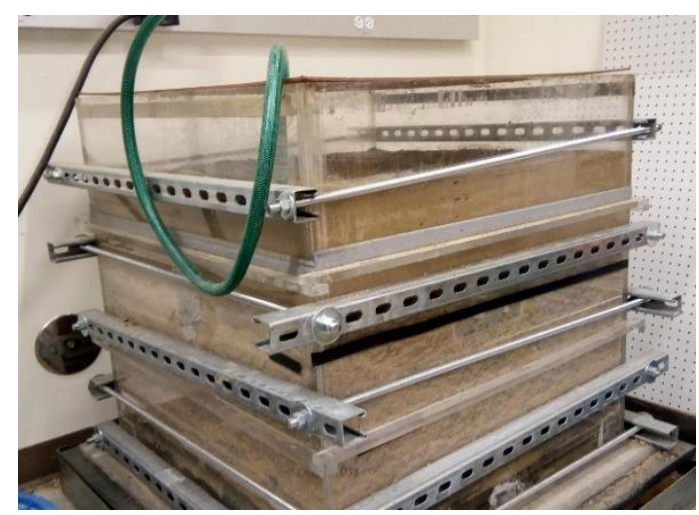

Figure 3.2 Transparent Box

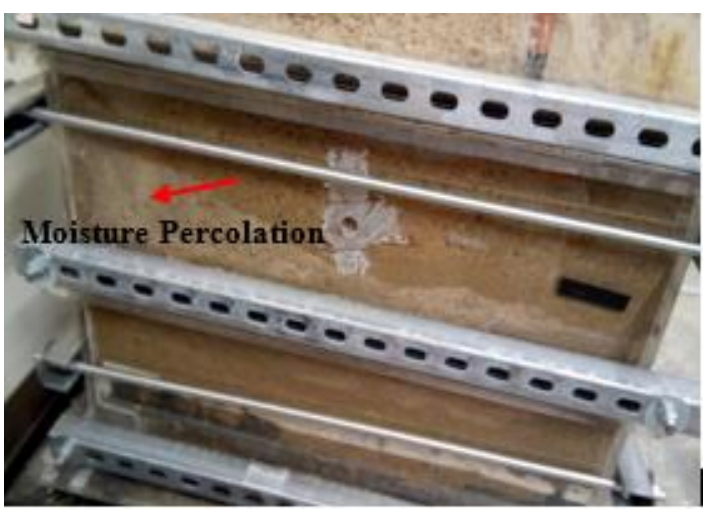

Figure 3.3 Moisture Percolation in the Box 
Garden soaker tubes were used to provide moisture to the expansive soils as shown in Figure 3.4. Two parallel soaker lines were installed (as shown in Figure 3.4) using connectors to ensure that sufficient moisture was available and also to ensure maximum possible heave in minimum possible time. This soaker system was connected to the water reservoir shown in Figure 3.5. This water reservoir is placed at a height of six feet above the top of the box to offer hydraulic gradient to enhance the saturation rate of the soil.

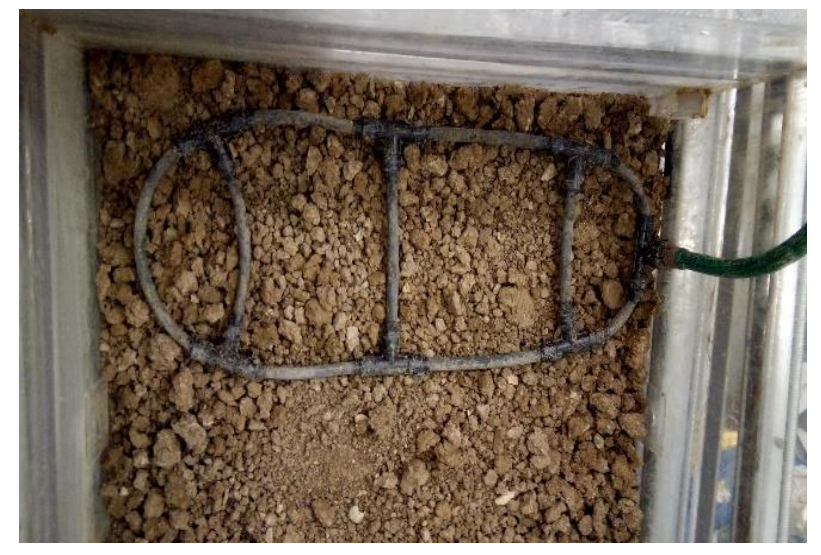

Figure 3.4 Soaker System Arrangement

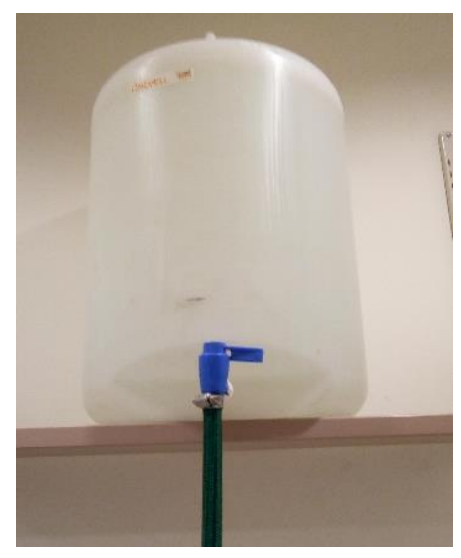

Figure 3.5 Water Reservoir

As the box is made of acrylic glass which is flexible and brittle compaction of soils and swell pressure from expansive soil could cause the side walls of the box to bend. This bending can cause lateral movement and additional stress at the joints which may lead to cracks in the box. To restrict the bending of side walls, steel struts were used to support the side walls so that there are no lateral movements. Figure 3.6 shows the struts used to reduce the bending of side walls of the box. 


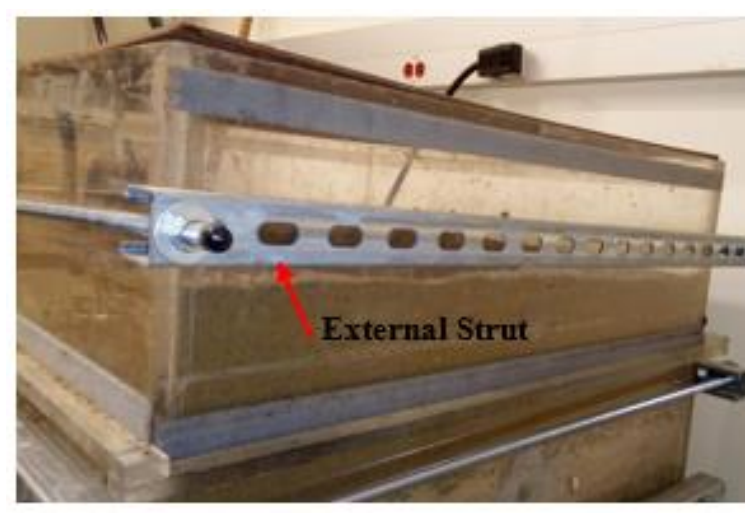

Figure 3.6 External Struts

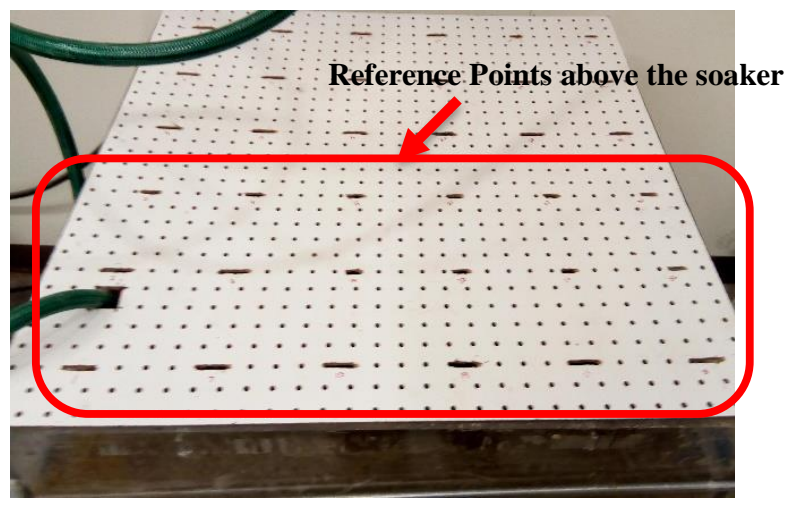

Figure 3.7 Grid Planer Sheet

The primary focus of the box test is to measure the surficial heave of the pavement section over time. A grid planer sheet is used to provide a reference plane to measure the surficial heave of the pavement surface which is shown in Figure 3.7. To measure the surficial heave over time, a total of 36 points (6 by 6 ) were selected as grid pattern. Vertical deformation is measured for each point over time. A laser distance measuring tool is used to measure the vertical deformation. The model of the laser distance measuring tool is Professional GLM 30 from BOSCH which is shown in Figure 3.8. It can measure up to $30 \mathrm{~m}$ and the accuracy of this tool is $1.5 \mathrm{~mm}$. This tool can measure distance, area, and volume in two different units (meter and feet).

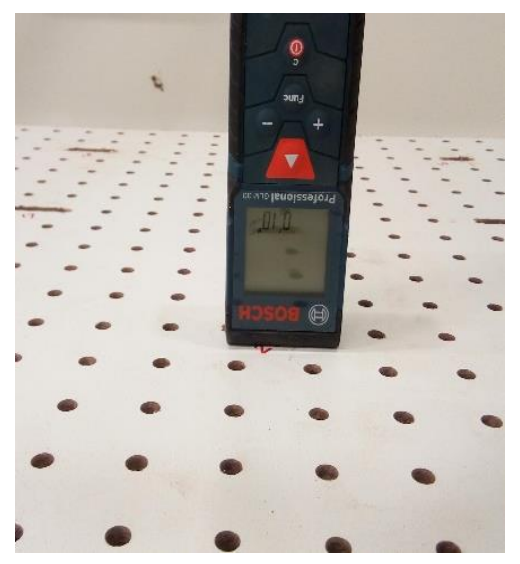

Figure 3.8 Laser Distance Measuring Tool 


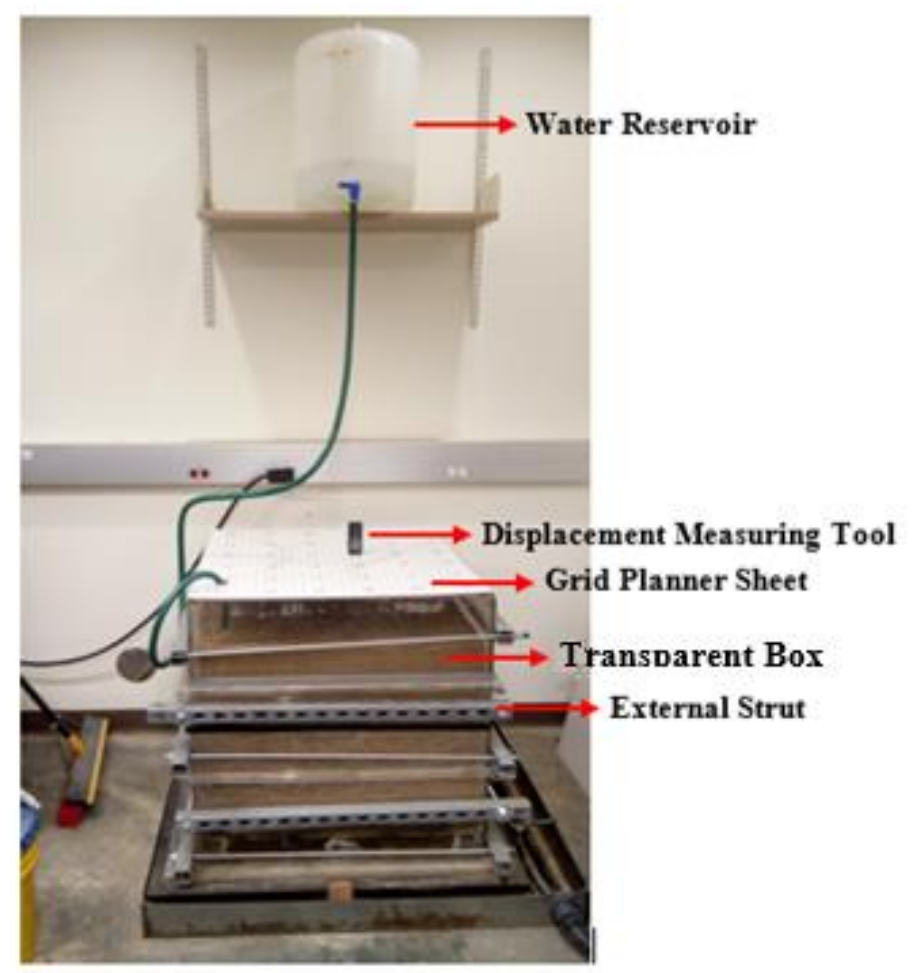

\section{Figure 3.9 Complete Set-up of the Large-Scale Box System}

\subsection{Materials used for the Large-Scale Box System}

To represent the pavement section in large-scale box test, base course and expansive subgrade materials were used as a control section. For reinforcement, geocell and geogrid are used to mitigate the swelling distresses. All these materials and their characteristics are discussed below.

\subsubsection{Expansive Subgrade}

In the box test study, an expansive soil sample was collected from a particular pavement section (milepost 0.0 to milepost 18.5) of US 95 highway in Owyhee County, Idaho. The soil sample was denoted as expansive soil-1 or ES-1. To characterize the soil sample, atterberg limit test, moisture-density relationship and hydrometer analysis are conducted. 


\subsubsection{Atterberg Limit Test}

Atterberg limit tests determine properties related to consistency of the soil. These include liquid limit (LL) and plastic limit (PL) which are necessary to define the potential of the swell-shrink behavior of soils with their respective plasticity indices. Difference between LL and PL values is the plasticity index (PI) and this index reveals the plastic characteristics of the soil. Atterberg limit test was conducted as per ASTM D4318. Oven dried $\left(105^{\circ} \mathrm{C}\right)$ and passed through a \#40 sieve soil samples were taken for the test. If the PI is greater than 35 than the swelling potential of soil is high (Army U. S., 1983). It is observed that the PI of the soil sample is greater than 35 and can be classified as highly expansive in nature. Table 3.1 represents the atterberg limit test results for ES-1.

\section{Table 3.1 Results of Atterberg Limit Tests}

\begin{tabular}{|c|c|c|c|c|}
\hline Material & LL (\%) & PL (\%) & PI (\%) & Nature of the Soil \\
\hline ES-1 & 111 & 40.4 & 71 & Expansive \\
\hline
\end{tabular}

\subsubsection{Moisture-Density relationship}

Proctor compaction method is used to determine the moisture-density relationship of a soil, specifically, the optimal water content (OMC) at which soil can reach its maximum dry density (MDD). This test is conducted per ASTM D698. A curve was then plotted between the dry unit weight and the moisture content of the materials. The optimum moisture content (OMC) and the maximum dry unit weight (MDD) were obtained from the plotted curve. Moisture-Density plot for ES-1 is shown in Appendix A. Table 3.2 presents the OMC and MDD value for ES-1 soil sample. In the box test, soil 
sample is compacted at $95-98 \%$ of MDD with moisture content of $25 \pm 3 \%$ which is located on the dry side of moisture-density plot.

Table 3.2 Results of Moisture Density Relationship

\begin{tabular}{|c|c|c|}
\hline Material & MDD $\left(\mathbf{k g} / \mathbf{m}^{\mathbf{3}}\right)$ & OMC (\%) \\
\hline ES-1 & 1095 & 32.5 \\
\hline
\end{tabular}

\subsubsection{Hydrometer Analysis}

Hydrometer analysis is used when a larger portion of soil is fine-grained and gradation for the particle size less than No. $200(.075 \mathrm{~mm})$ is needed. The whole process is followed for ES-1 soil as per ASTM D7928-17. Type 152H hydrometer is used for the hydrometer analysis. In the analysis, the portion of clay and silt is determined. More the expansive clay, more the swelling. Gradation plot for ES-1 is shown in Appendix A.

Table 3.3 shows the summary of gradation result for ES-1.

Table 3.3 Gradation Analysis Results

\begin{tabular}{|c|c|c|c|c|}
\hline Material & \% Gravel & Sand (\%) & \% Silt & \% Clay \\
\hline ES-1 & $0 \%$ & $4.5 \%$ & 19 & 76.5 \\
\hline
\end{tabular}

\subsubsection{Base Course}

Base course is one of the important layers which can play a significant role in pavement quality and serviceability. For large-scale box system, a typical base course material was used. Moisture-density relationship and gradation analysis were done as per ASTM D698 and ASTM 6913 respectively. Moisture-density relationship and gradation plots can be found in Appendix A. Table 3.4 summarize the results the characterization of 
base course materials. Based on the gradation analysis, the base course material was classified as poorly graded sand with gravel (SP) according to USCS soil classification.

Table 3.4 Base Course Characterization

\begin{tabular}{|c|c|c|c|}
\hline \multicolumn{4}{|c|}{ Moisture Density Relationship } \\
\hline Material & MDD (kg/m $\left.\mathbf{m}^{3}\right)$ & OMC (\%) & 95 \% of MDD (kg/m $\left.{ }^{3}\right)$ \\
\hline Base Course & 2315 & 8.5 & 2200 \\
\hline \multicolumn{3}{|c|}{ Gradation Analysis } \\
\hline Material & \% Gravel & Sand (\%) & \%Fines \\
\hline Base Course & $39.6 \%$ & $59 \%$ & 1.6 \\
\hline
\end{tabular}

\section{$\underline{3.3 .3 \quad \text { Geocell }}$}

A high-density polyethylene (HDPE) geocell was used to mitigate swelling in the experimental study (as shown in Figure 3.10). The depth and the thickness of the geocell were $152 \mathrm{~mm}$ and $1.5 \mathrm{~mm}$ respectively. There were 8 cells in the sample and the expanded cell size is $370 \mathrm{~mm}$ by $250 \mathrm{~mm}$. Properties were found from the manufacturer and stress-strain characteristics of the geocell material under uniaxial tension were found from the literature (Yang 2010; EnviroGrid 2017) and shown in Table 3.5.

Table 3.5 Geocell Material Characteristics

\begin{tabular}{|c|c|c|c|c|c|}
\hline Material & $\begin{array}{c}\text { Thickness } \\
(\mathbf{m m})\end{array}$ & $\begin{array}{c}\text { Depth } \\
(\mathbf{m m})\end{array}$ & $\begin{array}{c}\text { Density } \\
\left(\mathbf{k g} / \mathbf{m}^{\wedge} \mathbf{3}\right)\end{array}$ & $\begin{array}{c}\text { Tensile } \\
\text { Strength }(\mathbf{M P a})\end{array}$ & $\begin{array}{c}\text { Modulus at } \\
\mathbf{1 \%} \text { Strain } \\
(\mathbf{M P a})\end{array}$ \\
\hline $\begin{array}{c}\text { HDPE } \\
\text { Geocell }\end{array}$ & 1.5 & 150 & 950 & 12.4 & 392 \\
\hline
\end{tabular}




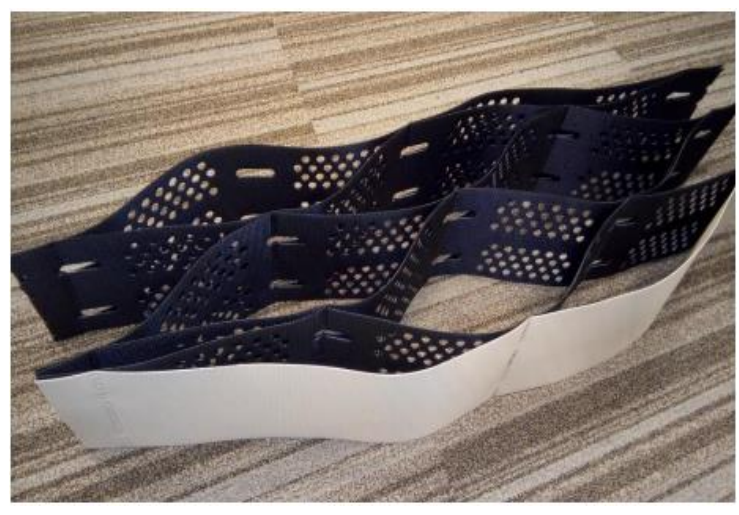

Figure 3.10 HDPE Geocell Sample

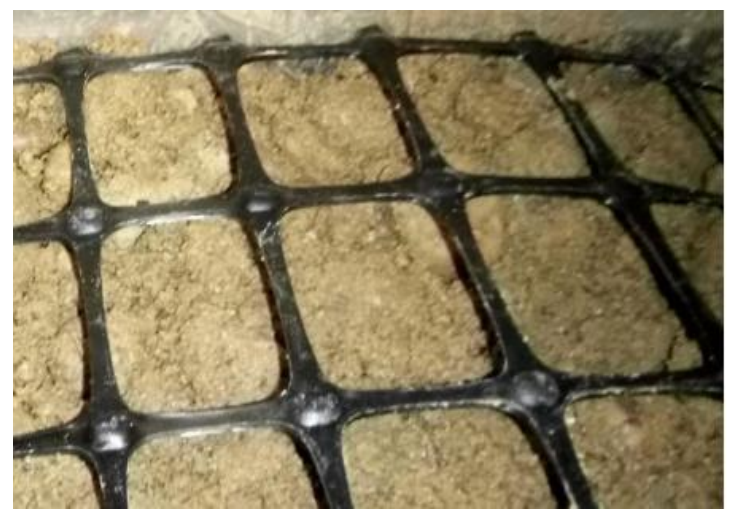

Figure 3.11 Biaxial Geogrid Sample

\subsubsection{Geogrid}

A biaxial geogrid material was used in the experimental study which is shown in

Figure 3.11. This material is composed of polypropylene resin which extruded into grid pattern (TenCate 2017). This material is inactive to any biological process and resistant to naturally encountered chemicals, alkalis, and acids. Grid aperture size of the sample was $25.4 \mathrm{~mm}$ in machine direction (MD) and $33.0 \mathrm{~mm}$ in cross machine direction (CMD). The thickness of the geogrid was $1.5 \mathrm{~mm}$. Mechanical properties of the geogrid sample were found from the manufacturer which is shown in Table 3.6.

Table 3.6 Geogrid Material Characteristics (TenCate 2017)

\begin{tabular}{|c|c|c|c|c|}
\hline Mechanical Properties & Test Method & Unit & \multicolumn{2}{|c|}{$\begin{array}{c}\text { Minimum Average Roll } \\
\text { Value }\end{array}$} \\
\cline { 4 - 5 } & & & MD & CMD \\
\hline Tensile Strength (ultimate) & ASTM & $\mathrm{kN} / \mathrm{m}$ & 19.2 & 28.8 \\
& D6637 & & & 9.0 \\
\hline $\begin{array}{c}\text { Tensile Strength (2\% } \\
\text { strain) }\end{array}$ & $\begin{array}{c}\text { ASTM } \\
\text { D6637 }\end{array}$ & $\mathrm{kN} / \mathrm{m}$ & 6.0 & 19.6 \\
\hline $\begin{array}{c}\text { Tensile Strength (5\% } \\
\text { strain) }\end{array}$ & $\begin{array}{c}\text { ASTM } \\
\text { D6637 }\end{array}$ & $\mathrm{kN} / \mathrm{m}$ & 11.8 & \multicolumn{2}{|c|}{93} \\
\hline \multicolumn{2}{|c|}{ Junction Efficiency } & $\%$ & \multicolumn{2}{|c|}{750000} \\
\hline \multicolumn{2}{|c|}{ Flexural Stiffness } & $\mathrm{mg}-\mathrm{cm}$ & \multicolumn{2}{|c|}{105} \\
\hline \multicolumn{2}{|c|}{ Aperture Stability } & $\mathrm{m}-\mathrm{N} / \mathrm{deg}$ & \multicolumn{2}{c|}{100} \\
\hline \multicolumn{2}{|c|}{ Resistance to Long-Term Degradation } & $\%$ & \multicolumn{2}{c|}{} \\
\hline \multicolumn{2}{|c|}{ Resistance to UV Degradation } & $\%$ & \multicolumn{2}{c|}{} \\
\hline
\end{tabular}




\subsection{Large-Scale Box Test Configurations}

Large-scale box test comprises of four configurations that include one control unreinforced section and three geosynthetic reinforced section. These configurations are as follows:

1. Control Section (CS)

2. Geocell Reinforcement (GC)

3. Geogrid Reinforcement (GG)

4. Hybrid Geosynthetic Reinforcement System (HGRS)

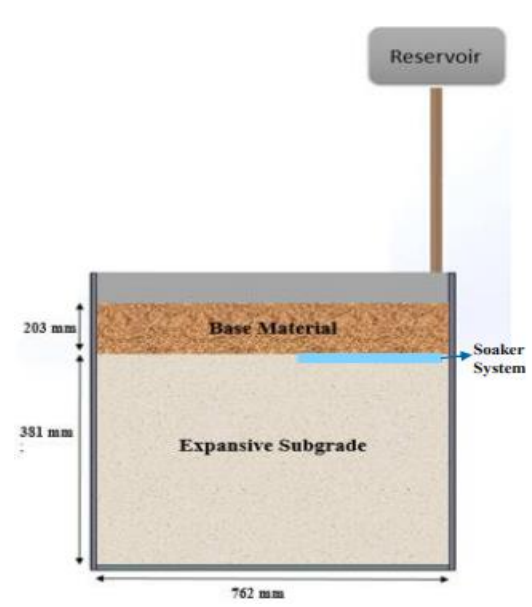

Control Section (CS)

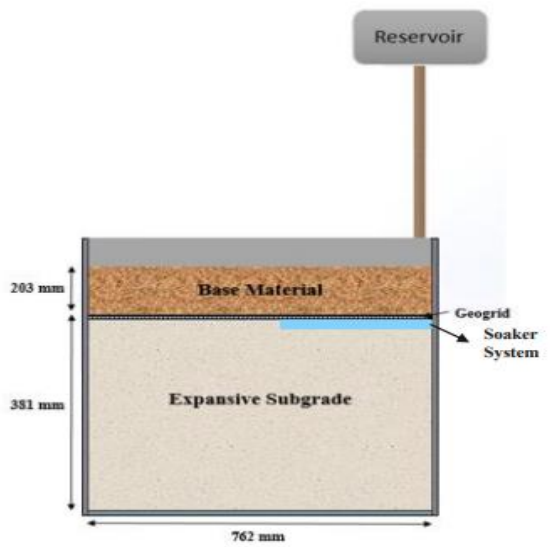

Geogrid Reinforcement (GG)

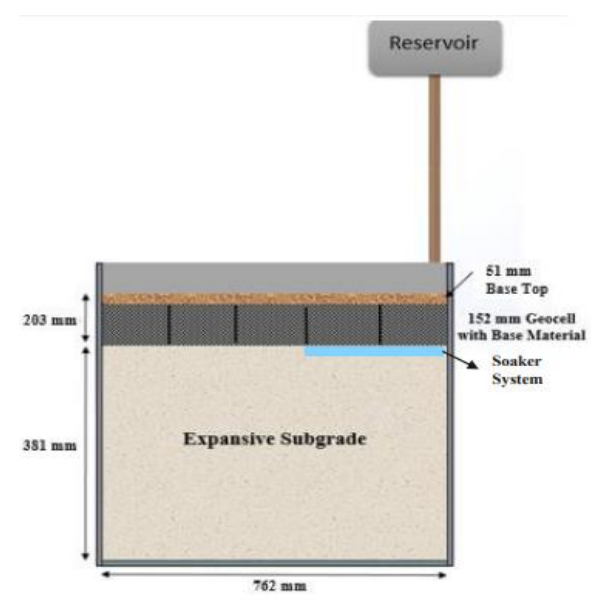

Geocell Reinforcement (GC)

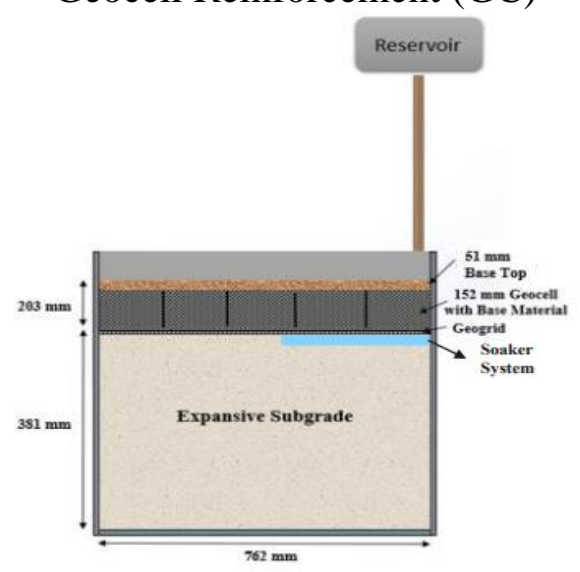

Hybrid Geosynthetic Reinforced System (HGRS)

Figure 3.12 Schematics of Test Configurations 
Each of the test configurations and the corresponding results is discussed in the following sections. Figure 3.12 shows the test configurations of the large scale box system.

\subsubsection{Control Section (CS)}

The initial test was aimed at establishing the baseline for heave potential of the expansive soil under a pavement section resting on a conventional base layer without reinforcement. Hence the control section without reinforcement (CS) was prepared and monitored for the differential heave on the surface. Base course and expansive subgrade (ES-1) samples were used for this section in the box which is shown in Figure 3.13. A $203 \mathrm{~mm}$ of base course material was placed over $381 \mathrm{~mm}$ of the expansive subgrade. The base course material was compacted at $90-95 \%$ of MDD with $6 \pm 1 \%$ of moisture content and subgrade was compacted at $95-98 \%$ of MDD with $25 \pm 3 \%$ of moisture content. Hand compaction was used to compact the materials. Figure 3.14 shows the compaction tool for the test. Base and subgrade were compacted in four and eight layers respectively.

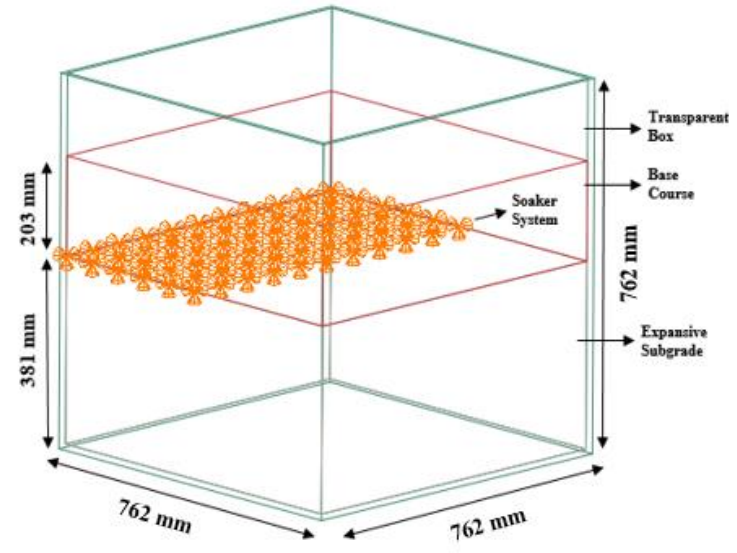

Figure 3.13 Schematic of Control

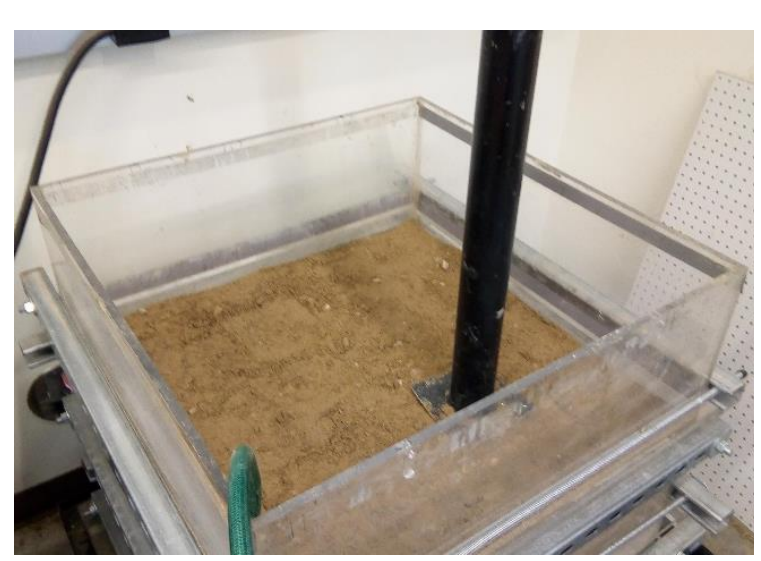

Figure 3.14 Hand Compaction Tool

\section{Section}


Soaker system arrangement was embedded at the top of the subgrade (half portion) shown in Figure 3.15 to initiate differential heaving. Base compaction was done in such a way that the soaker system arrangement was intact. Placement of soaker system arrangement was selected based on several trials to find out the efficacy of the system. In these trials, soaker system was placed at the bottom, at the middle and at the top of the subgrade and provided sufficient moisture for 15 days. No base layer was included for these trials. In these trials, up to $101.6 \mathrm{~mm}$ of surficial heave was observed when the soaker system was at the top. Typically, expansive subgrades are encountered by the moisture due to surface runoff during rainfall. The water percolates through base layers into the subgrade. The soil absorbs the moisture and swells based on its swelling potential and cracks and heaves start to appear at the pavement surface. Placement of the soaker system at the top of subgrade justifies that situation. Figure 3.16 shows the control section after compaction. A water reservoir was connected with soaker system to provide sufficient moisture. When the complete set up was done, the outlet valve of water reservoir was opened to supply moisture which is shown in Figure 3.17. Initially, surrounding soils near soaker system was encountered by the moisture and it started swelling. Water was percolated through the voids and saturated the adjacent soils with time. So differential swelling occurred within the system over time. A grid planner sheet is placed at the top of the box to provide a reference plane. Thirty-six reference points were marked on the planner sheet in a grid pattern. The vertical swelling was measured using laser displacement measuring tool as shown in Figure 3.18. The soil is allowed to swell for 15 days. Swelling data were recorded for all the 36 points over time which is shown in Appendix A. 


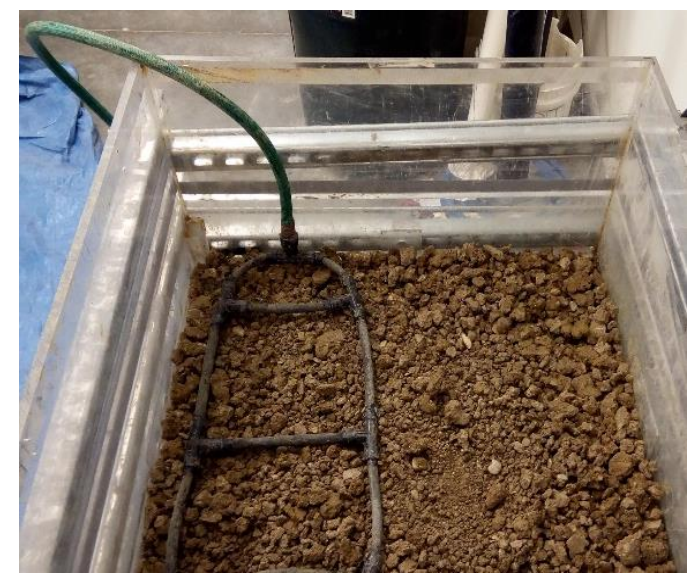

Figure 3.15 Placement of Soaker System at the Top Half of Subgrade

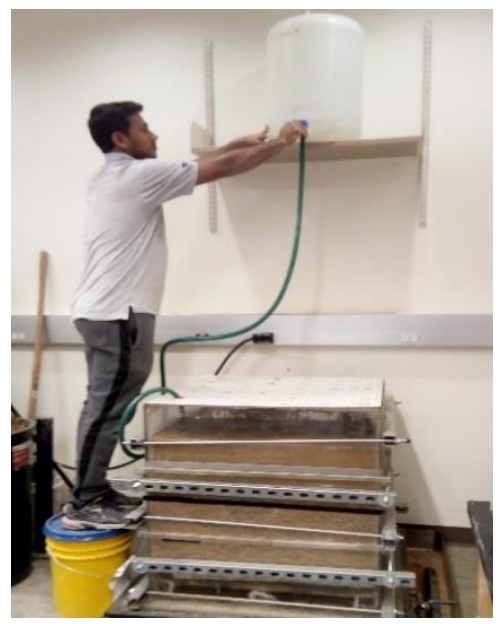

Figure 3.17 Moisture Supply through Water Reservoir

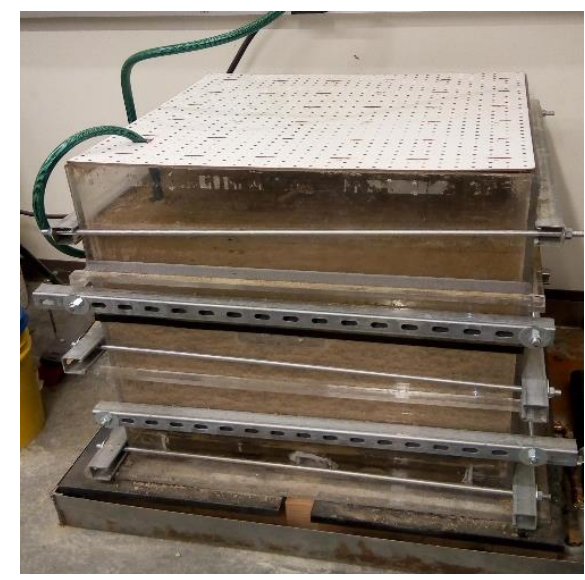

Figure 3.16 Control Section after Compaction

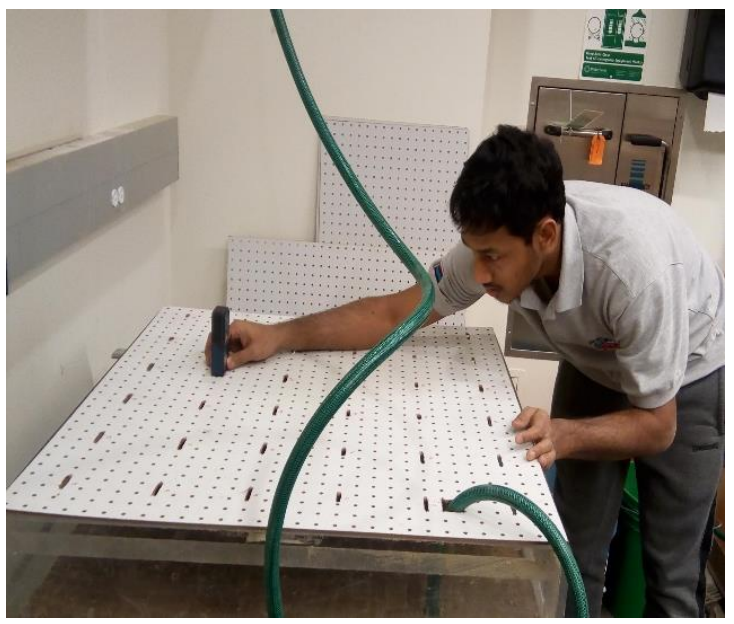

Figure 3.18 Measurement of Vertical Swelling

\subsubsection{Geocell Reinforcement (GC)}

After getting the results from the control section, geocell was used as reinforcing material for next test (as shown in Figure 3.19). HDPE geocells with $152 \mathrm{~mm}$ cell depth were embedded into the base course layer. Subgrade (ES-1) was prepared using the same process with the soaker system. Soaker system was embedded in the top half of the expansive soil section similar to the control section. Base course material was 


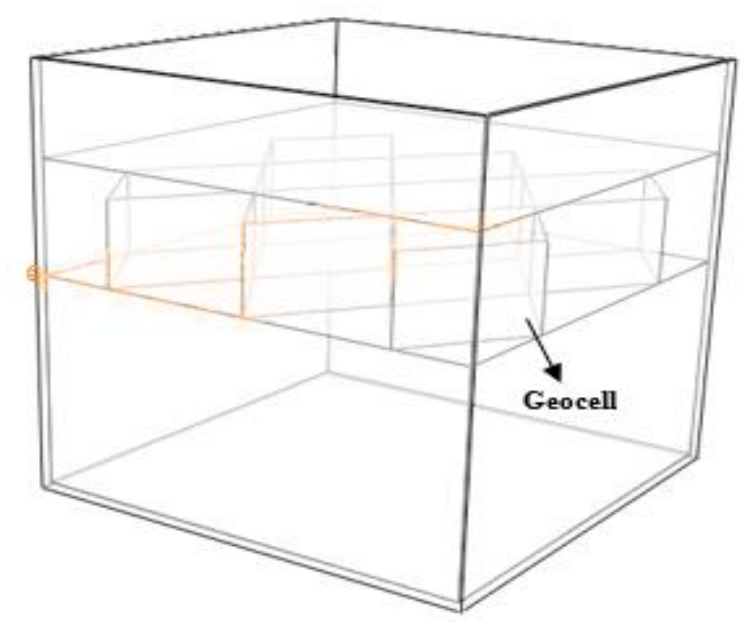

Figure 3.19 Schematic of GC Section

placed in two rounds. In first round, geocells and base course were placed and compacted which is shown in Figure 3.20 and then a $51 \mathrm{~mm}$ of base course layer was placed as cover. Figure 3.21 shows the GC section after compaction. Density and water content of the soils were maintained as per control section. When the sample preparation was done, grid planner sheet was placed at the top of the box as reference plane. The water reservoir was connected with the soaker system and started the test. The test was continued for 15 days as well to compare the results with control section. Swelling data of the test with time is presented in Appendix A.

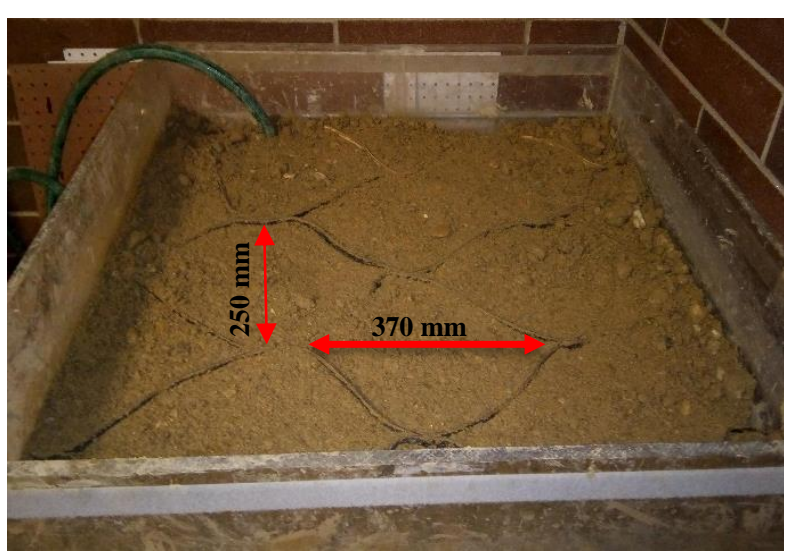

Figure 3.20 Geocell Placement

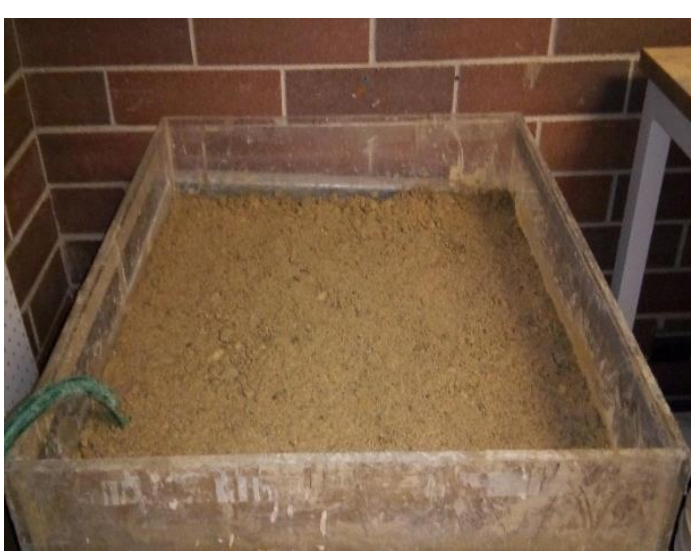

Figure 3.21 GC Section after Compaction 


\subsubsection{Geogrid Reinforcement (GG)}

In third test, biaxial geogrid was used to mitigate the swelling distresses in the pavement section. The pavement section with geogrid is shown in Figure 3.22. Geogrid is placed at the bottom layer of base as shows in Figure 3.23. Geogrid layer was anchored at the sides to introduce the tension effect. After compacting the subgrade according to control section,

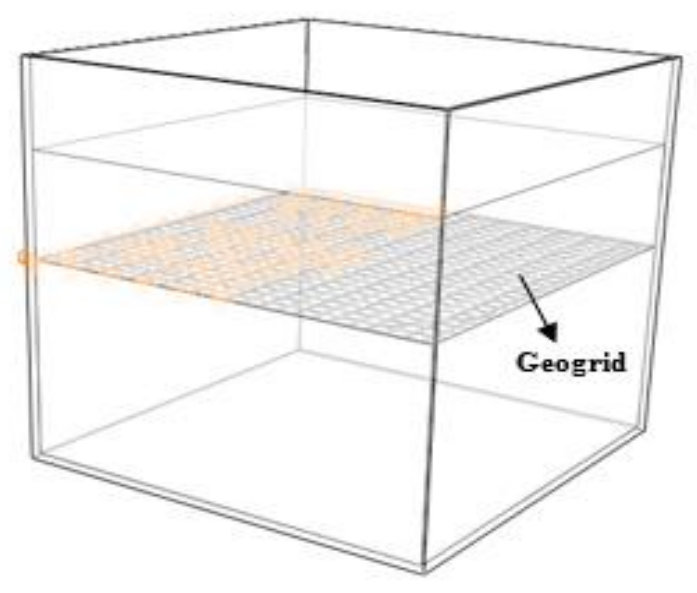

Figure 3.22 Schematic of GG Section

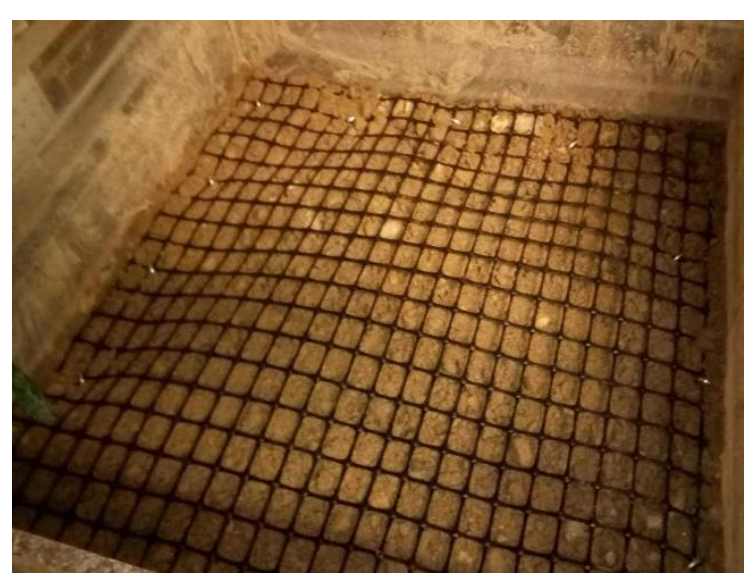

Figure 3.23 Geogrid Placement

the top of subgrade and geogrid was placed above that layer. Galvanized steel pegs were used to anchor the geogrid sheet. All the outer sides of the geogrid sheet were anchored into the soil with 5 pegs on each side with a total of 20 pegs. Figure 3.24 and Figure 3.25 show the steel peg and geogrid anchoring into the soils respectively. After fastening the geogrid sheet, base materials were placed and compacted as per control section. The thickness of the base and subgrade also maintained in accordance with control section. After completing the setup, similar procedures were followed for GG section and water was provided to the subgrade for 15 days. Surficial movements were measured and recorded for all 36 reference points over time which is shown in Appendix A. 


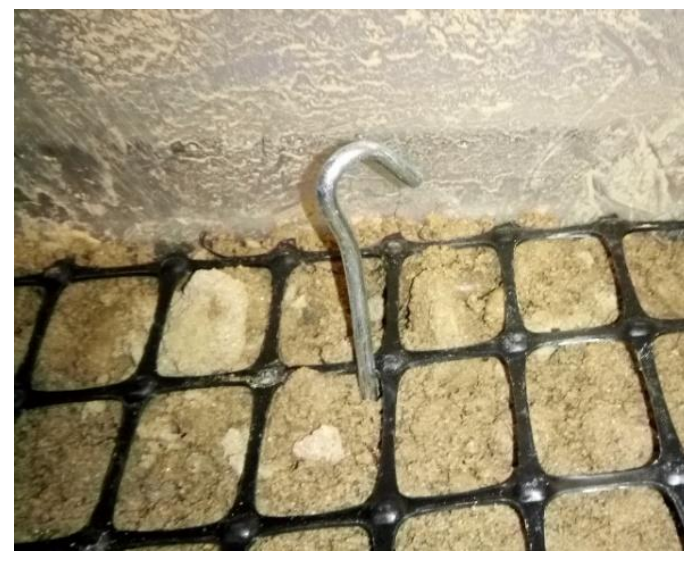

Figure 3.24 A photograph of Steel Peg

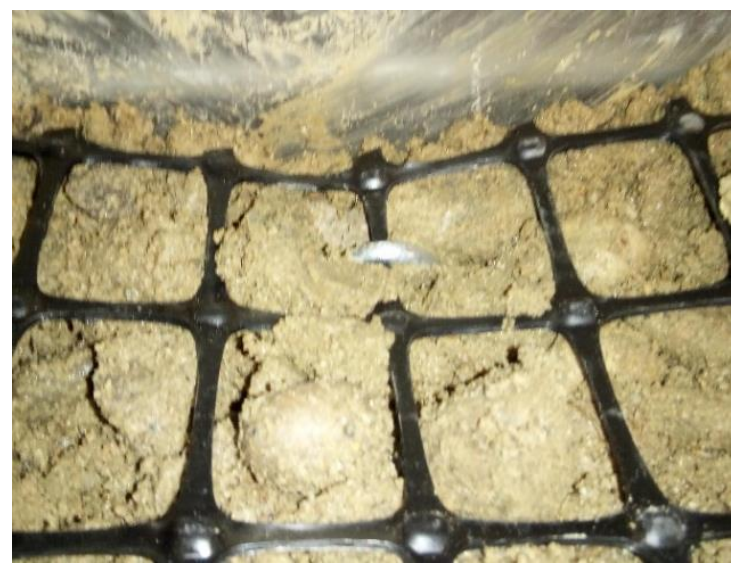

Figure 3.25 Anchoring Geogrid using Steel Peg

\subsubsection{Hybrid Geosynthetic Reinforcement System (HGRS)}

The final test of the large-scale box system was the pavement section with HGRS which is shown in Figure 3.26. HGRS is the combination of one geocell layer and one geogrid layer. The primary focus of this combination is to combine the advantages of geocell and geogrid in one system to dissipate swelling distresses.

All the procedures were same and geocell and geogrid were placed together. After compaction of subgrade, geogrid was placed like GG section and $50 \mathrm{~mm}$ of base layer was

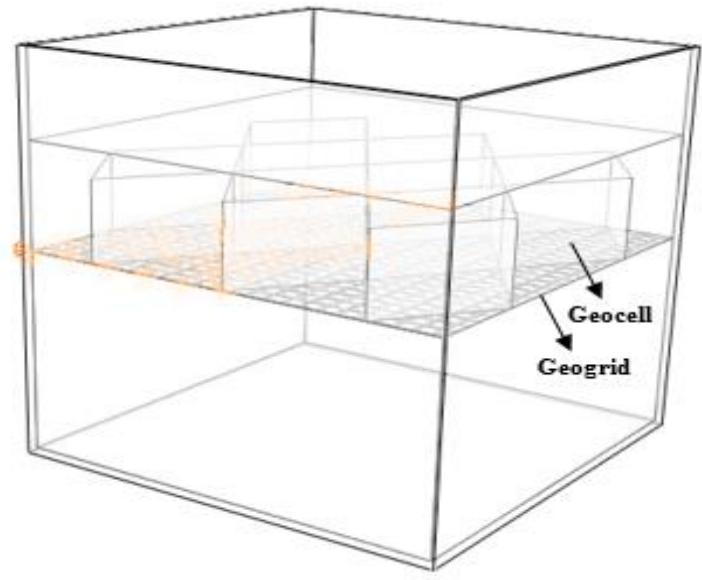

Figure 3.26 HGRS Section 
placed at the top of geogrid and compacted for interlocking. After that, geocell was placed in the box and filled base course materials and compacted. A similar process was followed like GC section until the all the cells were filled with base materials. The thickness of the base and subgrade were same as control section. Identical procedures were followed for HGRS section to provide moisture to the subgrade up to 15 days. Surficial movements were measured and recorded for all 36 reference points over time. Deflection plot for all the points over time is shown in Appendix A. Figure 3.27 and Figure 3.28 represents the geogrid and geocell installation in HGRS section respectively.

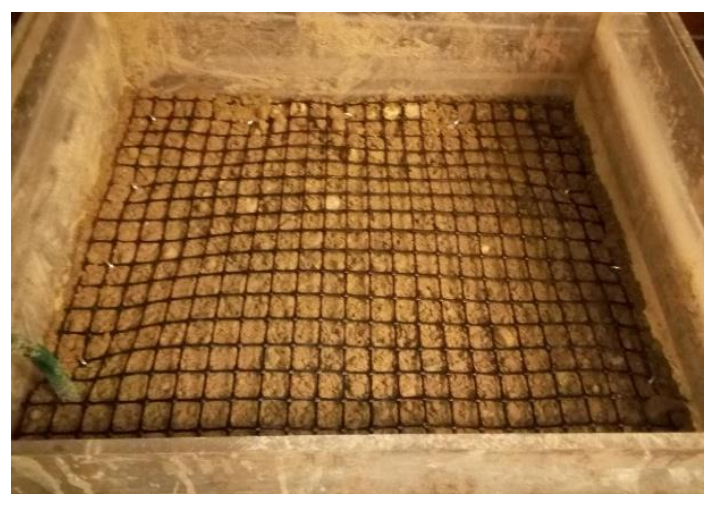

Figure 3.27 Geogrid Installation in HGRS Section

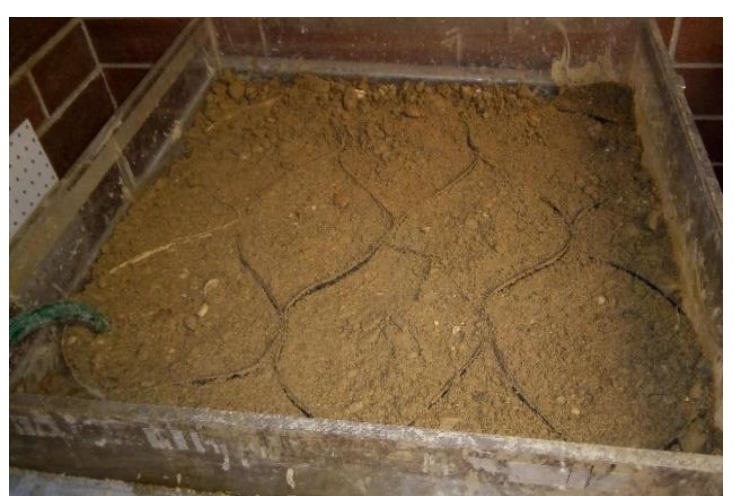

Figure 3.28 Geocell Installation in HGRS Section

\subsection{Large-Scale Box Test Results}

The main objective of the large-scale box test was to evaluate the effectiveness of HGRS to mitigate differential heave due to expansive subgrade and compare the results with the control section. The HGRS performance was also compared with GC and GG sections. Test results showed that all the reinforced systems significantly reduced the maximum heave of the pavement section compared to the control section. The performance of HGRS was dominant among the test results. Figure 3.29 shows the maximum heaving plot with time for all four sections tested using large-scale box. 


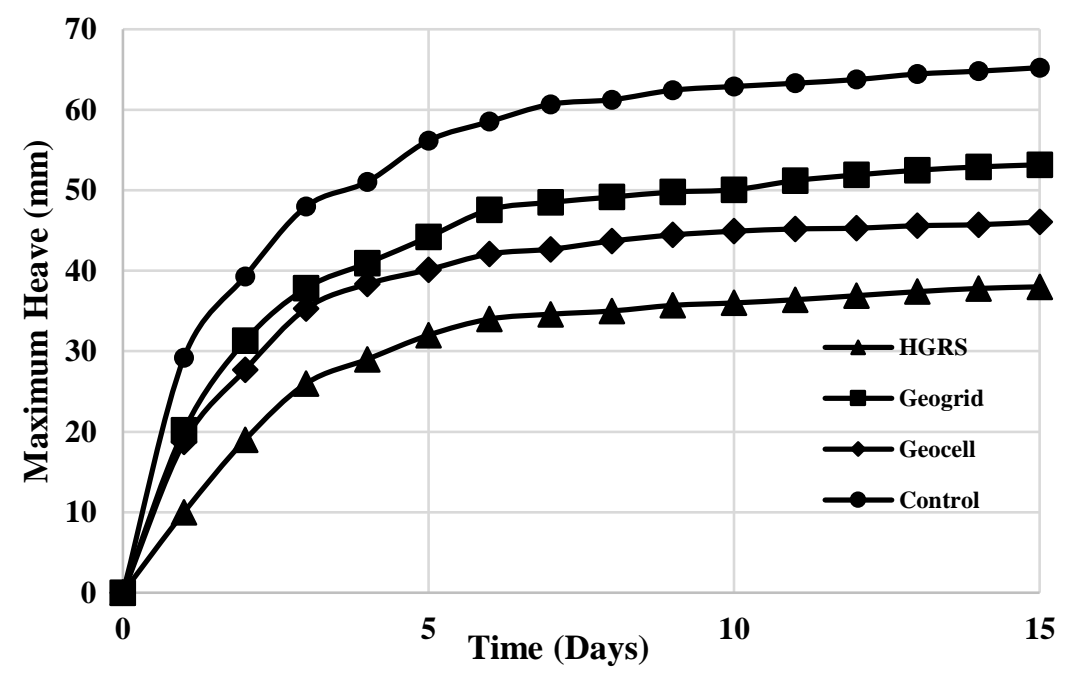

Figure 3.29 Maximum Heaving Plot over Time

It was found that the HGRS reduced the maximum surficial heave by $42 \%$ where as geocells and geogrid reduced the maximum surficial heave by $29 \%$ and $17 \%$, respectively. It was also revealed that the differential heave (the difference of maximum and minimum heave) on the pavement surface was also decreased considerably using the reinforcement application. HGRS application showed the highest improvement of differential heave by $62 \%$ compared to geocells $(\sim 45 \%)$ and geogrid $(\sim 31 \%)$. Test results of the large-scale box test are shown in Figure 3.30.

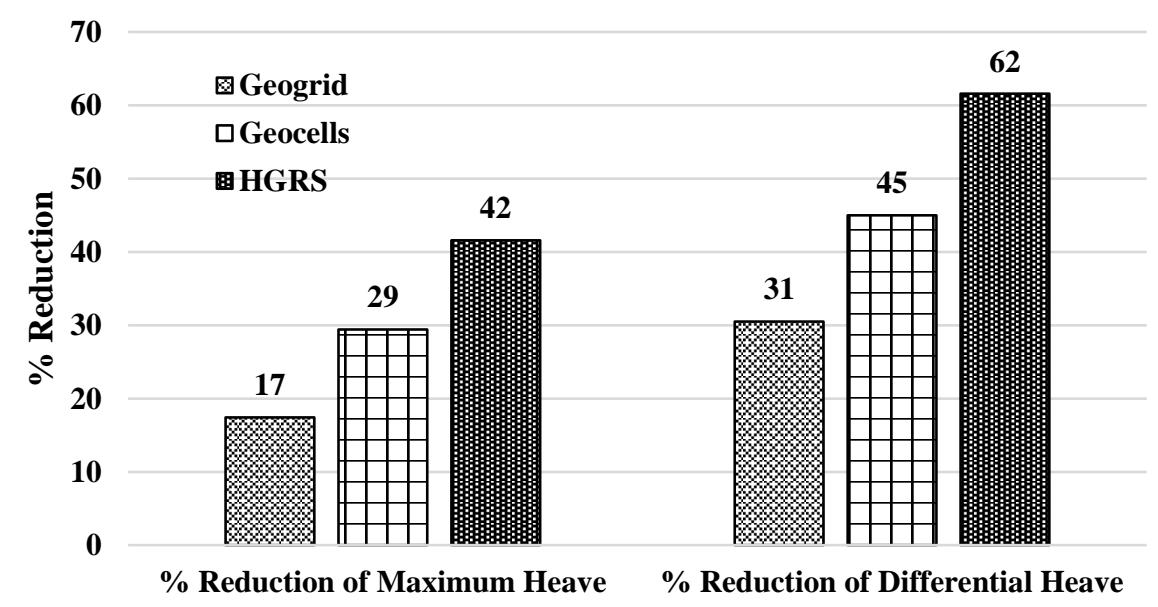

Figure 3.30 Comparisons of Percent Swell Reductions for the Three Reinforced Test Sections 


\subsection{Summary}

This chapter presented the findings from large-scale box test perfromed to replicate a pavement section with base and expansive subgrade with and without geosynthetic reinforcements. Detailed description of the box test was presented including the box set-

up, test variables and procedures in this chapter. Results obtained from the box test were presented in this chapter along with discussions.

The following inferences can be drawn from the large-scale box test results.

1. Geosynthetic systems are able to mitigate swelling distresses on the pavement surfaces with HGRS exhibiting better performance compared to geocells and geogrid.

2. Using geocells within base layer can trigger the improvement of swell mitigation by confinement of base course materials within the cells and increase the strength of the layer.

3. Interlocking and tension effect of geogrid within the base layer can induce the basal reinforcement which can resist the soils to move upward and decrease the swell potential at the surface.

4. In case of HGRS, confinement and tension effect both act together in the system and increase the stiffness of the base layer. Better performance of HGRS can be illustrated by this combined reinforcing mechanism. 


\section{CHAPTER 4: NUMERICAL ANALYSIS OF LARGE-SCALE BOX TEST}

\subsection{Introduction}

Finite element analysis has become widely accepted method to analyze versatile and complex geotechnical problems (Bortz 2015). This method has the capability to adapt many realistic situations more accurately than hypothetical methods based on infinite slab and other idealized conditions (Kuo and Huang 2006). The goal of the numerical analysis is to study how soils with differing swell potentials respond to various geosynthetic reinforcements including the HGRS. For this purpose, finite element models were developed to simulate each of the configurations of the large scale box test and the models were calibrated using the laboratory data from the box test. This chapter describes the development of the numerical models, their calibration procedure and the subsequent use of these models to conduct a parametric study. The objective of the parametric study was to illustrate the influence of the swelling characteristics of expansive soils and the stiffness of reinforced base on HGRS performance. Important outcomes from the numerical analysis are presented, and inferences are drawn concerning the reduction in swelling on the pavement surface due to geosynthetic reinforcements.

\subsection{Finite Element Model Development}

A commercially available finite element software, Abaqus Unified FEA, was used in this research. This software is very popular for its powerful and complete features and built-in material models for complex and sophisticated problems including applications in transportation engineering (Dassault Systems 2017). Simulation of expansive soils is especially tricky, since both volume and strength behavior changes with moisture and accurate prediction of expansive soil behavior will depend on the material models ability 
to account for both these changes. Abaqus Unified FEA has numerous integrated models that can handle swell-shrink behavior of soils with moisture variation. Within these models, it can simulate suction, volume change, and shear strength behaviors of expansive soils (Puppala et al. 2013).

To solve a problem accurately in Abaqus Unified FEA, geometry, material properties, boundary conditions and interaction properties need to be established properly. In this study, model geometries and boundary conditions for the numerical analysis were similar to the large-scale box test. Material properties were established through laboratory tests conducted on the subgrade and base materials used in the large-scale box test along with few correlations and literature sources. Four numerical models were developed to simulate the four configurations of the large-scale box test; (1) CS, (2) GC, (3) GG, and (4) HGRS. Details of these models are given below.

\subsubsection{Control Section Model (CSM)}

\subsubsection{Geometry}

The geometry and cross section of the control section model (CSM) were established from CS of the large-scale box test configurations. Same cross sections and dimensions of CS were followed to develop the CSM. A $762 \mathrm{~mm} \times 762 \mathrm{~mm} \times 203 \mathrm{~mm}$ granular base layer was overlaid on a $762 \mathrm{~mm} \times 762 \mathrm{~mm} \times 381 \mathrm{~mm}$ expansive subgrade layer in the model. Both the base expansive subgrade layers were modeled as three dimensional deformable solid elements. Figure 4.1 shows the geometry of CSM. 


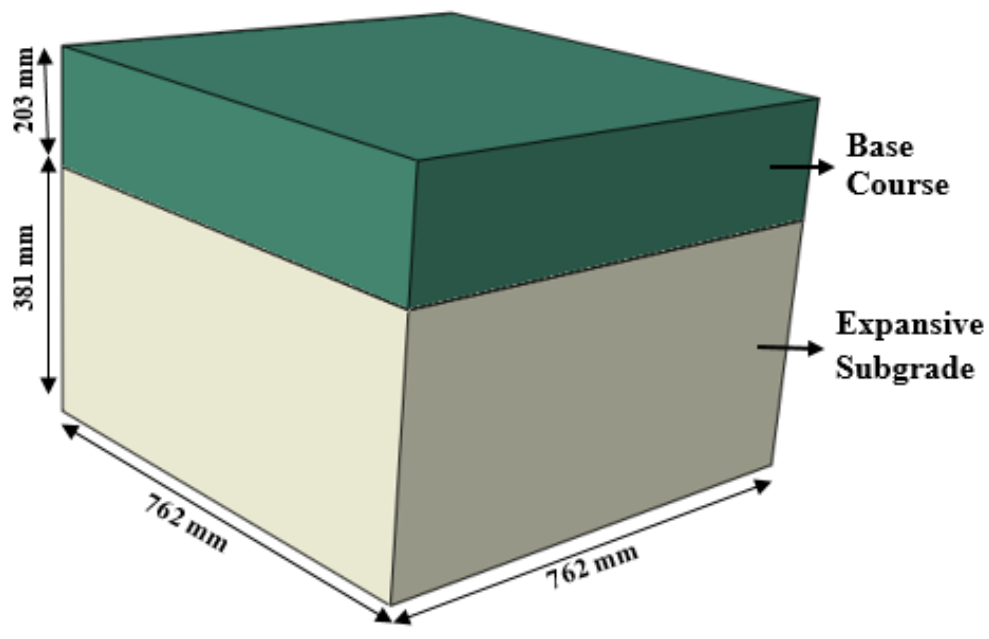

Figure 4.1 Geometry of the Control Section Model (CSM)

\subsubsection{Material Models}

Next step in the model development was to input the material properties for the two layers of the pavement section. Different material models were used to define the material properties of base and subgrade layers. The linear elastic model was used to simulate base material while the subgrade soil was simulated using both linear elastic and Mohr-Coulomb plasticity models. The modulus of the base material was correlated from the unsoaked California Bearing Ratio (CBR) test. The correlation of $\mathrm{CBR}$ and resilient modulus suggested by Mechanistic-Empirical Pavement Design Guide (MEPDG) was used (Guthrie and Jackson 2015). The result of CBR test is presented in Appendix A. The resilient modulus of subgrade soils was obtained from a previous research effort (Islam 2017). Plastic properties of the subgrade materials were established from the empirical correlations (Holtz and Kovacs 1981; Sorensen and Okkels 2013). A summary of the material properties used in the analysis for base and subgrade layers are listed in Table 4.1. 
Table 4.1 Engineering Properties of Pavement Materials used in the CSM

\begin{tabular}{|c|c|c|}
\hline Properties & Base & Expansive Subgrade \\
\hline Mass Density, $\rho\left(\mathrm{kg} / \mathrm{m}^{3}\right)$ & 2200 & 1095 \\
\hline Elastic Modulus, E, $(\mathrm{MPa})$ & 306 & 0.4 \\
\hline Poisson's Ratio, $v$ & 0.35 & 23.5 \\
\hline Internal Angle of Friction, $\phi$ & - & 7.8 \\
\hline Angle of Dilation, $\psi$ & - & 60 \\
\hline Cohesion, c $(\mathrm{kPa})$ & - & \\
\hline
\end{tabular}

Expansive subgrade experiences volumetric swelling due to the ingress of moisture

content. To predict this behavior, two additional material models were considered in this simulation. These two models illustrate the sorption and moisture swelling behaviors of expansive soils. A brief discussion of these two models and the laboratory tests performed to obtain the corresponding properties is given in the following subsections.

\subsection{Sorption Model}

The built-in sorption model replicates the suction behavior of soil particles with change in water content (Dassault Systemes 2017). This suction behavior is considered when the soil particles are in partially saturated condition. Typically, this suction value is quantified as negative pore liquid pressure which is also known as capillary pressure. Saturation value (s) depends on the certain limits of this negative capillary tension effect. The limit of the saturation lies within the range of absorption and exsorption behavior of soil particles. The behavior between absorption and exsorption is defined as scanning behavior. A typical absorption and exsorption behavior plot along with scanning curve are shown in Figure 4.2. 


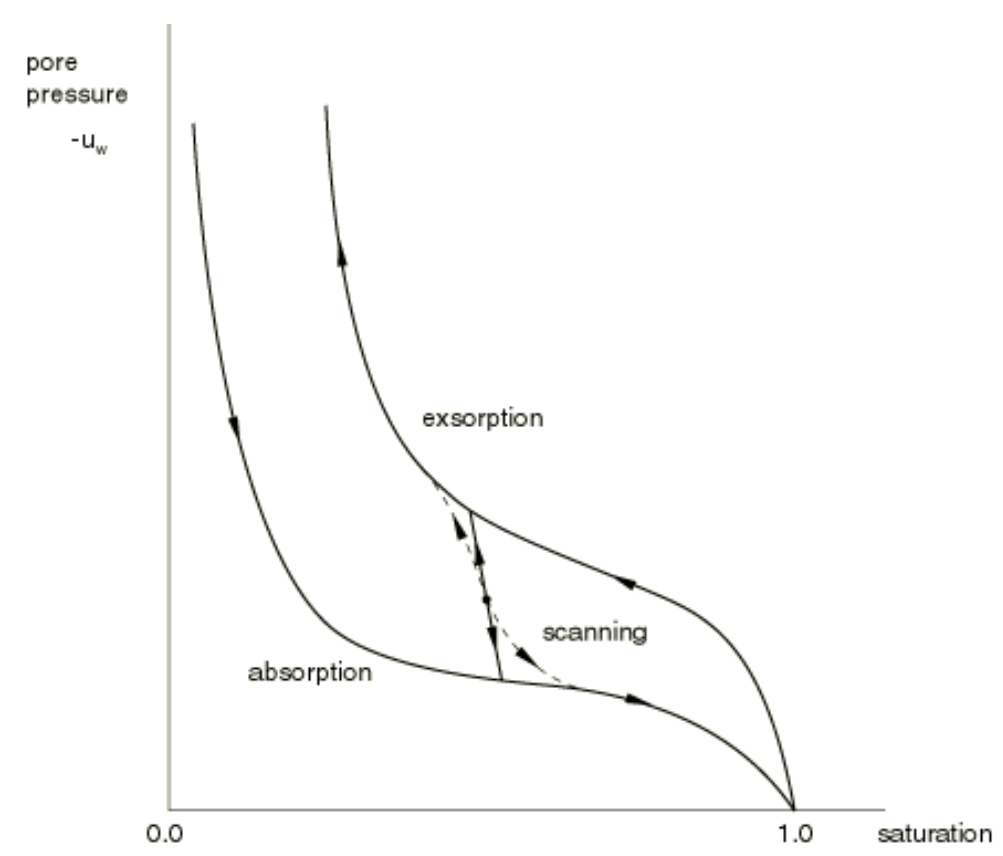

\section{Figure 4.2 Typical Absorption and Exsorption Behavior of Porous Medium (Dassault Systemes 2017)}

Soil Water Characteristic Curve (SWCC) defines the moisture affinity of soils which can illustrate the relationship between the water content and suction. Soil suction comprises of two components, matric suction and osmotic suction. Capillarity, texture, and surface adsorptive forces of the soil are the prime factors of matric suction, while the osmotic suction reflects the effect of dissolved salts in the pore fluid (Bulut et al. 2001). Standard ASTM D 5298 test method was used to establish SWCC for the ES-1 soil sample. This method can distinguish between total (matric + osmotic) and matric suction measurements. As per ASTM D 5298, soil samples were prepared at constant density and varying moisture contents. Diameter and height of the sample for the test were $76.2 \mathrm{~mm}$ and $152.4 \mathrm{~mm}$ respectively. Whatman\#42 (diameter $55 \mathrm{~mm}$ ) ashless filter paper was used to determine the soil suction. Matric suction was determined by placing a filter paper sandwiched between two protective filter papers and placed between the two halves of the soil sample that was previously cut. This allowed the sandwiched filter paper to be in 
physical contact with the soil sample and yet not get contaminated with the soil. The two halves of the soil sample were then taped to seal the filter papers inside the soil sample. The taped sample was placed inside a glass jar and another filter paper was placed on top of the sample. This filter paper was not allowed to touch the soil sample, and hence a 25.4 mm thick PVC pipe was used as a separator between the soil sample and the filter paper. The glass jar was then sealed and placed inside a temperature-controlled chamber for one week. This time allowed for equilibrium conditions and the filter papers to reach the same relative humidity levels as the overall soil sample. After equilibrium conditions were achieved, wet filter papers were removed from the samples and their moisture contents were determined. Filter papers must be handled carefully to avoid external moisture effect. Using the moisture content of the filter papers, suction values were determined from the calibration curves for the Whatman\#42 filter paper as given in ASTM D5298. Figure 4.3 and Figure 4.4 exhibit the sample preparation for the matric suction measurement and total section measurement using filter paper method respectively. Sorption behavior of the ES-1 soil sample is shown in Figure 4.5.

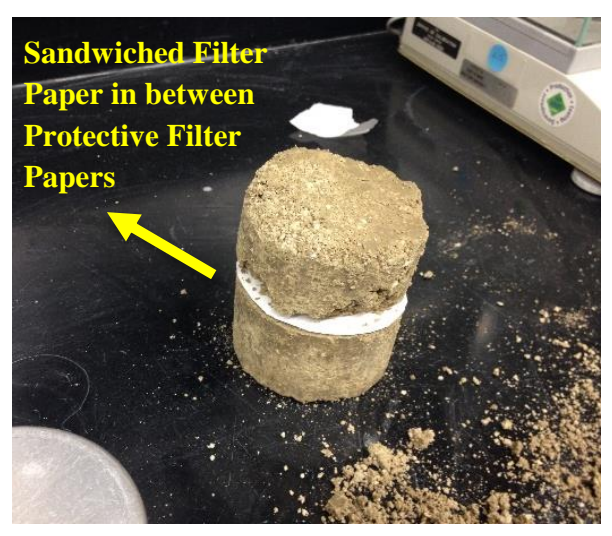

Figure 4.3 Soil Specimen Prepared for Matric Suction Measurement

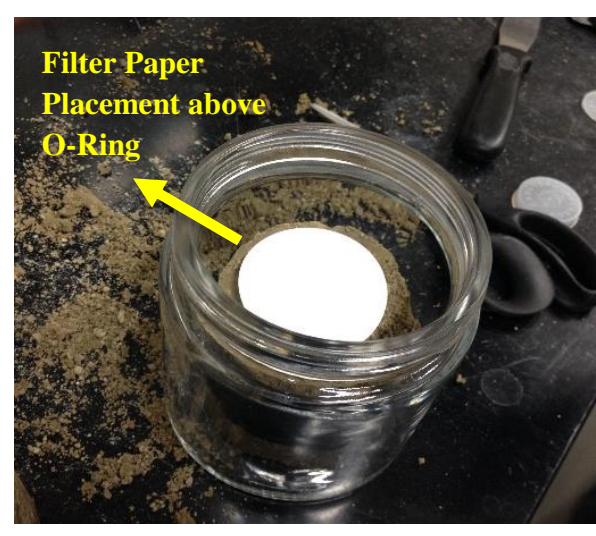

Figure 4.4 Soil Specimen Prepared for Total Suction Measurement 


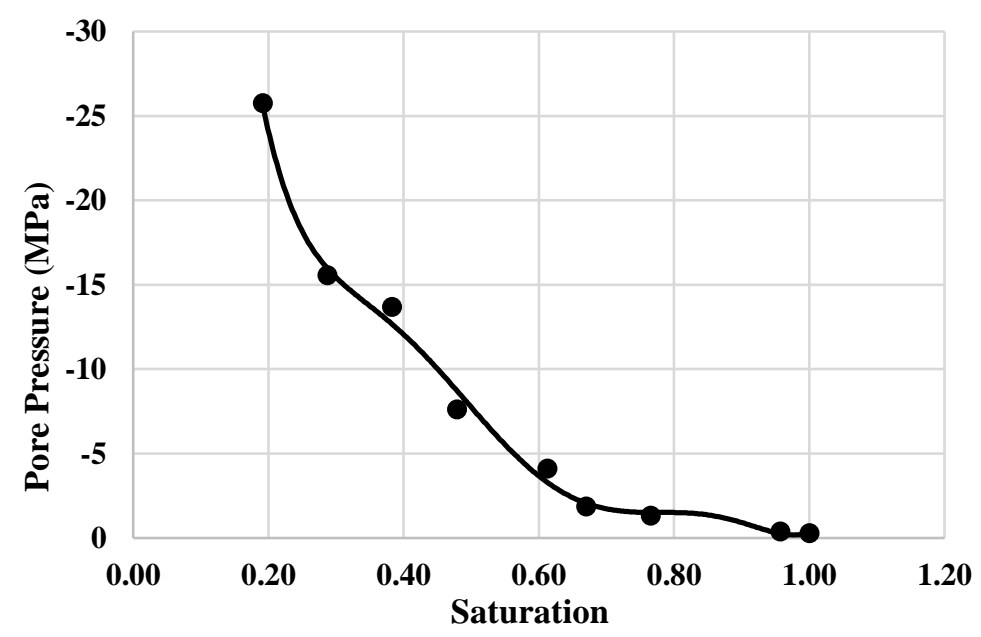

Figure 4.5 Input data for Sorption Behavior of ES-1 Soil

\subsection{Moisture Swelling Model}

Moisture swelling model in Abaqus Unified FEA can define the volumetric movement of soil with change in water content (Dassault Systemes 2017). This model uses the partial saturated condition of soil to define this volumetric swelling behavior. In partially saturated condition, the capillary pore pressure is negative within the soil particles. Due to the capillary pressure, water entrapped within the soil pores which results in swelling.

In this model, swelling behavior of a soil is categorized by swelling strain as a function of the degree of saturation. A typical volumetric swelling vs saturation curve is shown in Figure 4.6. This model is only applicable for the elements that can allow pore pressure. 


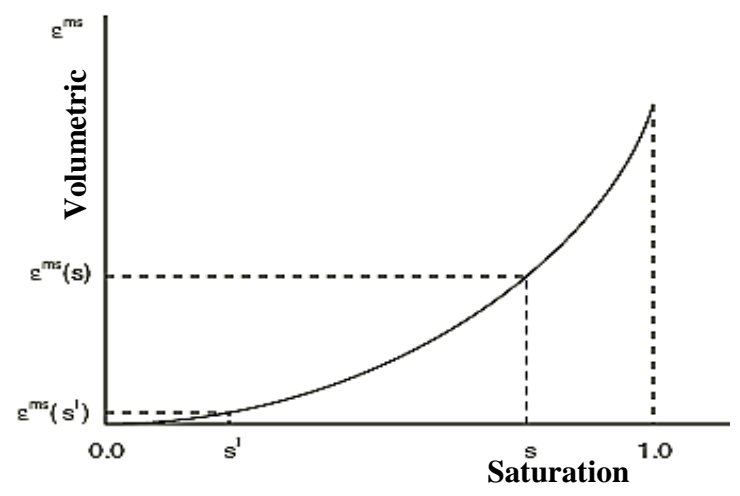

Figure 4.6 Typical Volumetric Swelling vs Saturation Curve of Porous Medium (Dassault Systemes 2017)

Volume change relationship of soil with moisture content can be determined by volumetric swell strain test developed by Punthutaecha et al. (2006). This test was conducted to determine the 3-D swell at different moisture levels and develop volumetric swelling vs saturation curve similar to the one in Figure 4.6. In this method, $76.2 \mathrm{~mm}$ diameter and $152.4 \mathrm{~mm}$ high soil samples were prepared at Optimum Moisture Content (OMC) and Maximum Dry Density (MDD). The soil sample was then placed in the oven to reach almost dry condition so that the volumetric movement can measure for the dry conditions. The dried samples were submerged under water to allow for swelling to occur. Porous stones were placed at the top and bottom of the samples to facilitate water ingress from top and bottom of the soil sample. To avoid surficial erosion, the soil sample was covered with a latex membrane. 


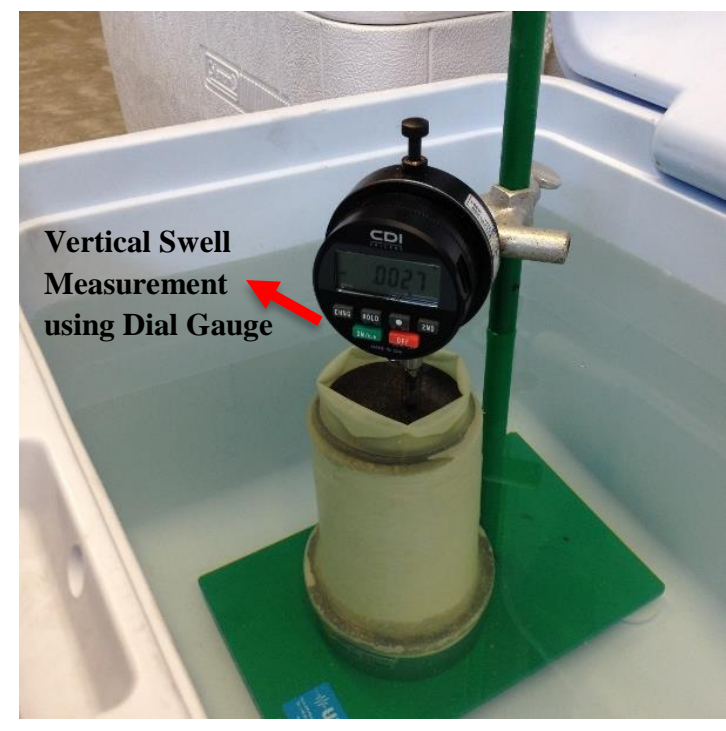

Figure 4.7 Inundation of Soil Sample in Water Bath

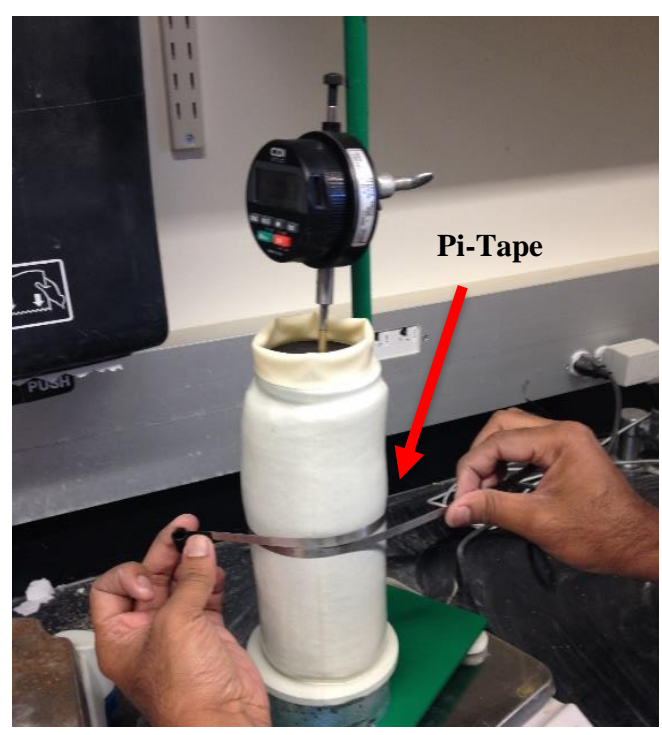

Figure 4.8 Measurement of Radial Swell using Pi-Tape

The soil sample was placed on a pedestal that had the arrangement to connect a dial gauge to measure vertical deformation which is shown in Figure 4.7. The radial movements were measured using a PI tape as shown in Figure 4.8. Vertical and radial swell strains were monitored until the soil sample reached at full saturation. The test was conducted at room temperature. In addition to the swell strains, the moisture changes in the sample were also monitored by measuring the sample weight at regular intervals along with swell strains. It was assumed that the increase in sample weight was primarily due to water absorption and care was taken to ensure that there was no soil loss during the volume measurements. Input data for volumetric swell behavior of the ES-1 soil sample was incorporated from volumetric free swell test which is shown in Figure 4.9. 


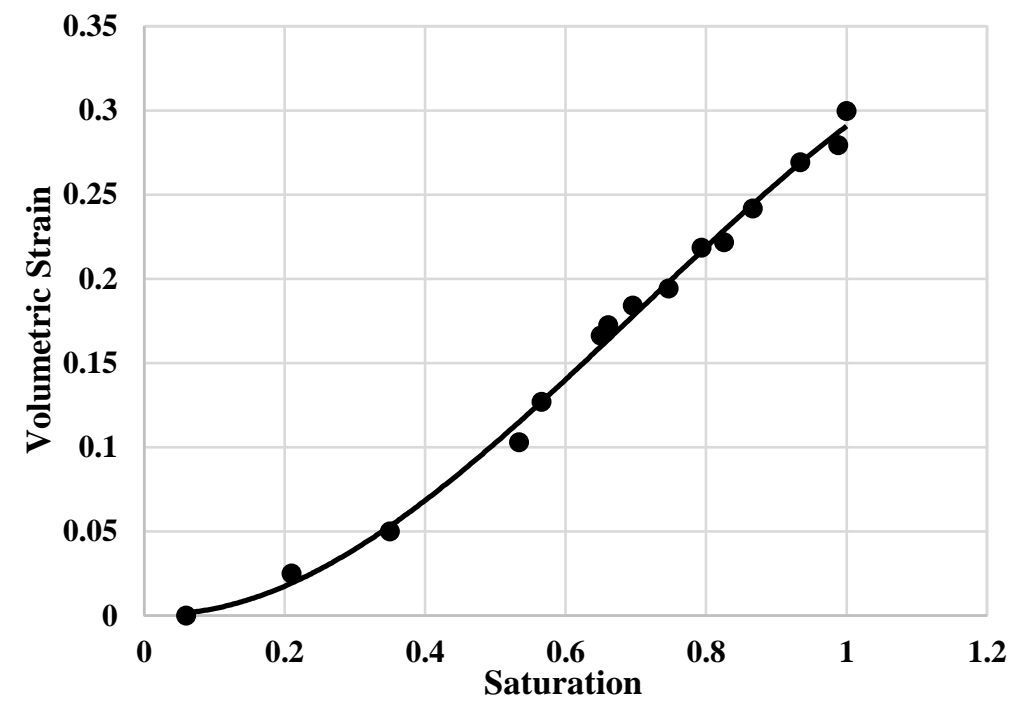

Figure 4.9 Input data for Moisture Swelling Model

\subsubsection{Boundary Conditions}

Boundary conditions were used in the model to replicate the control section in large-scale box test as closely as possible. Two types of Boundary Conditions (BC) were considered in this model -- displacement/rotation BC and pore pressure $\mathrm{BC}$. The displacement BCs were used to constrain the movements on the outer sides of the model while pore pressure $\mathrm{BC}$ was used to simulate the water source similar to the soaker system in the large-scale box test. All nodes in the $\mathrm{x}-\mathrm{z}$ plane of the model were restrained in all three directions using displacement/rotation BC. The outer surface nodes in the $\mathrm{x}-\mathrm{y}$ plane of the model were restricted from moving in the z-direction, and the outer surface nodes in the $y$-z plane were restricted from moving in the $\mathrm{x}$-direction. So all the sides of the model were restricted to any lateral movement. The model was only able to move in vertical direction (y-direction). The pore pressure BC was used in the top half of the expansive subgrade layer to simulate the soaker system in the box test. The pore pressure $\mathrm{BC}$ was placed on only one side of the box with a pore pressure head of $1.83 \mathrm{~m}$ (as shown in Figure 4.10) which led to the differential heave on the surface of the model. This BC 
was identical to the laboratory box test explained the previous chapter. Figure 4.10 shows all the BC in the CSM.

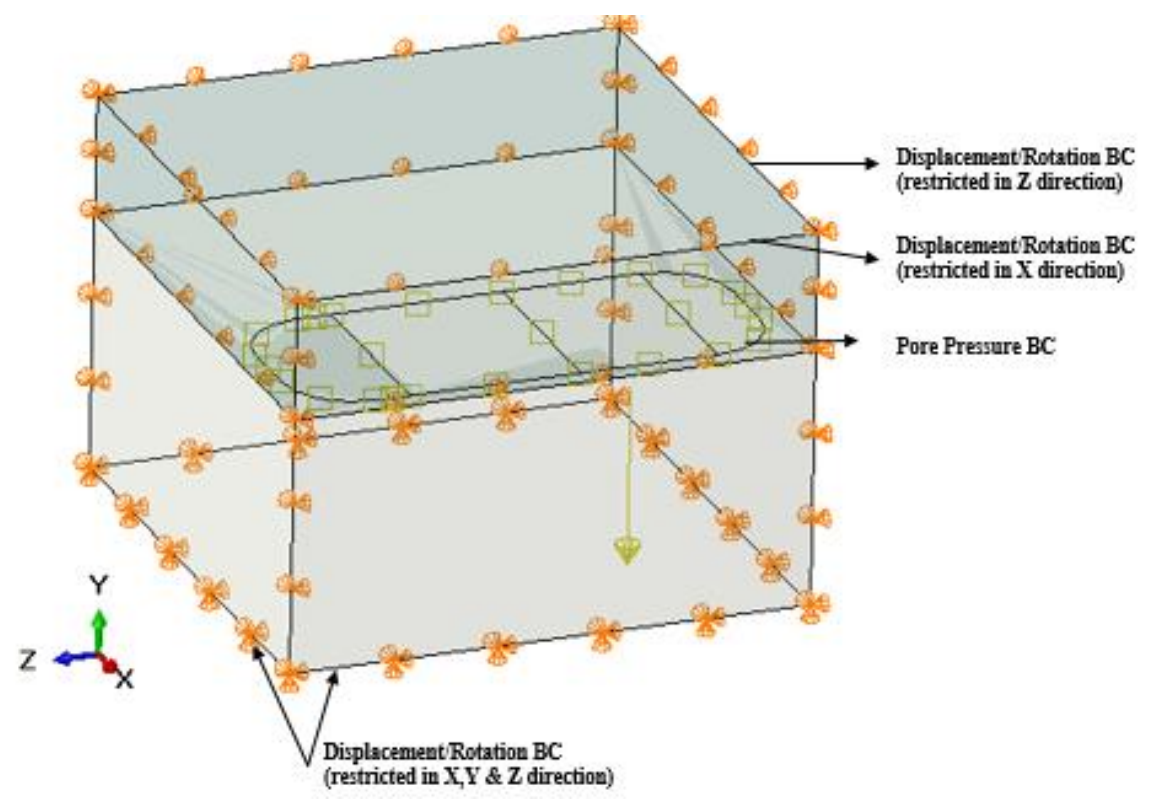

\section{Figure 4.10 Boundary Conditions in CSM}

\subsubsection{Mesh Size and Element Type}

Element types and mesh sizes can play significant role in finite element modeling.

Inadequate knowledge on meshing approach can lead to inaccurate results. Additionally, meshing size influence the final result and computational time. A convergence study was conducted to optimize the mesh size incorporating with the computational time. Figure 4.11 shows the convergence study to optimize the mesh size. 


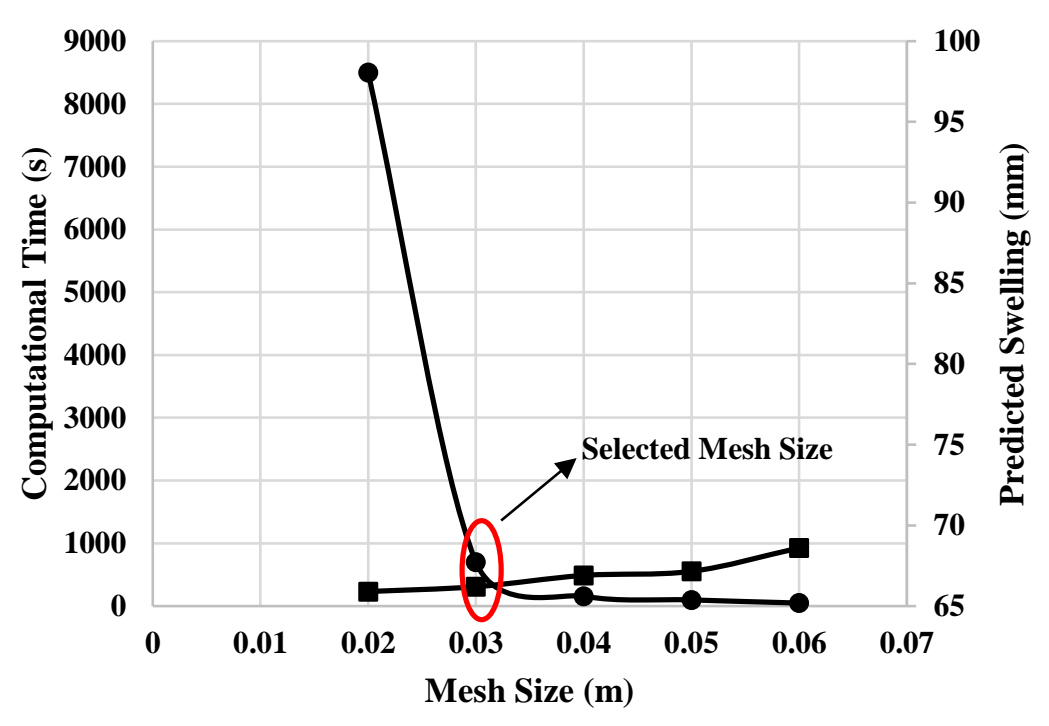

Figure 4.11 Convergence Study to Optimize Mesh Size

From the convergence study, it was found that there was no significant change in swelling for mesh size $.02 \mathrm{~m}$ and $0.03 \mathrm{~m}$. However, the computational time for the analysis increased about twelve times for $0.02 \mathrm{~m}$ mesh size compared to $0.03 \mathrm{~m}$ mesh size. Eventually, $0.03 \mathrm{~m}$ mesh size was selected to optimize the mesh size as well as balancing the computational time for the analysis. Figure 4.12 shows the meshing of the model section.

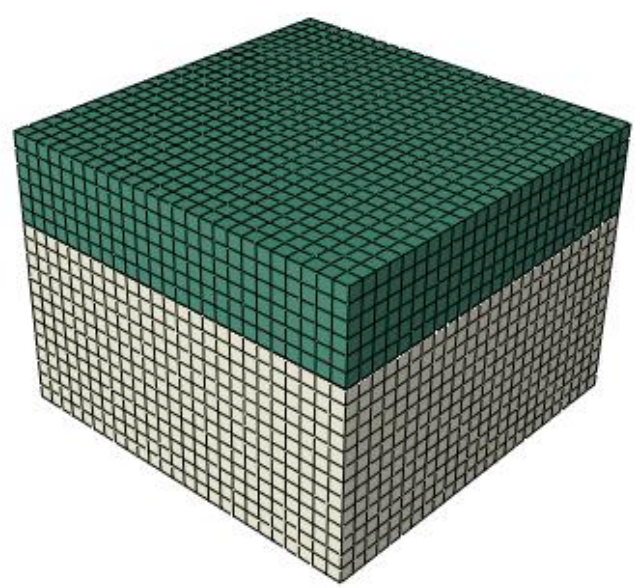

Figure 4.12 Meshing of the CSM Model Section 
Element types of the materials were selected based on their behaviors. For the base, three dimensional hexahedral, 8-noded reduced integrated stress/displacement element (C3D8R) not allowing pore pressure was selected. On the other hand, three dimensional hexahedral, 8-noded stress/displacement element (C3D8P) allowing pore pressure was chosen for subgrade. The C3D8P element type has the capability to analyze partially or fully saturated fluid flow through soils. Table 4.2 represents the summary of element types and element numbers of the model.

Table 4.2 Element Type and Numbers in CSM

\begin{tabular}{|c|c|c|c|}
\hline Material Type & Element Type & Number of Elements & Thickness (mm) \\
\hline Base & C3D8R & 4375 & 203 \\
\hline Expansive Subgrade & C3D8P & 9022 & 381 \\
\hline
\end{tabular}

\subsubsection{Interaction Properties and Initial Conditions}

Interaction module is an important feature in Abaqus to establish the mechanical and thermal contact between the regions or surroundings especially when the model considers multi-layer systems. Tie constraint was used for the base and subgrade interaction. This feature ties two separate surfaces together and restricts any relative motion between them (Dassault Systemes 2017). This type of constraint allows fusing together two regions even with dissimilar meshes within the surfaces of the regions. Top surface of subgrade was used as master surface and bottom surface of base was used as slave surface to define the tie constraint property.

To simulate a lab set up in a model, it is essential to incorporate the initial conditions of lab set up in the model. Moreover, the analysis was time dependent transient, so an initial condition was needed to initiate the swelling and sorption 
behaviors of the soils at that condition. Initial conditions are input into the model in the form of an initial void ratio $\left(\mathrm{e}_{\mathrm{o}}\right)$, initial pore pressure $\left(\mathrm{U}_{\mathrm{o}}\right)$ and the initial saturation level $\left(\mathrm{S}_{\mathrm{o}}\right)$. Suction value and swelling are directly related to the degree of saturation, so it is important to define the initial saturation value in the model. Otherwise, Abaqus will consider full saturation in the model which may not be accurate. Initial void ratio of the subgrade was defined from the density-void ratio relationship. The initial conditions used in this modeling effort are listed in Table 4.3.

Table 4.3 Initial Conditions of the CSM

\begin{tabular}{|l|c|}
\hline \multicolumn{1}{|c|}{ Property } & Value \\
\hline Initial void ratio, $\mathrm{e}_{\mathrm{o}}$ & 1.53 \\
\hline Initial pore pressure, $\mathrm{U}_{\mathrm{w}}(\mathrm{MPa})$ & -7.62 \\
\hline Initial saturation, $\mathrm{S}_{\mathrm{o}}$ & 0.48 \\
\hline Permeability $(\mathrm{m} / \mathrm{s})$ & $8 \mathrm{E}-10$ \\
\hline
\end{tabular}

\subsubsection{Model with Geocell Reinforcement (MGC)}

\subsubsection{Geometry}

Model with geocell reinforcement (MGC) was incorporated from the GC section of large-scale box test. Same cross section and geometry for subgrade was obtained from the CSM. The base course was divided into two parts- reinforced base section and top base cover. Reinforced base section was defined as geocell reinforced base section. The thickness of reinforced base was obtained from the depth of geocell which was $152 \mathrm{~mm}$. Rest of the $51 \mathrm{~mm}$ of base material was defined as top base cover. Length and width of the reinforced base and top base cover were same as subgrade. The geometry of geocell was replicated from the original geocell dimensions. Three dimensional shell element was used to develop geocells. Eight cells were created as per original geocell section. The dimension 
of each cell was $370 \mathrm{~mm}$ by $250 \mathrm{~mm}$ and the thickness of the cell was $1.5 \mathrm{~mm}$. Geocells were embedded within the reinforced base layer and placed above the subgrade. Top base cover was overlaid on the reinforced base layer. Figure 4.13 and Figure 4.14 represent the overall geometry of MGC and the geometry of geocell respectively.

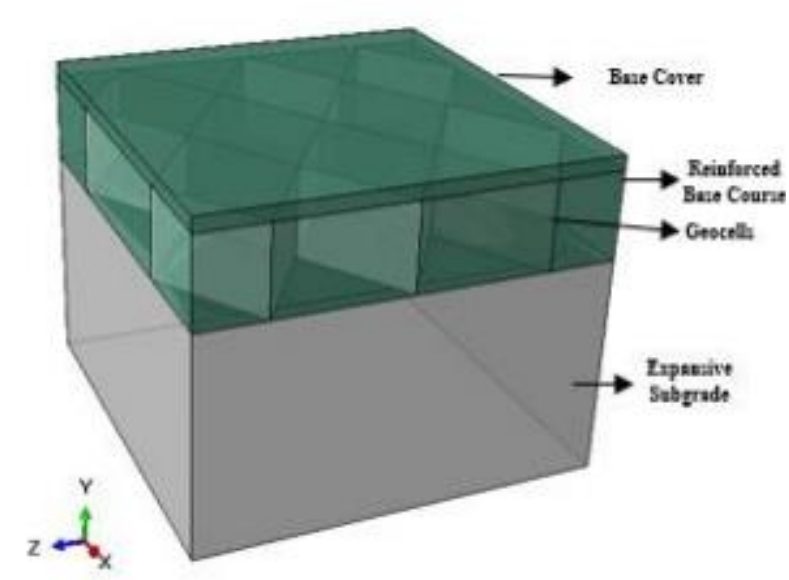

Figure 4.13 Geometry of MGC

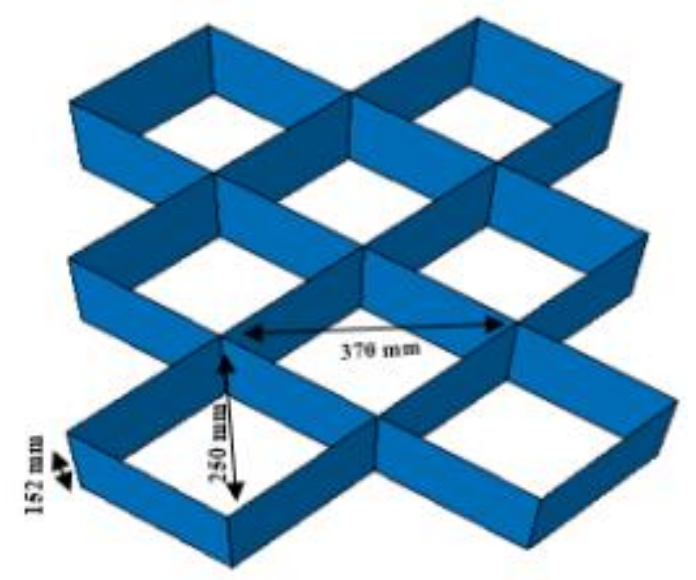

Figure 4.14 Geometry of the Geocell

\subsubsection{Material Properties}

Same material models from CSM were used for subgrade in this model. Sorption and moisture swelling models were initiated to predict the swelling behavior of soils. The inclusion of geocells can enhance the stiffness of the base layer. Confinement and reinforcing mechanism of geosynthetics are well established method to stabilize granular materials (Perkins and Ismeik 2007; Yuu et al. 2008; Yang 2010; Han 2015). As a result, the stiffness of the base layer is increased (Pokharel 2010; Han et al. 2011; Kief and Rajagopal 2011). The improvement of base layer can be incorporated using the increased modulus of the base layer. Inclusion of geocell can increase the modulus of base layer by 1.5-5.0 times based on the infill material, subgrade, and stiffness of geosynthetics and relative position of confined layer (Kief et al. 2011). This stiffness of reinforced base was 
established by trying to match the predicted differential heaving with the experimental values from GC and it was found that the modulus of the reinforced system was increased by 3.1 times than unreinforced system. Except stiffness, all the other properties remained the same for reinforced base. In case of base cover, same properties of unreinforced base were adopted. Geocells were considered as homogeneous shell elements in which the thickness is very small compared to its length and width. Linear elastic material model was used to define the properties of geocells. A summary of the material properties are listed in Table 4.4.

Table 4.4 Engineering Properties of Pavement Materials used in the MGC

\begin{tabular}{|c|c|c|c|c|}
\hline Properties & Base Cover & $\begin{array}{c}\text { Reinforced } \\
\text { Base }\end{array}$ & Geocells & $\begin{array}{c}\text { Expansive } \\
\text { Subgrade }\end{array}$ \\
\hline $\begin{array}{c}\text { Mass Density, } \rho \\
\left(\mathrm{kg} / \mathrm{m}^{3}\right)\end{array}$ & 2200 & 2200 & 950 & 1095 \\
\hline $\begin{array}{c}\text { Elastic Modulus, E, } \\
(\mathrm{MPa})\end{array}$ & 306 & 950 & 392 & 146 \\
\hline $\begin{array}{c}\text { Poisson's Ratio, } v \\
\text { Internal Angle of } \\
\text { Friction, } \phi\end{array}$ & 0.35 & 0.35 & 0.3 & 0.4 \\
\hline Angle of Dilation, $\psi$ & - & - & - & 23.5 \\
\hline Cohesion, c $(\mathrm{kPa})$ & - & - & - & 7.8 \\
\hline
\end{tabular}

\subsubsection{Boundary Conditions}

Similar type of boundary conditions (BC) of CSM were applied for this model.

The bottom-most surface in the $\mathrm{x}-\mathrm{z}$ plane of the model was restrained in all three directions using displacement/rotation BC. So it restricted the movements in any direction. The outer surfaces in the $x-y$ plane of the model were restricted from moving in the $\mathrm{z}$-direction, and the outer surfaces in the $\mathrm{y}-\mathrm{z}$ plane were restricted from moving in the $\mathrm{x}$-direction. So all the sides of the model were restricted from any lateral movement like 
the CSM. Similar pore pressure BC like CSM was used to simulate the source of water and to incorporate GC section in the box test. This differential water source condition initiated the differential heave in the model. The model was only able to move in vertical direction (y-direction). Figure 4.15 shows all the BC in the MGC.

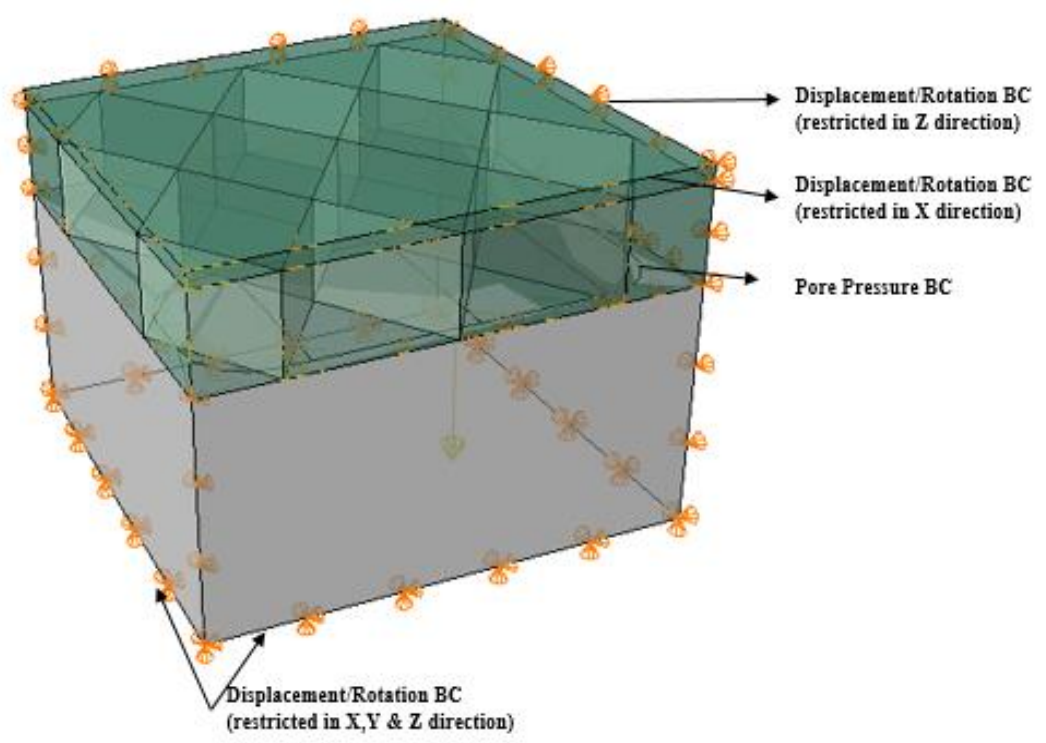

Figure 4.15 Boundary Conditions of MGC

\subsubsection{Mesh Size and Element Type}

Mesh size for the base and subgrade was selected as $0.03 \mathrm{~m}$ which was chosen based on convergence study from CSM. Mesh size of the geocell was considered as 0.023 m. Figure 4.16 and Figure 4.17 represent the meshing of overall model and geocells respectively. Based on the behavior of the materials, C3D8R and C3D8P were selected as element types for base and subgrade respectively. For geocells, 4-noded, reduced integrated three dimensional shell element (S4R) was selected. Shell element is defined as a solid element in which thickness is very small compared to its length and width. Table 4.5 illustrates the element types and element numbers used in the MGC. 
Table 4.5 Element Type and Element Numbers in MGC

\begin{tabular}{|c|c|c|c|}
\hline Material Type & Element Type & Number of Elements & Thickness (mm) \\
\hline Base Cover & C3D8R & 625 & 51 \\
\hline Reinforced Base & C3D8R & 3330 & 152 \\
\hline Geocell & S4R & 1680 & - \\
\hline Expansive Subgrade & C3D8P & 9022 & 381 \\
\hline
\end{tabular}

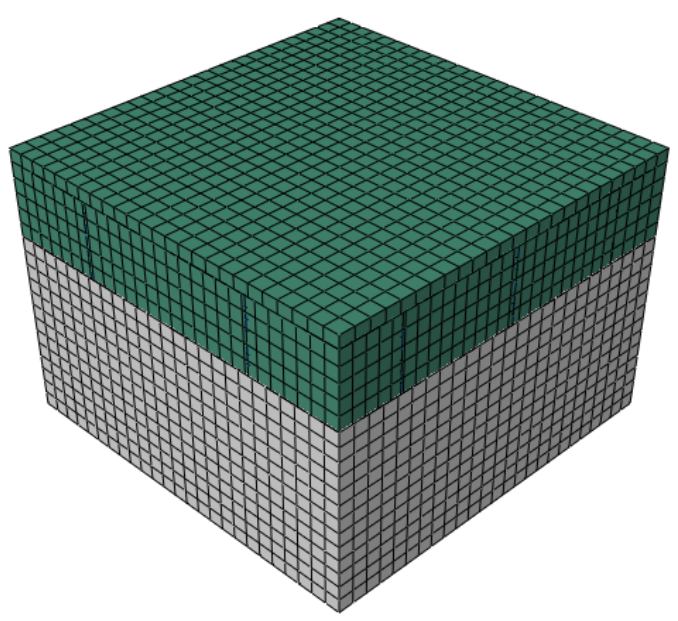

Figure 4.16 Meshing Approach of MGC

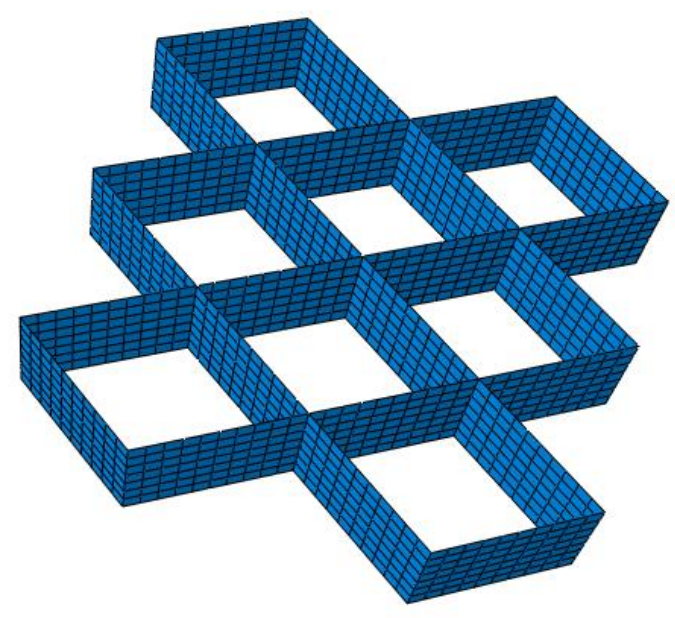

Figure 4.17 Meshing Approach of Geocell

\subsubsection{Interaction Properties and Initial Conditions}

Tie constraint was used for the base cover, reinforced base and subgrade interaction. The top surface of subgrade was used as slave surface and bottom surface of reinforced base was used as master surface. On the other hand, top surface of reinforced base was used as master surface and bottom surface of base cover was used as slave surface. For geocells and reinforced base, the embedded region constraint was used to define their interaction. This technique is used to specify an element or a group of elements that lie embedded in a group of host elements whose response will be used to constrain the translational degrees of freedom. It is used to specify that an element or 
group of elements is embedded in "host" elements. In this model, reinforced base was considered as host element to embed the geocells. Initial condition of the model was similar to the CSM so that the integrity was maintained.

\subsubsection{Model with Geogrid Reinforcement (MGG)}

\subsubsection{Geometry}

Model with geogrid reinforcement (MGG) was simulated from the GG section of large-scale box test. Same cross section and geometry for subgrade was obtained from the CSM model. The base course was divided into two parts- top base layer and reinforced base slayer. In this model, reinforced base section was defined as geogrid reinforced base section. The inclusion of geogrid in granular base course increase the stiffness surrounding zone of the base layer. This zone of influence was quantified by Schuettpelz et al. (2009). They showed that the granular base course with geogrid provided strengthening effects approximately $30 \mathrm{~mm}$ in thickness on either side of the geogrid. So the thickness of the reinforced base layer was selected as $60 \mathrm{~mm}$ which was compatible with the thickness of zone of influence. Rest of the $143 \mathrm{~mm}$ of base material was defined as top base layer. Length and width of the reinforced base and top base layers were identical with subgrade. Three-dimensional deformable shell element was used to develop geogrid. This element was assigned as membrane to offer strength in the plane of the surface with no bending stiffness. For the simplification of the modeling approach and computational time, geogrid roll was considered as geogrid membrane sheet. Length, width and the thickness of the geogrid sheet were $762 \mathrm{~mm}, 762 \mathrm{~mm}$ and $1.5 \mathrm{~mm}$ respectively. The geogrid sheet was embedded within the reinforced base layer and placed above the subgrade. The top base 
layer was overlaid on the reinforced base layer. Figure 4.18 represents the overall geometry and of the model.

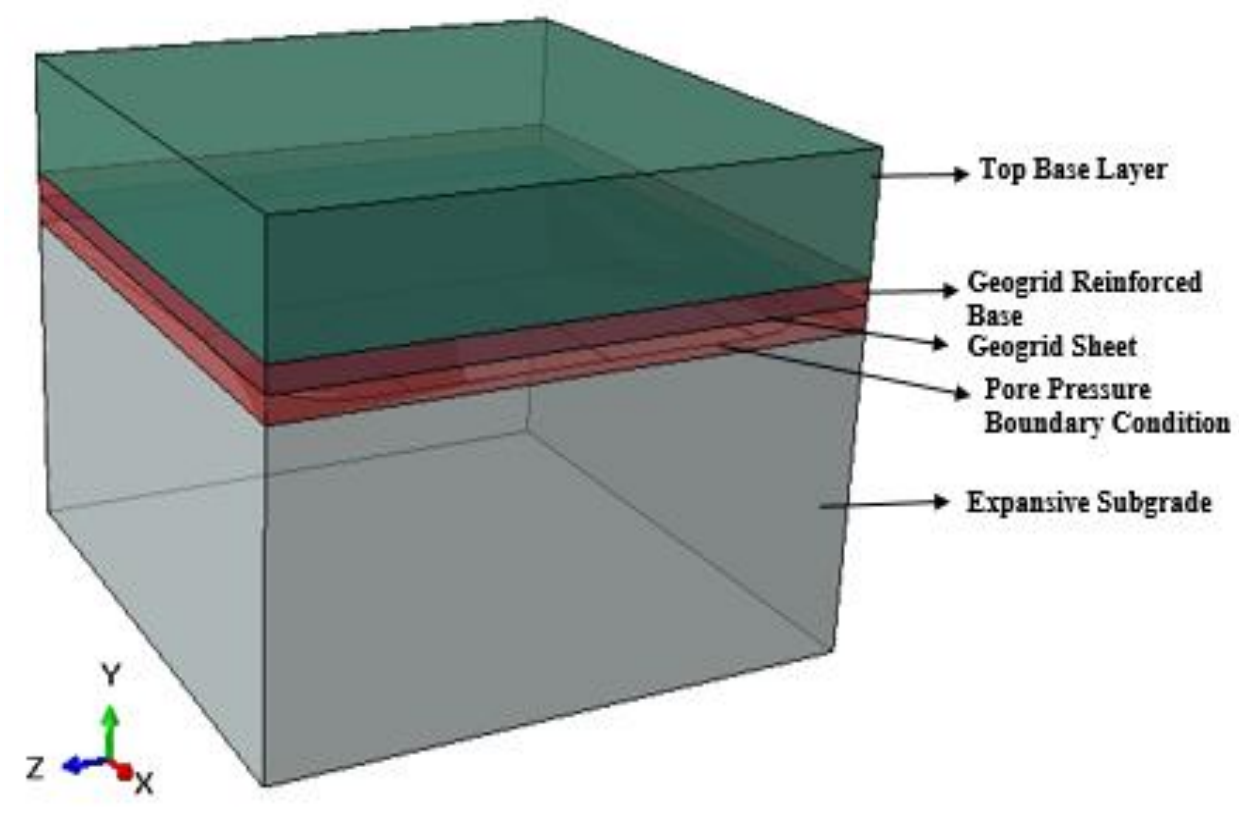

Figure 4.18 Geometry of MGG

\subsubsection{Material Properties}

Identical models were obtained for subgrade in this model. Sorption and moisture swelling models were initiated to predict the swelling behavior of soils. Inclusion of geogrid can enhance the stiffness of the surrounding base layer. This stiffness of reinforced base was quantified by trying to match the predicted differential heaving with the experimental values from GG. It was found that the modulus of the reinforced system was 1.96 times than unreinforced case. Except stiffness, all the other properties remained the same for reinforced base. In case of top base layer, same properties of unreinforced base were adopted. Geogrid sheet was considered as three-dimensional membrane element in which strength is offered in the plane of the surface with no bending stiffness. Linear elastic 
material model was used to define the properties of geogrid sheet. A summary of the material properties for this model are listed in Table 4.6.

Table 4.6 Engineering Properties of Pavement Materials Used in the MGG

\begin{tabular}{|c|c|c|c|c|}
\hline Properties & $\begin{array}{c}\text { Top Base } \\
\text { Layer }\end{array}$ & $\begin{array}{c}\text { Reinforced } \\
\text { Base }\end{array}$ & $\begin{array}{c}\text { Geogrid } \\
\text { Sheet }\end{array}$ & $\begin{array}{c}\text { Expansive } \\
\text { Subgrade }\end{array}$ \\
\hline $\begin{array}{c}\text { Mass Density, } \rho \\
\left(\mathrm{kg} / \mathrm{m}^{3}\right)\end{array}$ & 2200 & 2200 & - & 1095 \\
\hline $\begin{array}{c}\text { Elastic Modulus, E, } \\
(\mathrm{MPa})\end{array}$ & 306 & 600 & 450 & 146 \\
\hline $\begin{array}{c}\text { Poisson's Ratio, } v \\
\begin{array}{c}\text { Internal Angle of } \\
\text { Friction, } \phi\end{array}\end{array}$ & -0.35 & 0.35 & 0.3 & 0.4 \\
\hline Angle of Dilation, $\psi$ & - & - & - & 23.5 \\
\hline Cohesion, c $(\mathrm{kPa})$ & - & - & - & 60 \\
\hline
\end{tabular}

\subsubsection{Boundary Conditions}

Similar type of boundary conditions of CSM were applied for MGG. Bottommost surface in the $\mathrm{x}-\mathrm{z}$ plane of the model was restrained in all three directions using displacement/rotation BC. So it restricted the movements in any direction. The outer surfaces in the $\mathrm{x}-\mathrm{y}$ plane of the model were restricted to move in the $\mathrm{z}$-direction, and the outer surfaces in the $\mathrm{y}-\mathrm{z}$ plane were restricted to move in the $\mathrm{x}$-direction. So all the sides of the model were restricted to any lateral movement like the CSM. Same pore pressure BC from CSM was used to incorporate GG section in the box test. This differential water source condition initiated the differential heave in the model. The model was only able to move in vertical direction ( $\mathrm{y}$ - direction). Figure 4.19 shows all the $\mathrm{BC}$ in the MGG. 


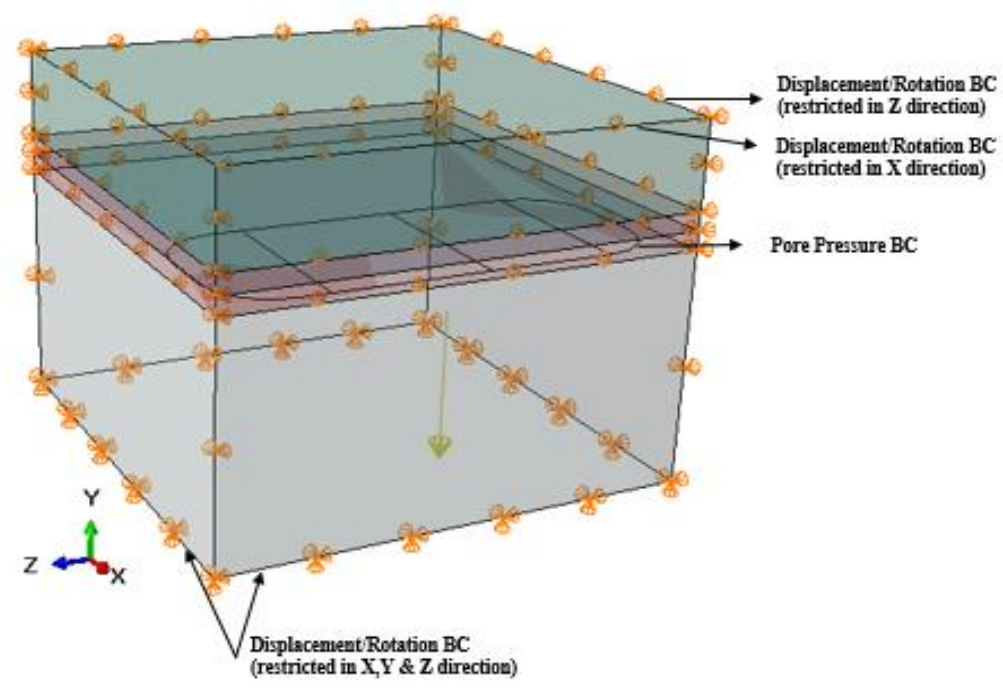

Figure 4.19 Boundary Conditions of MGG

\subsubsection{Mesh Size and Element Type}

Mesh size for the base and subgrade was selected as $0.03 \mathrm{~m}$ based on convergence study from CSM model. Mesh size of the geocell was considered as $0.023 \mathrm{~m}$. Figure 4.20 and Figure 4.21 represent the meshing approach of overall model and the geogrid plane respectively. Based on the behavior of the martials, C3D8R and C3D8P were selected as element types for top base, reinforced base and subgrade respectively. For geogrid sheet, 4-noded, quadrilateral membrane reduced integrated element (M3D4R) was selected. The membrane is defined thin surfaces in space that offer strength in the plane of the surface with no bending stiffness. Table 4.7 illustrates the details of the element types and numbers of the MGG.

Table 4.7 Element Type and Element Numbers in MGG

\begin{tabular}{|c|c|c|c|}
\hline Material Type & Element Type & Number of Elements & Thickness (mm) \\
\hline Top Base & C3D8R & 3125 & 143 \\
\hline Reinforced Base & C3D8R & 1250 & 60 \\
\hline Geogrid Sheet & M3D4R & 625 & 1.5 \\
\hline Expansive Subgrade & C3D8P & 9022 & 381 \\
\hline
\end{tabular}




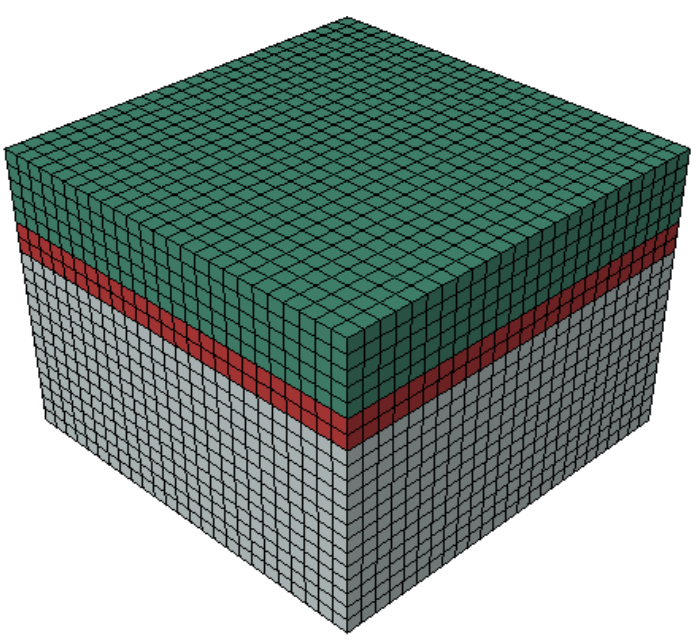

Figure 4.20 Meshing Approach of MGG

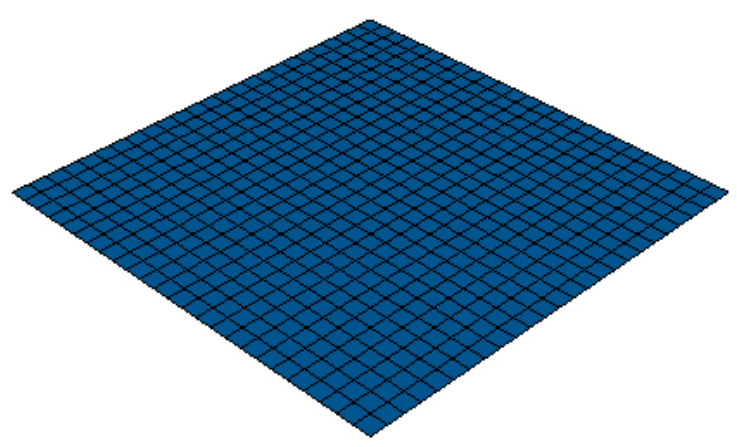

Figure 4.21 Meshing Approach of Geogrid Sheet

\subsubsection{Interaction Properties and Initial Conditions}

Similar type of constraint was used for the top base, reinforced base and subgrade layers. Their interaction surfaces were tied together to restrict any relative motion between them. In this case, top surface of subgrade was used as master surface and bottom surface of reinforced base was used as slave surface for subgrade-reinforced base interaction. On the other hand, top surface of reinforced base was used as slave surface and bottom surface of base cover was used as master surface for reinforced base and top base layer. Geogrid sheet was embedded into the reinforced base and the embedded region constraint was used to define their interaction to constrain the translational degrees of freedom. In this model, reinforced base was considered as host element. Initial condition of the model was similar to the CSM so that the integrity of the analysis could be maintained. 


\subsubsection{Model with Hybrid Geosynthetic Reinforcement System (MHGRS)}

\subsubsection{Geometry}

The model with Hybrid Geosynthetic Reinforcement System (MHGRS) was comprised of geocell and geogrid reinforcement which simulated the HGRS section of large-scale box test. The cross section of the model was comprised of a $153 \mathrm{~mm}$ geocell reinforced layer overlying a $50 \mathrm{~mm}$ of geogrid reinforced base layer overlying the subgrade layer. Geogrid reinforced base comprised of reinforced base with embedded geogrid sheet. The zone of influence for the geogrid was $30 \mathrm{~mm}$ on both side of geogrid. Due to overlapping with geocell reinforced section and maintaining the same overall thickness of base, upper zone of influence was considered as $20 \mathrm{~mm}$. On the other hand, length and width of the geocell reinforced base and top base cover were same to subgrade. Formation of geocells and geogrid were identical to MGC and MGG respectively. Both of the geosynthetic materials were embedded within the reinforced base layer. Figure 4.22 shows the geometry of MHGRS.

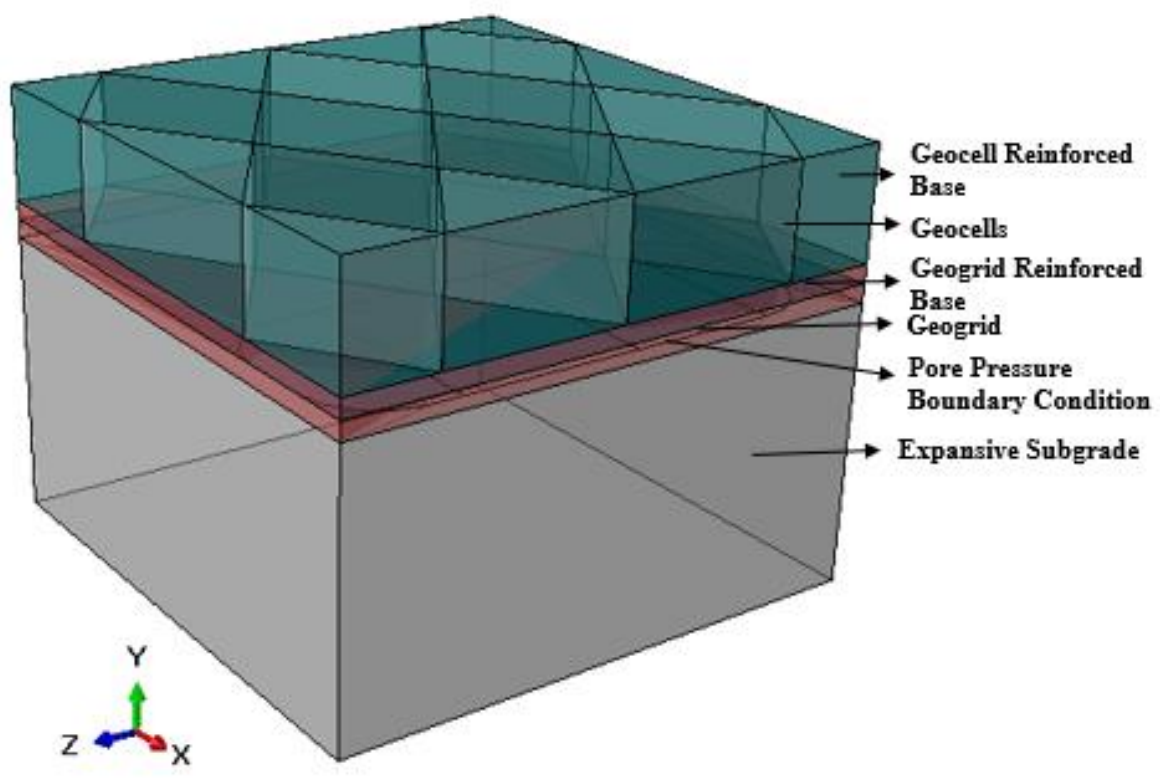

Figure 4.22 Geometry of MHGRS 


\subsubsection{Material Properties}

Material properties for the MHGRS were adopted from the previous numerical models. Same sorption and moisture swelling models were used for the swelling behavior of expansive subgrade. In this model, combined influence of geocells and geogrid reinforcement were implemented by increasing the stiffness of the base layer. This stiffness value of the base layer was established by trying to match the predicted differential heaving with the experimental values. It was found that the modulus of reinforced base system increased by 6.5 times compared to unreinforced case. The geocells enhanced the stiffness of unreinforced base by confinement and geogrid stabilize the base by interlocking and tension effect. Other than the stiffness value of reinforced bases, all the other properties remained the same as the previous models. Linear elastic material model was used to define the properties of base, geocells and geogrid. A summary of the material properties is listed in Table 4.8 .

Table 4.8 Engineering Properties of Pavement Materials used in the MHGRS

\begin{tabular}{|c|c|c|c|c|c|}
\hline Properties & $\begin{array}{c}\text { Geocell } \\
\text { Reinforced } \\
\text { Base } \\
\end{array}$ & Geocells & $\begin{array}{c}\text { Geogrid } \\
\text { Reinforced } \\
\text { Base } \\
\end{array}$ & $\begin{array}{c}\text { Geogrid } \\
\text { Sheet }\end{array}$ & $\begin{array}{l}\text { Expansive } \\
\text { Subgrade }\end{array}$ \\
\hline $\begin{array}{l}\text { Mass Density, } \rho \\
\left(\mathrm{kg} / \mathrm{m}^{3}\right)\end{array}$ & 2200 & 950 & 2200 & - & 1095 \\
\hline $\begin{array}{c}\text { Elastic Modulus, } \\
\text { E, }(\mathrm{MPa}) \\
\end{array}$ & 2000 & 392 & 2000 & 450 & 179 \\
\hline Poisson's Ratio, v & 0.35 & 0.3 & 0.35 & 0.3 & 0.4 \\
\hline $\begin{array}{l}\text { Internal Angle of } \\
\text { Friction, } \phi\end{array}$ & - & - & - & - & 23.5 \\
\hline $\begin{array}{l}\text { Angle of } \\
\text { Dilation, } \psi\end{array}$ & - & - & - & - & 7.8 \\
\hline $\begin{array}{l}\text { Cohesion, } \\
\mathrm{c}(\mathrm{kPa})\end{array}$ & - & - & - & - & 60 \\
\hline
\end{tabular}




\subsubsection{Boundary Conditions}

Boundary conditions (BC) were used to simulate the boundary effect of the HGRS section in the MHGRS model. The bottom-most surface in the x-z plane of the model was restrained in all three directions using displacement/rotation $\mathrm{BC}$ like the other three models. The outer surfaces in the $x-y$ plane of the model were restricted to move in the z-direction, and the outer surfaces in the $\mathrm{y}-\mathrm{z}$ plane were restricted to move in the $\mathrm{x}$ direction. So all the sides of the model were restricted to any lateral movement of the control model. The pore pressure $\mathrm{BC}$ was used in the top half of the expansive subgrade layer to simulate the source of water and to incorporate HGRS section in the box test. This differential water source condition initiated the differential heave in the model. The model was only able to move in vertical direction (y-direction). Figure 4.23 shows all the $\mathrm{BC}$ in the MHGRS.

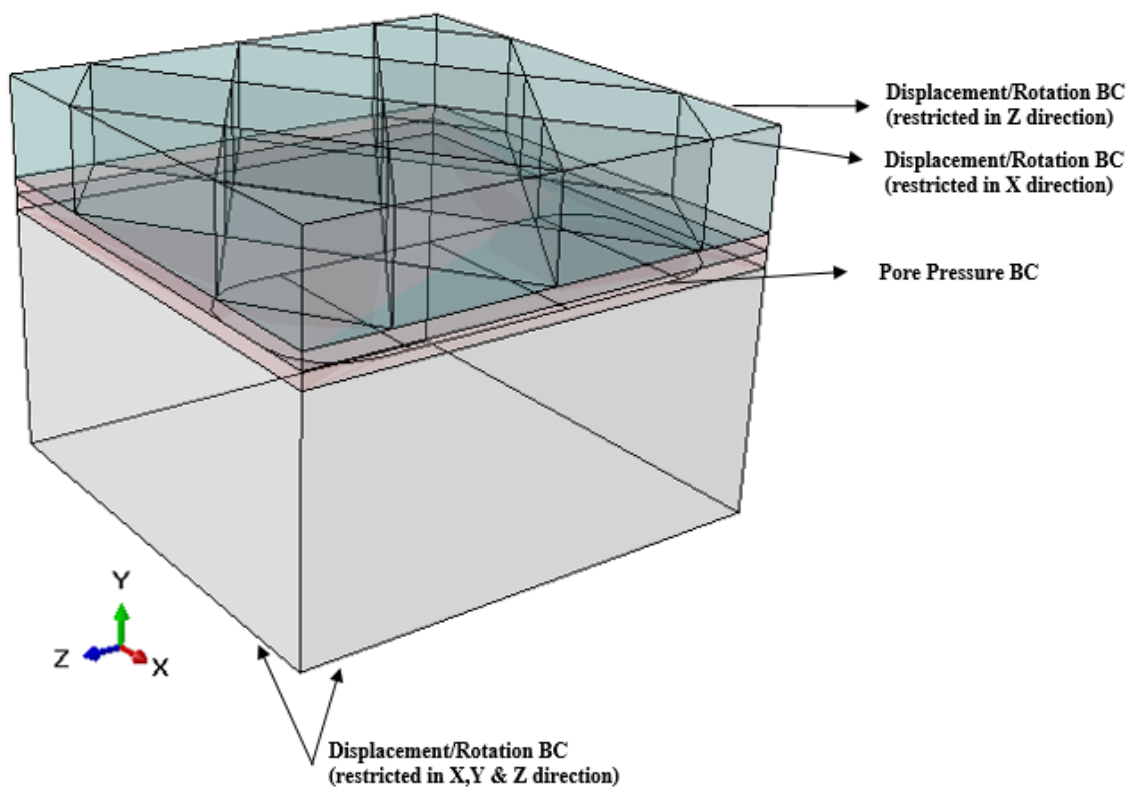

Figure 4.23 Boundary Conditions of MHGRS 


\subsubsection{Mesh Size and Element Type}

Mesh size for the reinforced bases and subgrade was selected as $0.03 \mathrm{~m}$ which was chosen based on convergence study from CSM model. Mesh size of the geocell and geogrid sheet were considered as $0.023 \mathrm{~m}$ and $0.03 \mathrm{~m}$ respectively. Figure 4.24 represents the meshing of overall MHGRS. Considering the materials behavior, C3D8R and C3D8P were selected as element types for bases and subgrade respectively. 4-noded reduced integrated three-dimensional shell element (S4R) was selected for geocells whereas 4noded, quadrilateral membrane reduced integrated element (M3D4R) was chosen for geogrid sheet. Table 4.9 illustrates a brief summary of the element types and element numbers in MHGRS.

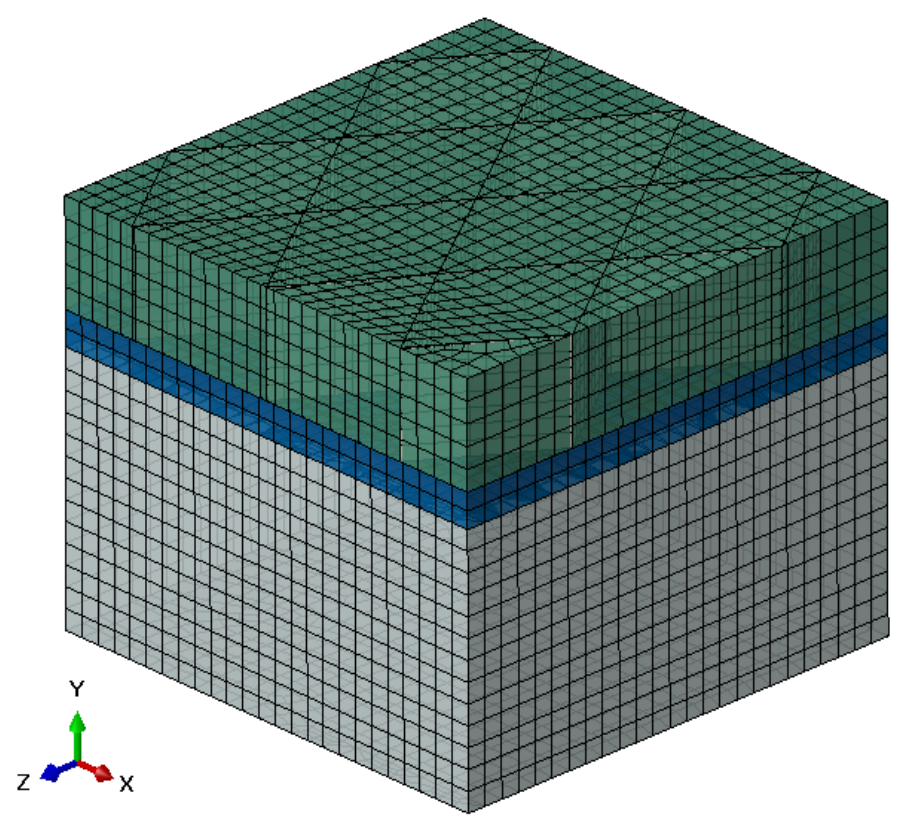

Figure 4.24 Meshing Approach of MHGRS 
Table 4.9 Element Type and Element Numbers in MHGRS

\begin{tabular}{|c|c|c|c|}
\hline Material Type & Element Type & Number of Elements & Thickness (mm) \\
\hline Geocell Reinforced Base & C3D8R & 3325 & 153 \\
\hline Geocell & S4R & 1680 & - \\
\hline $\begin{array}{c}\text { Geogrid Reinforced } \\
\text { Base }\end{array}$ & C3D8R & 1250 & 50 \\
\hline Geogrid Sheet & M3D4R & 625 & 1.5 \\
\hline Expansive Subgrade & C3D8P & 9022 & 381 \\
\hline
\end{tabular}

\subsubsection{Interaction Properties and Initial Conditions}

Tie constraint was used for the interaction between the reinforced bases and subgrade. The top surface of subgrade was used as slave surface and bottom surface of geogrid reinforced base was used as master surface. The top surface of geogrid reinforced base was used as slave surface and bottom surface of geocell reinforced base was used as master surface. Geocells and geogrid sheet were embedded within the base layers using the embedded region constraint. This technique is used to specify an element or a group of elements that lie embedded in a group of host elements whose response will be used to constrain the translational degrees of freedom. It is used to specify that an element or group of elements is embedded in "host" elements. In this model, geocell reinforced base was considered as host element for geocells and geogrid reinforced base was considered as host element for geogrid sheet. The Same initial conditions were followed by the MHGRS. 


\subsection{Calibration Approach and Numerical Analysis Results}

The primary objective of the numerical analysis is to simulate the large-scale box test matrix and predict the heaving precisely. Corresponding material properties, boundary conditions and interactions were used to develop and calibrate the numerical models. Same initial conditions were followed for all the numerical analyses and these conditions were similar to the laboratory box test. Initially, the control model (CSM) was calibrated by controlling the moisture infiltration rate into the subgrade to match the time vs surficial heaving as shown in Figure 4.22. After calibration, identical moisture infiltration rate of control model (CSM) was adopted to calibrate the reinforced models. In the reinforced models, the improvement was quantified using the increased modulus of reinforced base layer. Only the modulus of the reinforced base layer was updated to calibrate the models and match the results from large scale box test. Figure 4.25 shows the calibration results using finite element method (FEM).

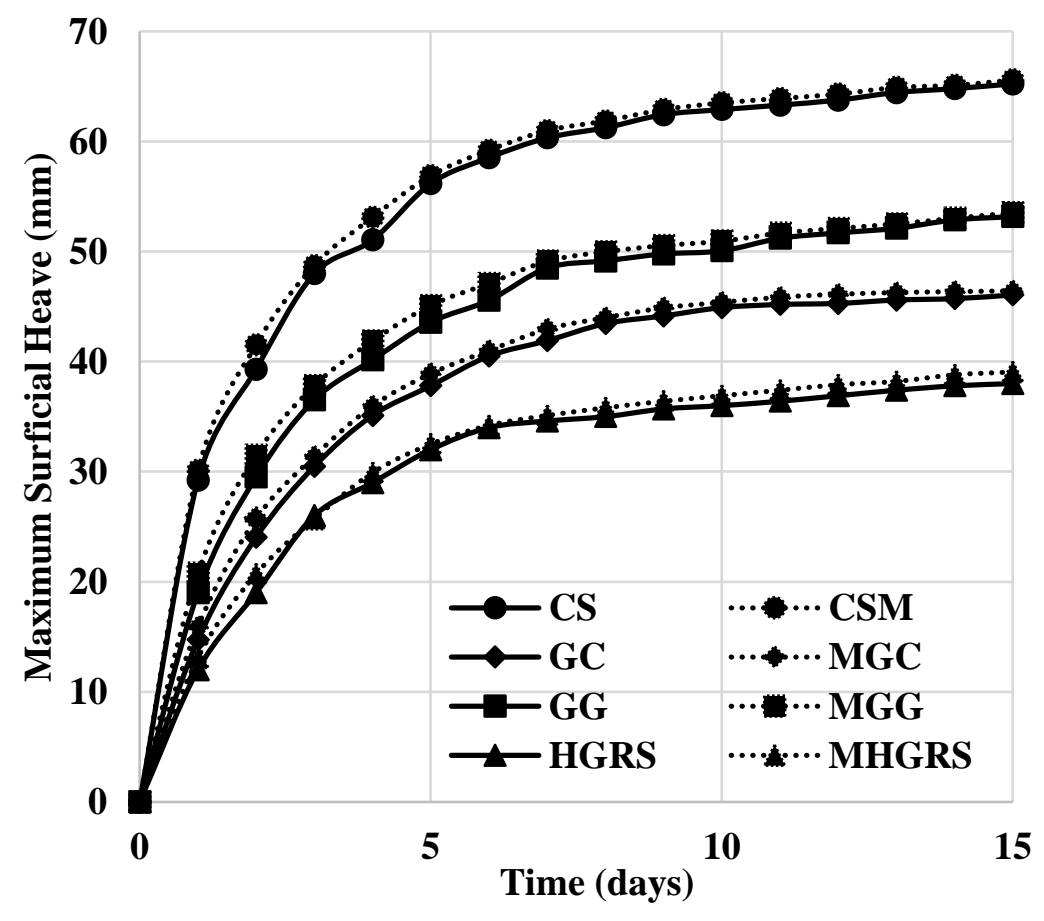

Figure 4.25 Calibration Results from the Numerical Analysis 
Calibration results showed that the numerical analysis predicted the heave quite accurately. The pavement surface above the pore pressure $\mathrm{BC}$ exhibited the maximum surficial heave, on the other hand, minimum surficial heave was measured at the other half of the pavement surface with no pore pressure BC. These trends were followed for all the tests as well as the numerical models. Figure 4.26 shows the results of the numerical models with and without reinforcement.
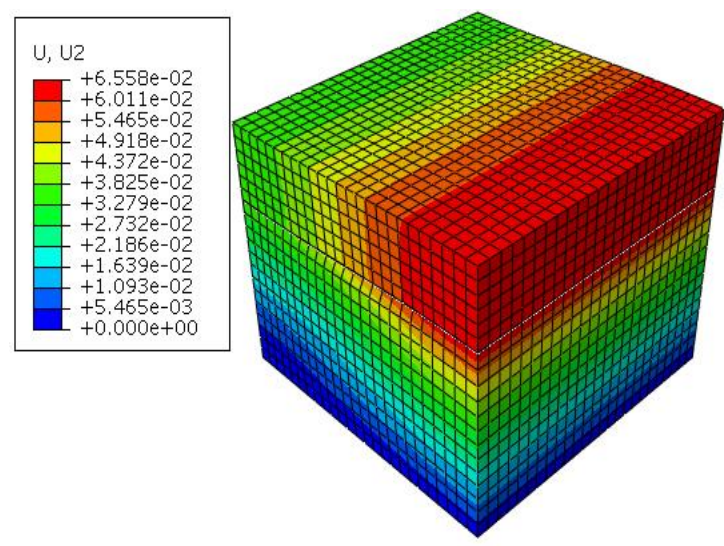

(a) Control Model (CSM)
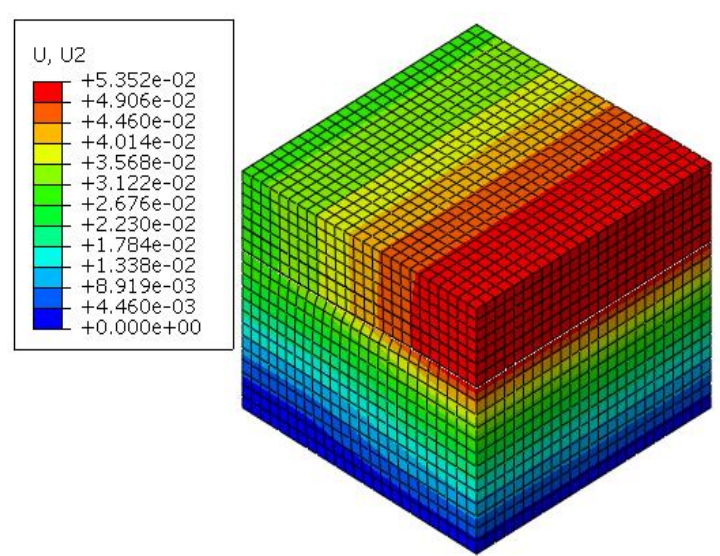

(c) Geogrid (MGG)

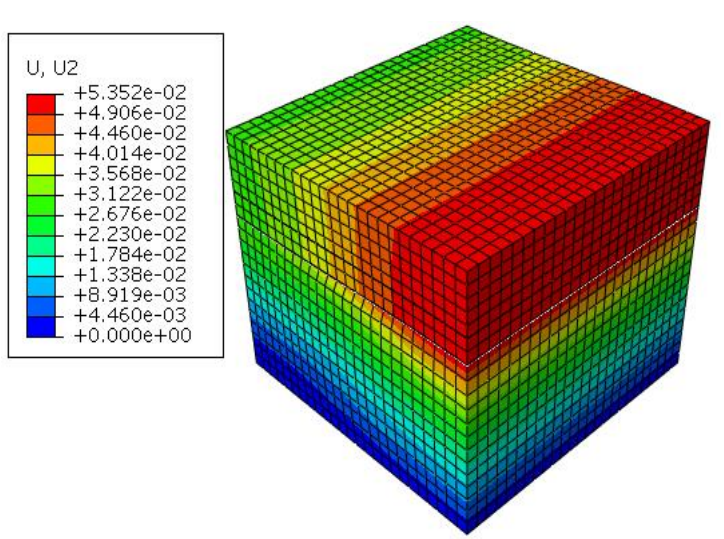

(b) Geocell (MGC)

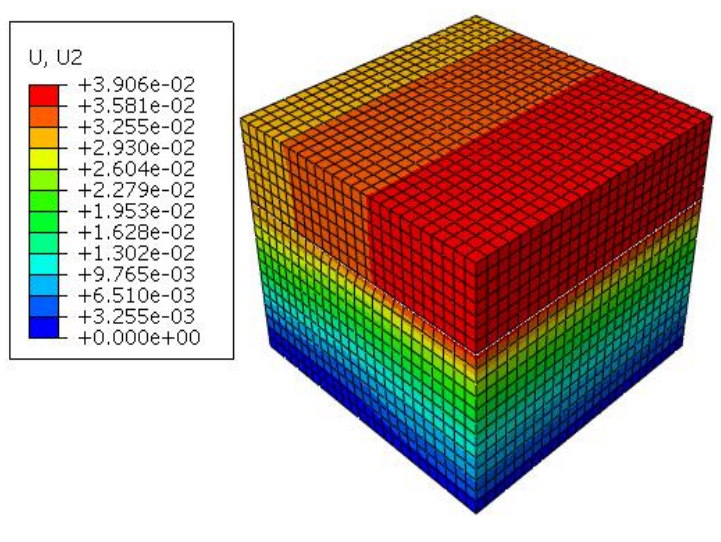

(d) HGRS (MHGRS)

Figure 4.26 Displacement Contours for the Numerical Models

Contour plots from numerical models (as shown in Figure 4.26) clearly show that the geosynthetic reinforcement reduces the maximum vertical deflection as well as 
differential movement compared to CSM. Figure 4.27 illustrates the comparison of the large scale box test and the numerical analysis. Maximum heaving along with the differential heave are closely matched for both lab and numerical analysis.

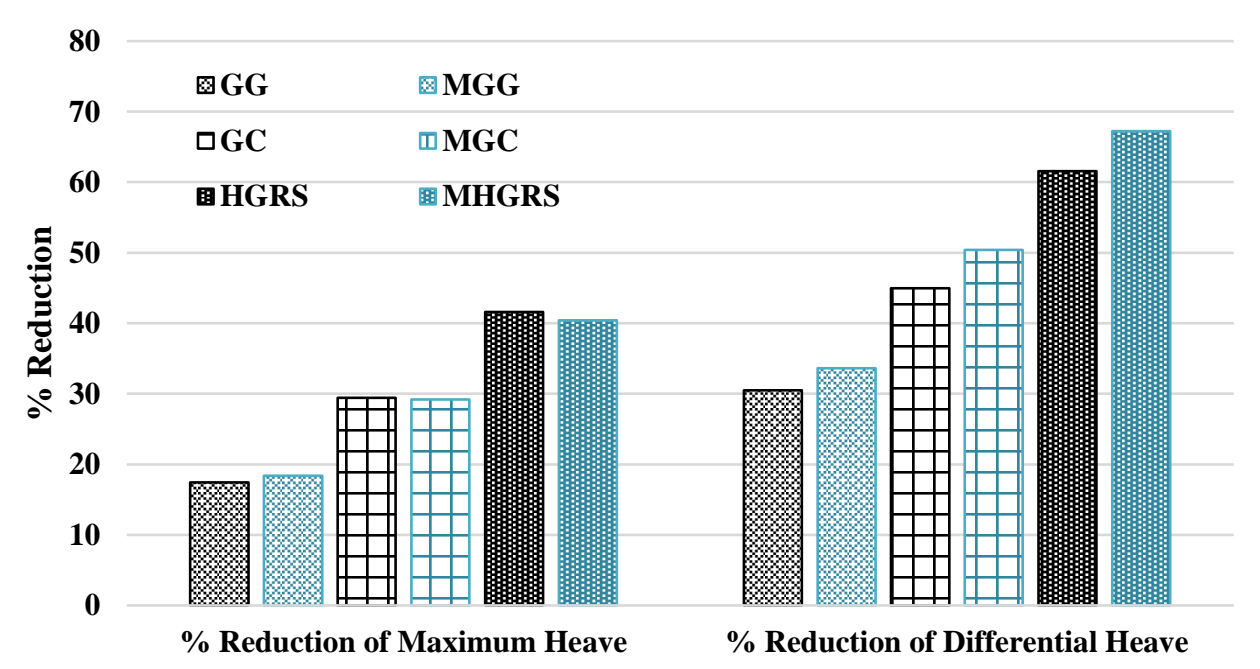

Figure 4.27 Comparison of Experimental and Numerical results

\subsection{Parametric Study to Evaluate HGRS Performance}

A parametric study was conducted to evaluate the factors that can influence the performance of Hybrid Geosynthetic Reinforcement System (HGRS) to mitigate differential heave. Two different parametric features are chosen for the parametric study which is- a) swell characteristics of expansive soils and b) modulus of reinforced base. A detailed procedure of parametric study is discussed, followed by the results of the parametric study in this chapter.

\subsubsection{Varying Subgrade Swell Characteristics}

Two different expansive soil samples were selected for the parametric study. The expansive soils were differentiated by plasticity index (PI). PI is a fair method to classify a soil as expansive soil. According to Department of Army (1983), if the PI of a soil is greater than 35 than it is classified as expansive soil. For the parametric study, soil samples 
were selected in such a way that the PI of ES-1 soil was in between the two soils. That means, one soil was more expansive than ES-1 soil and it was denoted as ES-2. The other soil sample was less expansive than ES-1 soils and denoted as ES-3. Both the soil samples were collected from the same recurrent damaged section of US 95 highway. Characteristics of ES-2 and ES-3 soils were determined from the laboratory analysis. Table 4.10 presents the properties of ES-2 and ES-3 soil samples.

Table 4.10 Properties of the ES-2 and ES-3 Soil Samples

\begin{tabular}{|l|c|c|}
\hline Soil & ES-2 & ES-3 \\
\hline Liquid Limit (\%) & 153 & 83 \\
\hline Plastic Limit (\%) & 66 & 41 \\
\hline Plasticity Index (\%) & 87 & 42 \\
\hline Maximum Dry Density $\left(\mathrm{kg} / \mathrm{m}^{3}\right)$ & 1021 & 1045 \\
\hline Optimum Moisture Content (\%) & $29.6 \%$ & $30 \%$ \\
\hline
\end{tabular}

Soil water characteristic curve and volumetric swell with moisture content were determined by using the same laboratory processes. Figure 4.28 shows the SWCC plot for ES-2 and ES-3 soils and Figure 4.29 represents the volumetric swell test results for ES-2 and ES-3 soils. Same material properties for base and geosynthetics were used for the parametric studies. Calibrated models were used to evaluate the effect of HGRS performance and compared with other geosynthetic materials. 


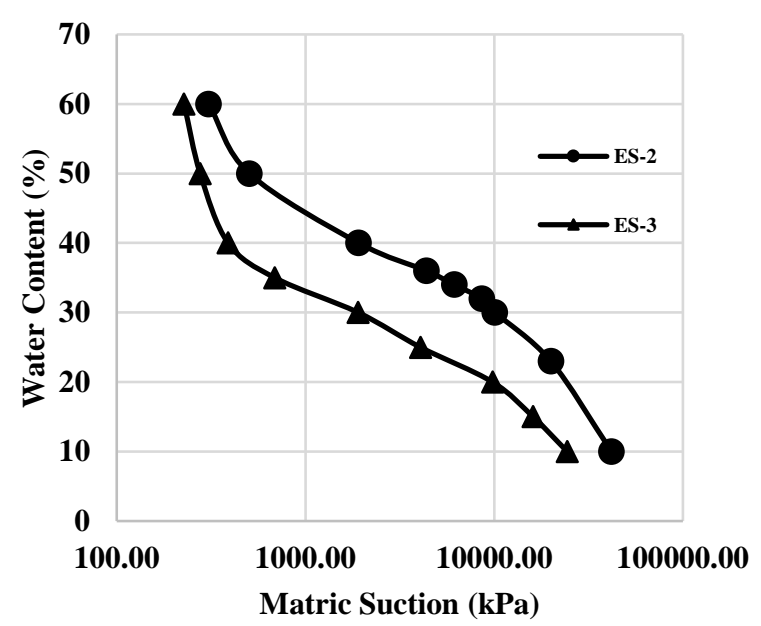

Figure 4.28 SWCC Plots for ES-2 and ES-3

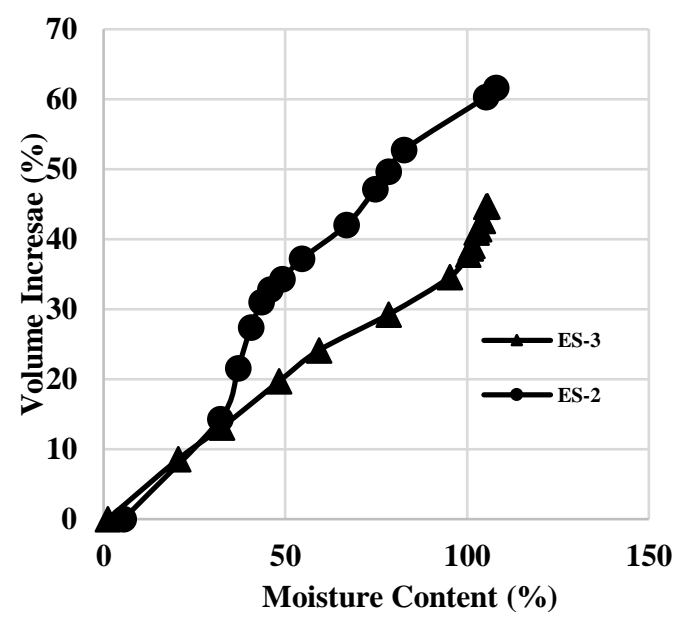

Figure 4.29 Volumetric Swell Test Results for ES-2 and ES-3

To develop the numerical models for ES-2 and ES-3 soils, corresponding geometry, boundary conditions and meshing approaches were followed. SWCC and volumetric swelling data were used to incorporate sorption and moisture swelling models of corresponding soil samples to simulate the swelling behavior. Table 4.11 presents the engineering properties of the respective soil samples as input for the numerical analysis.

Table 4.11 Engineering Properties of ES-2 and ES-3 as Input for Numerical Models

\begin{tabular}{|c|c|c|c|}
\hline Properties & Base & ES-2 & ES-3 \\
\hline Mass Density, $\rho\left(\mathrm{kg} / \mathrm{m}^{3}\right)$ & 2200 & 1020 & 1045 \\
\hline $\begin{array}{c}\text { Elastic Modulus, } \mathrm{E}, \\
(\mathrm{MPa})\end{array}$ & 300 & 185 & 138 \\
\hline $\begin{array}{c}\text { Poisson's Ratio, } v \\
\text { Internal Angle of } \\
\text { Friction, } \phi\end{array}$ & 0.35 & 0.4 & 0.4 \\
\hline Angle of Dilation, $\psi$ & - & 21 & 8.5 \\
\hline Cohesion, c' (kPa) & - & 7 & 46 \\
\hline Initial Void Ratio, $\mathrm{e}_{\mathrm{o}}$ & - & 131 & 1.39 \\
\hline Initial Saturation, $\mathrm{S}_{\mathrm{o}}$ & - & 1.64 & .47 \\
\hline
\end{tabular}


Numerical analysis was conducted for both the soils to measure the effect of HGRS performance. It was found that the swelling potential of the soil had a proportional relationship with the swell characteristics of the expansive soils. Soils with higher swell characteristics exhibited higher heave. The performances of geosynthetic reinforcement were also reflected based on the swelling potential of the soils. Figure 4.30 and Figure 4.31 show the vertical deformation contours for ES-2 and ES-3 soils with HGRS respectively.

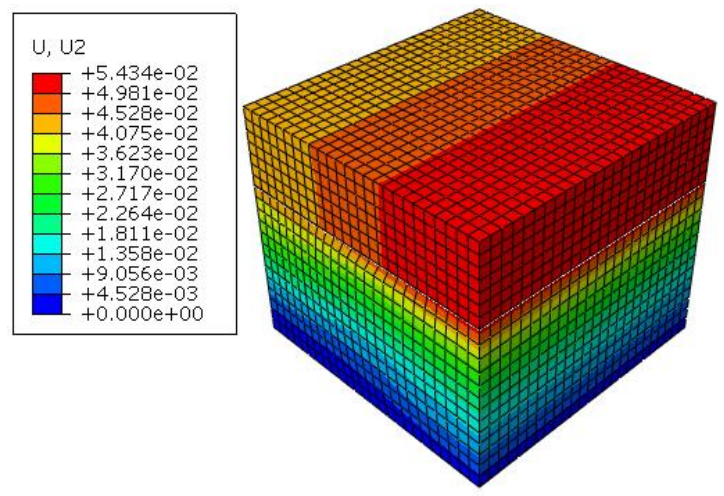

Figure 4.30 Vertical Deformation Contour of HGRS for ES-2

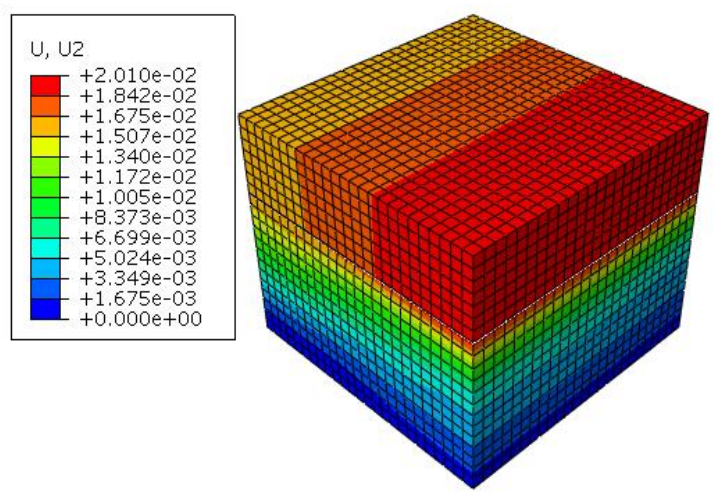

Figure 4.31 Vertical Deformation Contour of HGRS ES-3

Percent reduction of maximum heave and differential heave magnitudes were computed for all geosynthetic-reinforced configurations, the results are plotted in Figure 4.32 and Figure 4.33 respectively. Though the maximum heave decreased with the decrease of swell potential of soils, percent reduction of maximum heave was very minimal for all the soils. On the other hand, reduction of differential heave was increased with the decrease of swell potential of the soils which were between $22.5 \%$ to $70.79 \%$ for different reinforcement combinations with varying soil types. All cases, HGRS showed best performance. Higher percentage of improvement was shown for expansive soil with low swelling potential from this parametric study. 


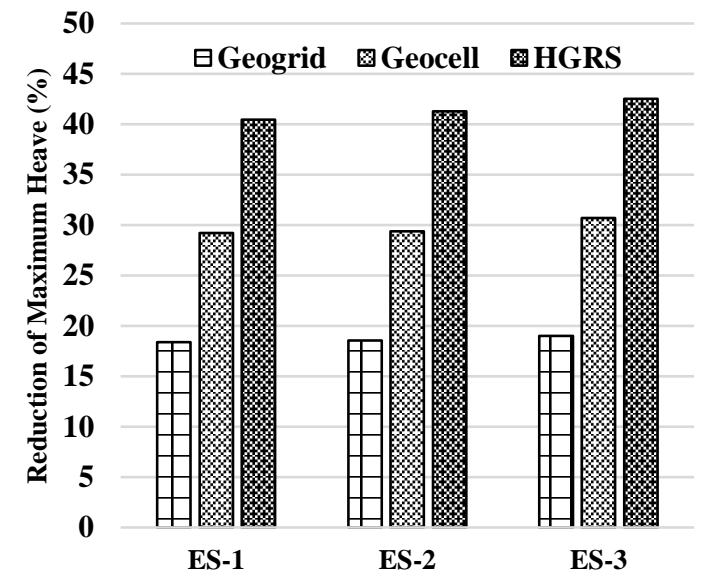

Figure 4.32 Percent Reduction of Maximum Heave for Different soils

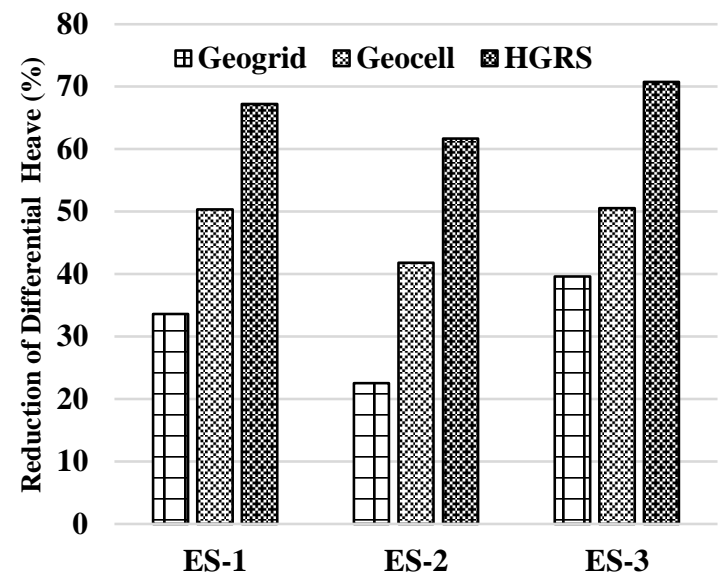

Figure 4.33 Percent Reduction of Differential Heave for Different soils

\subsubsection{Varying Reinforced Base Elastic Modulus}

Inclusion of geosynthetics within the base layer increase the stiffness of base layer (Han et al. 2010; Pokharel 2010; Kief and Rajagopal 2011). A parametric study was conducted with varied elastic modulus value of the reinforced base layer and the performance of HGRS was evaluated and compared with geocells and geogrid reinforcement. The modulus values considered in the current study were: $600 \mathrm{kPa} ; 950$ $\mathrm{kPa} ; 1500 \mathrm{kPa} ; 3000 \mathrm{kPa}$ and $6000 \mathrm{kPa}$. Calibrated models from numerical analysis were used for the parametric study. Maximum and differential heave magnitudes were measured from the numerical analysis corresponding to the different modulus values.

Figure 4.34 and Figure 4.35 present the results of $\%$ reduction for maximum heave and $\%$ reduction for differential heave respectively. As seen from the figures, the reduction of maximum and differential heave at the pavement surface varied between $18 \%$ to $43 \%$ and $33 \%$ to $85 \%$ respectively for different reinforcement combinations with varying modulus of reinforced base layer. It is clearly evident that increasing in modulus results in decreasing the maximum heave as well as differential heave magnitudes and HGRS exhibited the best performance. 


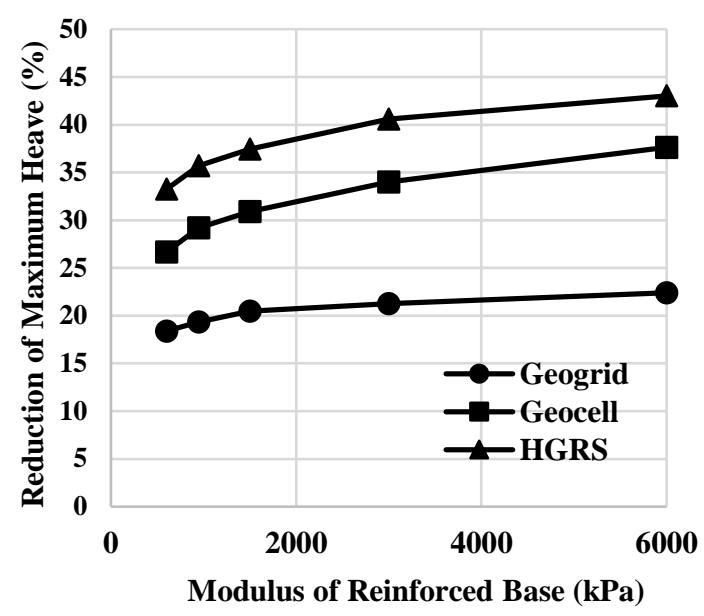

Figure 4.34 \% Reduction of Maximum Heave for Reinforced Base Layer with varying Modulus

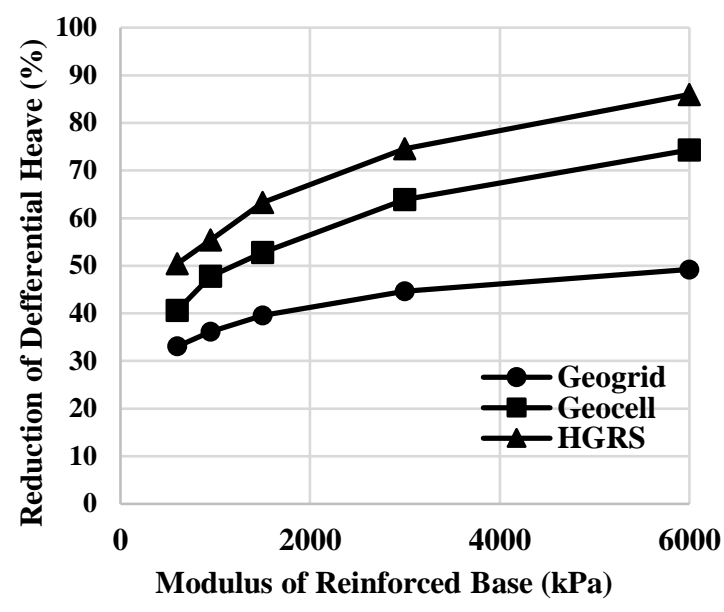

Figure 4.35 \% Reduction of Differential Heave for Reinforced Base Layer with varying Modulus

\subsection{Summary}

This chapter presented the numerical analysis to simulate the large-scale box test results for a pavement section to predict the swelling responses with and without reinforcement. A detailed description of the numerical modeling along with material models were presented in this chapter. The models were calibrated using box test results along with discussions. Finally, results obtained from the parametric study was also presented in this chapter.

The following inferences can be drawn from the numerical analysis results.

1. Numerical approach can predict the heaving potential of expansive soils.

Geosynthetic systems are able to mitigate swelling distresses on the pavement surfaces. And HGRS can exhibit better performance compared to geocells and geogrid.

2. Geocell reinforced base layer can triggered the improvement of swell mitigation in MGC model. Geocell confinement of base course materials was illustrated 
using higher modulus of reinforced base layer which was 3.1 times the unreinforced base layer. This stiffer layer acts as a mattress system to mitigate the swelling.

3. Interlocking and tension effect of geogrid within the base layer was illustrated by the zone of influence. This zone of influence has a higher stiffness than the regular base. From the calibration, it was found that geogrid increased the modulus of unreinforced base by 1.96 times and reduced the heave.

4. Confinement and tension effect both act together in the HGRS system and form a composite layer. This composite layer increases the stiffness of the base layer significantly. From the calibration it was found that the HGRS system increased the modulus of reinforced base by 6.5 times.

5. Parametric study revealed that the reinforcing effect was higher on expansive soils with low swell potential than expansive soils with high swell potential and reinforced base layer with higher elastic moduli exhibited better performance. 


\section{CHAPTER 5: SUMMARY, CONCLUSIONS, AND RECOMMENDATIONS}

\subsection{Introduction}

The final chapter comprises of a brief summary of the research tasks performed under the scope of this research effort, along with important findings. Inferences have been made from the findings of the study to reach conclusions. Lastly, recommendations have been made for future research that would lead to a better understanding of the problem with corresponding solutions.

\subsection{Summary and Conclusions}

The main objective of this research effort was to evaluate the performance of hybrid reinforcement system to mitigate differential heaving problems due to expansive subgrades as a candidate remedial measure. Geocells, Geogrid and HGRS were used for this research effort. A laboratory-based large-scale box system was developed to evaluate the HGRS performance to mitigate swelling distresses in the system. On the other hand, numerical modeling efforts focused on simulating the box test matrix and conducted parametric study to evaluate the effectiveness of HGRS for reducing expansive soilrelated differential heave in pavements. All research objectives were fully accomplished; important findings from the research tasks are summarized below.

1. Large scale-box test results illustrated the evidence of improvement for the geosynthetic reinforcement to mitigate swelling related problem in pavements;

2. Geocell reinforcement led to a $45 \%$ reduction in differential heave whereas geogrid inclusion led to a $31 \%$ reduction; 
3. HGRS combination exhibited the best performance and reduced the differential heave by $62 \%$. The improvement can be illustrated by the combined reinforcing effect (confinement and tension effect) of HGRS over its individual components.

4. Numerical approach simulated the large-scale box system and predicted the heaving phenomenon;

5. The parametric study showed that the soils with higher swell characteristics led to a greater surficial distresses on the pavement surfaces. Reinforcing effect was higher for low swell potential soils than high swell potential soils. Additionally, stiffer reinforced base layer showed better performance for all the geosynthetic configurations.

\subsection{Recommendations for Future Research}

Based on findings from this research study, the following recommendations are made for future research efforts.

1. Development of a full scale field study on pavement section to accommodate the findings of large-scale box test and to evaluate the realistic applicability of HGRS as a remedial measure to mitigate expansive soil-related differential heave in pavements over other mitigation approaches;

2. Evaluation of the reinforcing effect of multi-layer geosynthetic systems over swell related distresses on the pavement.

3. Determination of influencing factor of reinforced base that contributes toward the improvement of the base layer. 


\section{REFERENCES}

ASTM D. 4318-93 (1994). Standard test method for the liquid limit, plastic limit and plasticity index of soils. Annual Book of ASTM Standards 4 (1994): 551-561.

ASTM D5298-10 (2010), Standard test method for measurement of soil potential (suction) using filter paper, ASTM International, West Conshohocken, PA

Abed, A. (2007). Numerical simulation of a trial wall on expansive soil in Sudan. Plaxis Bulletin, 21, 14-18.

Adem, H. H., and Vanapalli, S. K. (2016). Heave prediction in a natural unsaturated expansive soil deposit under a lightly loaded structure. Geotechnical and Geological Engineering, 34(4), 1181-1192.

Adem, H. H., and Vanapalli, S. K. (2013). Constitutive modeling approach for estimating 1-D heave with respect to time for expansive soils. International Journal of Geotechnical Engineering, 7(2), 199-204.

Adem, H. H., \& Vanapalli, S. K. (2015). Review of methods for predicting in situ volume change movement of expansive soil over time. Journal of Rock Mechanics and Geotechnical Engineering, 7(1), 73-86.

Alonso, E. E., Gens, A., and Josa, A. (1990). Constitutive model for partially saturated soils. Géotechnique, 40(3), 405-430.

Alonso, E. E., Vaunat, J., and Gens, A. (1999). Modelling the mechanical behaviour of expansive clays. Engineering Geology, 54(1), 173-183. 
Al-Qadi, I. L., Brandon, T. L., and Bhutta, S. A. (1997). Geosynthetics stabilized flexible pavements (No. Volume 2).

Al-Qadi, I. L., Buttlar, W., Baek, J., and Kim, M. (2009). Cost-effectiveness and performance of overlay systems in Illinois volume 1: effectiveness assessment of HMA overlay interlayer systems used to retard reflective cracking. Illinois Center for Transportation (ICT).

Al-Qadi, I. L., Dessouky, S., Tutumluer, E., and Kwon, J. (2011). Geogrid mechanism in low-volume flexible pavements: accelerated testing of full-scale heavily instrumented pavement sections. International Journal of Pavement Engineering, 12(02), 121-135.

Army, U. S. (1983). Foundations in expansive soils. Technical Manual, Headquarters, Department of the Army.

Barksdale, R. D., Brown, S. F., and Chan, F., (1989). Potential benefits of geosynthetics in flexible pavement systems. National Cooperative Highway Research Program Report No. 315, Transportation Research Board, National Research Council, Washington, DC, USA, $56 \mathrm{p}$.

Bathurst, R. J., and Jarrett, P. M. (1988). Large-scale model tests of geocomposite mattresses over peat subgrades (No. 1188).

Berg, R. R., Christopher, B. R. and Perkins, S.W. (2000). Geosynthetic reinforcement of the aggregate base/subbase courses of flexible pavement structures-GMA white paper II. Geosynthetic Materials Association, Roseville, MN, USA, 176p. 
Black, P. J., and Holtz, R. D. (1999). Performance of geotextile separators five years after installation. Journal of Geotechnical and Geoenvironmental Engineering, 125(5), 404-412.

Bohn, H. L., and McNeal, B. L. (1985). O Connor, GA Soil Chemistry. New York, John Willey \& Sons.

Bolzon, G., Schrefler, B. A., and Zienkiewicz, O. C. (1996). Elastoplastic soil constitutive laws generalized to partially saturated states. Géotechnique, 46(2), 279289.

Bortz, B. S. (2015). Geocellular confinement systems in low-volume paved roads (Doctoral dissertation, Kansas State University).

Briaud, J. L., Zhang, X., and Moon, S. (2003). Shrink test-water content method for shrink and swell predictions. Journal of Geotechnical and Geoenvironmental Engineering, 129(7), 590-600.

Bulut, R., Lytton, R. L., and Wray, W. K. (2001). Soil suction measurements by filter paper. In Expansive clay soils and vegetative influence on shallow foundations (pp. 243-261).

Cancelli, A., Montanelli, F., Rimoldi, P., and Zhao, A., (1996). Full scale laboratory testing on geosynthetics reinforced paved roads. International Symposium on Earth Reinforcement. Fukuoka, pp. 573-578.

Chang, T. T., Chang, C. H., and Pei, S. W. (2007). Investigation of the bearing capacity and dynamic-elastic behavior of mechanical stabilization of sandy subgrade using geocells. In Transportation Research Board 86th Annual Meeting (No. 07-1445). 
Chen, F.H. (1988). Foundations on expansive soils. Elsevier Science Publishing Co., Inc., Amsterdam

Chen, F. H. (2012). Foundations on expansive soils (Vol. 12). Elsevier.

Chittoori, B., Tamim, M. M., Gajurel, A., and Mishra, D. (2017). Evaluating the ability of swell prediction models to predict the swell behavior of excessively high plastic soils. Proceedings of the Second Pan American Conference on Unsaturated Soils, November 12-15, 2017, Texas, USA.

Chittoori, B. C. S., Mishra D., Bruce D., and Ingram J. (2016). Recurrent pavement damage from underlying expansive soil deposits - Idaho experience. 95th Annual Meeting of the Transportation Research Board, January 10-14, 2016, Washington, D.C

Chittoori, S., Pedarla, A., Puppala, A.J., Hoyos, L.R., Nazarian, S, and Saide, S. (2011). Leachate studies on lime and portland cement treated expansive clays. Geo-Fontiers 2011, ASCE.

Coduto, D. P. (2015). Foundation design: principles and practices. Pearson.

Dafalla, M. A., and Shamrani, M. A. (2011). Road damage due to expansive soils: Survey of the phenomenon and measures for improvement. In Design, Construction, Rehabilitation, and Maintenance of Bridges (pp. 73-80).

Das, B. M. (2004), Principles of Geotechnical Engineering, 5th edn, Thomson.

Das, B. M. (2006), Principles of Geotechnical Engineering, 6th edn, Thomson. 
Das, B. M. (2010) "Use of Geogrid in Subgrade-Ballast System of Railroads Subjected to Cyclic Loading for Reducing Maintenance." California State University, Sacramento, USA.

Dash, S. K., Sireesh, S., and Sitharam, T. G. (2003). Model studies on circular footing supported on geocell reinforced sand underlain by soft clay. Geotextiles and Geomembranes, 21(4), 197-219.

Dessouky, S. H. (2015) Pavement Repairs’ Long-Term Performance over Expansive Soil. In IFCEE (pp. 380-387).

Dassault Systemes (2017, October 14). Abaqus Unified FEA. Retrieved from https://www.3ds.com/products-services/simulia/products/abaqus/

Djellali, A., Ounis, A., and Saghafi, B. (2012). Behavior of flexible pavements on expansive soils. International Journal of Transportation Engineering, 1(1), 1-14.

Dondi, G., (1994). Three-dimensional finite element analysis of a reinforced paved road. Proceedings of the Fifth International Conference on Geotextiles, Geomembrane and Related Products, Singapore, pp. 95-100.

EnviroGrid® Geocell. (n.d.). Retrieved May 02, 2017, from http://www.conteches.com/products/erosion-control/temporary-andpermanent/envirogrid-geocell

Estabragh, A. R., Pereshkafti, M. R. S., Parsaei, B., and Javadi, A. A. (2013). Stabilised expansive soil behaviour during wetting and drying. International Journal of Pavement Engineering, 14(4), 418-427. 
Fannin, R.J., and Sigurdsson O. (1996). Field observations on stabilization of unpaved roads with geosynthetics. ASCE Journal of Geotechnical Engineering 122 (7), 544553.

Fredlund D. G. (1997). An introduction to unsaturated soil mechanics. In: Unsaturated soil engineering practice, geotechnical special publication. Reston, Virginia, USA: American Society of Civil Engineers;. pp. 1-37.

Fredlund, D. G., and Hung, V. Q. (2001). Prediction of volume change in an expansive soil as a result of vegetation and environmental changes. In Expansive Clay Soils and Vegetative Influence on Shallow Foundations (pp. 24-43).

Fredlund, D. G., and Morgenstern, N. R. (1976). Constitutive relations for volume change in unsaturated soils. Canadian Geotechnical Journal, 13(3), 261-276.

Fredlund, D. G., and Morgenstern, N. R. (1978). Stress state variables for unsaturated soils. Journal of Geotechnical and Geoenvironmental Engineering, 104(ASCE 14170 Proc Paper).

Fredlund, D. G., and Rahardjo, H. (1993). Soil mechanics for unsaturated soils. John Wiley \& Sons.

Gens, A., and Alonso, E. E. (1992). A framework for the behaviour of unsaturated expansive clays. Canadian Geotechnical Journal, 29(6), 1013-1032.

Giroud, J. P., and Noiray, L. (1981). Geotextile-reinforced unpaved road design. Journal of Geotechnical and Geoenvironmental Engineering, 107(ASCE 16489). 
Giroud, J. P., Ah-Line, C., and Bonaparte, R. (1984). Design of unpaved roads and trafficked areas with geogrids. In Polymer grid reinforcement (pp. 116-127). Thomas Telford Publishing.

Goode, J. C. (1982). Heave prediction and moisture migration beneath slabs on expansive soils. M.S. Thesis, Colorado State University, Fort Collins, CO.

$\mathrm{Gu}, \mathrm{J}$. (2011). Computational modeling of geogrid reinforced soil foundation and geogrid reinforced base in flexible pavement (Doctoral dissertation, Hebei University of Technology).

Gupta, R. (2009). A study of geosynthetic reinforced flexible pavement system.

Guthrie, W. S., and Jackson, K. D. (2015). Laboratory resilient modulus measurements of aggregate base materials in Utah (No. UT-16.12).

Hamberg, D. J. (1985). A simplified method for predicting heave in expansive soils. MSc thesis, Colorado State Univ., Fort Collins, Colo.

Hammitt, G. M., and Ahlvin, R. G. (1973). Membranes and encapsulation of soils for control of swelling. Publication of: Frost I Jord/Norway/, 2(Workshop Proceedings).

Han, J. (2015). Principles and practice of ground improvement. John Wiley \& Sons.

Han, J., Pokharel, S. K., Yang, X., Manandhar, C., Leshchinsky, D., Halahmi, I., and Parsons, R. L. (2011). Performance of geocell-reinforced RAP bases over weak subgrade under full-scale moving wheel loads. Journal of Materials in Civil Engineering, 23(11), 1525-1534.

Hardcastle, J. H. (2003). Evaluation and treatment of expansive volcanic soils US-95, Owyhee County, Idaho. Boise, ID, University of Idaho. 
Haas, R., Walls, J., and Carroll, R.G., (1988). Geogrid reinforcement of granular bases in flexible pavements. Transportation Research Report 1188, 19-27.

Halliday, A.R. and Potter, J.F. (1984). The performance of a flexible pavement constructed on a strong fabric. Transport and Road Research Laboratory, Report 1123, Crowthorne, Berkshire, UK, 15p.

Heyer, L. C. (2012). Swell, stiffness and strength of expansive soil-rubber (ESR) mixtures at various scales: effect of specimen and rubber particle sizes (Doctoral dissertation, Colorado State University. Libraries).

Holtz, R. D., Christopher, B. R., and Berg, R. R. (1997). Geosynthetic Engineering, BiTech Publisher, Richmond, B.C., Canada.

Holtz, W.G. and Gibbs, H.J., (1956). Engineering properties of expansive clays. Transaction of ASCE, Vol. 121, 641-667.

Holtz, R. D., and Kovacs, W. D. (1981). An introduction to geotechnical engineering (No. Monograph).

Hussein, E. A. (2001). Viscoplastic Finite Element Model for Expansive Soils. EJGE paper, 122.

Hussein, M. G., and Meguid, M. A. (2016). A three-dimensional finite element approach for modeling biaxial geogrid with application to geogrid-reinforced soils. Geotextiles and Geomembranes, 44(3), 295-307.

Ingles, O. G., and Metcalf, J. B. (1972). Soil stabilization principles and practice (Vol. 11, No. Textbook). 
Islam, K. M. (2017). Subsurface Characterization of Flexible Pavements Constructed Over Expansive Soil Subgrades and Selection of Suitable Rehabilitation Alternatives. Boise State University Theses and Dissertations. 1305.

Johnson, D., Patrick, D. M., and Division, S. M. (1975). A review of engineering experiences with expansive soils in highway subgrades. Report No. FHWA-RD-7548

Jones, D.E. and Holtz, W.G. (1973). Expansive soils - the hidden disaster. Civil Eng., ASCE, New York, NY pp 87-89, Aug. 1973.

Jones, L. D., and Jefferson, I. (2012). Expansive soils (pp. 413-441). ICE Publishing.

Kao, J. C., Sung, W. P., and Chen, R. (Eds.). (2014). Green building, materials and civil engineering. CRC Press.

Kassiff, G., Livneh, M., and Wiseman, G. (1969). Pavements on expansive soils. Jerusalem Academic Press.

Keif, O. (2015). Hybrid geosynthetic solution for rail tack on expansive clay, Goesynthetics conference, Feb 15-18, 2015, Portland, Oregon.

Kief, O., and Rajagopal, K. (2008). Three dimensional cellular confinement system contribution to structural pavement reinforcement. In Geosynthetics India'08 Seminar.

Kief, O., Schary, Y., and Pokharel, S. K. (2015). High-modulus geocells for sustainable highway infrastructure. Indian Geotechnical Journal, 45(4), 389-400.

Kief, O., Schary, Y., and Pokharel, S. K. (2015). High-modulus geocells for sustainable highway infrastructure. Indian Geotechnical Journal, 45(4), 389-400. 
Khattab, S. A. A, Al Mukhtar. M and Fleureau. M. J (2007). Long term stability characteristics of a lime treated plastic soil. ASCE, Journal of materials in civil engineering, Vol. 19, No. 4, April 2007, pp. 358-366

Khodaii, A., Fallah, S., and Nejad, F. M. (2009). Effects of geosynthetics on reduction of reflection cracking in asphalt overlays. Geotextiles and Geomembranes, 27(1), 1-8.

Koerner, R. M. (2012). Designing with geosynthetics (Vol. 1). Xlibris Corporation.

Kuo, C., Huang, C. (2006). Three-dimensional pavement analysis with nonlinear subgrade materials. Journal of Materials in Civil Engineering, v 18, n 4, August, p 537-544.

Kwon, J., Kim, M., and Tutumluer, E. (2005). Interface modeling for mechanistic analysis of geogrid reinforced flexible pavements. In Advances in pavement engineering (pp. 1-15).

Latha, G. M., and Murthy, V. S. (2007). Effects of reinforcement form on the behavior of geosynthetic reinforced sand. Geotextiles and Geomembranes, 25(1), 23-32.

Leng, J., and Gabr, M. A., (2005), "Numerical Analysis of Stress-deformation Response in Reinforced Unpaved Road Sections”, Geosynthetics International, Vol.12, No.2, pp.111-119.

Leshchinsky, B. A. (2011). Enhancing ballast performance using geocell confinement. In Geo-Frontiers 2011: Advances in Geotechnical Engineering (pp. 4693-4702).

Leshchinsky, B., and Ling, H. (2012). Effects of geocell confinement on strength and deformation behavior of gravel. Journal of Geotechnical and Geoenvironmental Engineering, 139(2), 340-352. 
Leshchinsky, B., and Ling, H. I. (2013). Numerical modeling of behavior of railway ballasted structure with geocell confinement. Geotextiles and Geomembranes, 36, $33-43$.

Lloret, A., and Alonso, E. E. (1980). Consolidation of unsaturated soils including swelling and collapse behaviour. Géotechnique, 30(4), 449-477.

Lytton, R. L., and Kher, R. K. (1970). Prediction of moisture movement in expansive clays. Center for Highway Research, University of Texas at Austin.

Makusa, G. P. (2012). Soil stabilization methods and materials in engineering practice. Luleå, Sweden: Luleå University of Technology.

Malhotra, M., and Naval, S. (2013). Stabilization of Expansive Soils Using Low Cost Materials, 2(11), 181-184.

Marr, S. A., Gilbert, R. B., and Rauch, A. F. (2004). A practical method for predicting expansive soil behavior. In Geotechnical Engineering for Transportation Projects (pp. 1144-1152).

McGown, A., Kupec, J., Heerten, G., and Von Maubeuge, K. (2005). Testing biaxial geogrids for specification and design purposes. In Geosynthetics Research and Development in Progress (pp. 1-11).

McKinney, R. L., Kelly, J. E. and McDowell, C. (1974). The Waco Ponding Project, Research Rep. 188-7, Center for Highway Research, university of Texas at Austin, Texas.

Mitchell, P. W. (1979). The structural analysis of footings on expansive soil. Research Report No. 1. Adelaide, Australia: Kenneth W.G. Smith and Associates. 
Miura, N., Sakai, A., Taesiri, Y., Yamanouchi, T., and Yasuhara, K. (1990). Polymer grid reinforced pavement on soft clay grounds. Geotextiles and Geomembranes, 9(1), 99123.

Nazzal, M. D., Abu-Farsakh, M. Y. and Mohammad, L. N., (2010). Implementation of a critical state two-surface model to evaluate the response of geosynthetic reinforced pavements. International Journal of Geomechanics, Vol. 10, No. 5, p202-212.

Nelson, J.D. and Miller, D.J.(1992). Expansive soils: problems and practice in foundation and pavement engineering. John Wiley \& Sons, Inc. New York.

Nottingham, K. N. (1988). Swelling soils-oregon line to elephant butte.In IntraDepartmental Correspondence to District 3 Materials Engineer, Idaho Transportation Department, p. 23.

Olive, W. W., Chleborad A. F., Frahme C. W., Schlocker J., Schneider R. R., and Shuster R. L. (1989). Swelling clays map of the conterminous United States. US Geological Survey Publication, USGS, USA

Overton, D. D., Chao, K. C., and Nelson, J. D. (2006). Time rate of heave prediction for expansive soils. In GeoCongress 2006: Geotechnical Engineering in the Information Technology Age (pp. 1-6).

Perkins, S.W. and Ismeik, M. (1997). A Synthesis and Evaluation of Geosyntheticreinforced Base Course Layers in Flexible Pavements: Part I Experimental Work. Geosynthetics International, Vol. 4, No. 6, pp. 549-604. 
Perkins, S. W., (2001). Mechanistic-empirical modeling and design model development of geosynthetic reinforced flexible pavements, Montana Department of transportation, Helena, Montana, Report No. FHWA/MT-01-002/99160-1A.

Perkins, S.W., Christopher, B.R., Cuelho, E.L., Eiksund, G.R., Hoff, I., Schwartz C.W., Svanø, G. and Want, A. (2004). Development of design methods for geosynthetic reinforced flexile pavements. FHWA-DTFH61-01-X- 00068, Final report, 263p.

Petry, T.M. and Little, D.N. (2002) Review of stabilization of clays and expansive soils in pavement and lightly loaded structures - History, practice and future. Journal of Materials in Civil Engineering, 14 (6), 447-460.

Plaxis (2017, October 14). New Constitutive Models in FLAC3D 6.0. Retrieved from https://www.itascacg.com/software/products/flac3d/new-in-600/new-constitutive$\underline{\text { models-in-flac } 3 \mathrm{~d}-60}$

Pokharel, S. K. (2010). Experimental study on geocell-reinforced bases under static and dynamic loading (Doctoral dissertation, University of Kansas).

Pokharel, S. K., Han, J., Leshchinsky, D., Parsons, R. L., and Halahmi, I. (2009). Behavior of geocell-reinforced granular bases under static and repeated loads. In Contemporary Topics in Ground Modification, Problem Soils, and GeoSupport (pp. 409-416).

Poor, A.R. (1978), „Experimental Residential Foundation Design on Expansive Clay Soils $^{\text {ee }}$, Rep. No. TR-3-78, Final Rep., Construction Research Center, University of Texas at Arlington, Texas 
Poor, A. R. (1979). Data Supplement for Remedial Measures for Houses Damaged by Expansive Clays. Department of Housing and Urban Development, Office of policy development \& research.

Punthutaecha, K., Puppala, A. J., Vanapalli, S. K., and Inyang, H. (2006). Volume change behaviors of expansive soils stabilized with recycled ashes and fibers. Journal of materials in Civil Engineering, 18(2), 295-306.

Puppala, A. J., Chittoori, B., and Saride, S. (2012). Sulfate induced heaving of a taxiway: a case study. Indian Geotechnical Journal, 42(4), 257-266.

Puppala, A. J., Manosuthikij, T., and Chittoori, B. C. (2013). Swell and shrinkage characterizations of unsaturated expansive clays from Texas. Engineering Geology, 164, 187-194.

Rajeev, P., and Kodikara, J. (2011). Numerical analysis of an experimental pipe buried in swelling soil. Computers and Geotechnics, 38(7), 897-904.

Richards, B. G. (1974). Behavior of unsaturated soils. Soil Mechanics-New Horizons, 112-157.

Saride, S., Sitharam, T. G., and Puppala, A. J. (2011). The function of basal geogrids in minimizing rutting of geocell reinforced subgrades. In Geo-Frontiers 2011: Advances in Geotechnical Engineering (pp. 4645-4652).

Schuettpelz, C., Fratta, D., and Edil, T. (2009). Evaluation of the zone of influence and stiffness improvement from geogrid reinforcement in granular materials. Transportation Research Record: Journal of the Transportation Research Board, (2116), 76-84. 
Sebesta, S. (2002). Investigation of Maintenance Base Repairs over Expansive Soils: Year 1 Report (No. FHWA/TX-03/0-4395-1).

Sheng, D., Fredlund, D. G., and Gens, A. (2008). A new modelling approach for unsaturated soils using independent stress variables. Canadian Geotechnical Journal, 45(4), 511-534.

Sitharam, T.G. and Hedge, A. (2013). "Design and construction of geocell foundation to support the embankment on settled red mud.", Geotextiles and Geomembranes," 41 (2013), 53-63.

Sitharam, T. G., Sireesh, S., and Dash, S. K. (2005). Model studies of a circular footing supported on geocell-reinforced clay. Canadian Geotechnical Journal, 42(2), 693703.

Singh, V. K., Prasad, A., and Agrawal, R. K. (2007). Effect of soil confinement on ultimate bearing capacity of square footing under eccentric-inclined load. The Electronic Journal of Geotechnical Engineering, 12.

Snethen, D. R. (1979). Technical guidelines for expansive soils in highway subgrades (No. FHWA-RD-79-51 Final Rpt.).

Snethen, D. R. (1980). Characterization of expansive soils using soil suction data. In Expansive Soils: (pp. 54-75). ASCE.

Sorensen, K. K., and Okkels, N. (2013). Correlation between drained shear strength and plasticity index of undisturbed overconsolidated clays. In Proceedings of the 18th International Conference on Soil Mechanics and Geotechnical Engineering, Paris (pp. 1-6). 
Steinberg, M. L. (1977). Ponding an expansive clay cut: evaluations and zones of activity. Transportation Research Record, (641).

Steinberg M (1998) Geomembranes and the control of expansive soils in construction. McGraw-Hill, New York.

TenCate. (n.d.). Retrieved October 09, 2017, from http://www.tencate.com/amer/geosynthetics/knowledge-library/technical-datasheets/default.aspx

Thu, T. M., Rahardjo, H., and Leong, E. C. (2007). Elastoplastic model for unsaturated soil with incorporation of the soil-water characteristic curve. Canadian Geotechnical Journal, 44(1), 67-77.

Tsorani, G. (2008). Neoweb technical properties, technical paper, PRS, Tel-Aviv.

U.S. Route 95. (2016, December 24). In Wikipedia, The Free Encyclopedia. Retrieved 09:07, March 2, 2017, from https://en.wikipedia.org/w/index.php? title=U.S._Route_95\&oldid=756406284.

Vessely, M., and Wu, J. (2002). Feasibility of geosynthetic inclusion for reducing swelling of expansive soils. Transportation Research Record: Journal of the Transportation Research Board, (1787), 42-52.

Vu, H. Q., and Fredlund, D. G. (2002). Using volume change indices for twodimensional swelling analysis. In Proceedings of the 55th Canadian geotechnical and 3rd joint IAHCNC and CGS groundwater specialty conferences, Niagara Falls, Ontario, Canada (pp. 505-11). 
Vu, H. Q., and Fredlund, D. G. (2004). The prediction of one-, two-, and threedimensional heave in expansive soils. Canadian Geotechnical Journal, 41(4), 713737.

Vu, H. Q., and Fredlund, D. G. (2006). Challenges to modelling heave in expansive soils. Canadian Geotechnical Journal, 43(12), 1249-1272.

Webster, S. L. (1981). Investigation of Beach Sand Trafficability Enhancement Using Sand-Grid Confinement and Membrane Reinforcement Concepts. Report 2. Sand Test Sections 3 and 4 (No. WES/TR/GL-79-20). ARMY ENGINEER WATERWAYS EXPERIMENT STATION VICKSBURG MS GEOTECHNICAL LAB.

Webster, S. L., and Alford, S. J. (1978). Investigation of Construction Concepts for Pavements across Soft Ground (No. WES-TR-S-78-6). ARMY ENGINEER WATERWAYS EXPERIMENT STATION VICKSBURG MISS.

Webster, S. L., and Watkins, J. E. (1977). Investigation of construction techniques for tactical bridge approach roads across soft ground (No. WES-TR-S-77-1). ARMY ENGINEER WATERWAYS EXPERIMENT STATION VICKSBURG MISS.

West, T. R. (1995), Geology Applied to Engineering, Prentice Hall. Workplace Health and Safety Queensland 2007, Risk Management Code of Practice 2007, Supplement 1 -Hazard Identification

Wheeler, S. J., Sharma, R. S., and Buisson, M. S. R. (2003). Coupling of hydraulic hysteresis and stress-strain behaviour in unsaturated soils. Géotechnique, 53(1), 4154. 
Wong, T. T., Fredlund, D. G., and Krahn, J. (1998). A numerical study of coupled consolidation in unsaturated soils. Canadian Geotechnical Journal, 35(6), 926-937.

Woodward-Clude-Sherard and Associates. (1968). Final report of field survey: Remedial methods applied to houses damaged by high volume change soils. Federal Housing Administration, FHA Contract H-799, 94.

Wray W. K. (1997). Using soil suction to estimate differential soil shrink or heave. In: Unsaturated soil engineering practice, geotechnical special publication 68. Reston, Virginia, USA: American Society of Civil Engineers. pp. 66-87

Wray, W. K., El-Garhy, B. M., and Youssef, A. A. (2005). Three-dimensional model for moisture and volume changes prediction in expansive soils. Journal of Geotechnical and Geoenvironmental Engineering, 131(3), 311-324.

Yang, X. (2010). Numerical analyses of geocell-reinforced granular soils under static and repeated loads (Doctoral dissertation, University of Kansas).

Yuu, J., Han, J., Rosen, A., Parsons, R. L., and Leshchinsky, D. (2008, March). Technical review of geocell-reinforced base courses over weak subgrade. In First Pan American geosynthetics conference, Cancun, Mexico (pp. 2-5).

Zhang, X. (2005). Consolidation theories for saturated-unsaturated soils and numerical simulation of residential buildings on expansive soils (Doctoral dissertation, Texas A\&M University).

Zhou, H., and Wen, X. (2008). Model studies on geogrid-or geocell-reinforced sand cushion on soft soil. Geotextiles and Geomembranes, 26(3), 231-238. 
Zornberg, J. G. (2011). Advances in the use of geosynthetics in pavement design. Geosynthetics India'11, 23-24 September 2011, IIT Madras, Chennai PP $1,21$.

Zornberg, J. G., and Gupta, R. (2009). Reinforcement of pavements over expansive clay subgrades. In Proceedings of the 17th International Conference on Soil Mechanics and Geotechnical Engineering (Vol. 1, pp. 765-768).

Zornberg, J. G., and Gupta, R. (2010). Geosynthetics in pavements: North American contributions. In Theme Speaker Lecture, Proceedings of the 9th International Conference on Geosynthetics, Guarujá, Brazil, May (Vol. 1, pp. 379-400).

Zornberg, J. G., Prozzi, J. P., Gupta, R., Luo, R., McCartney, J. S., Ferreira, J. Z., and Nogueira, C. (2008). Validating mechanisms in geosynthetic reinforced pavements (No. FHWA/TX-08/0-4829-1).

Zornberg, J. G., Roodi, G. H., Ferreira, J., and Gupta, R. (2012). Monitoring performance of geosynthetic-reinforced and lime-treated low-volume roads under traffic loading and environmental conditions. In GeoCongress 2012: State of the Art and Practice in Geotechnical Engineering (pp. 1310-1319). 


\section{APPENDIX A}

\section{Large-Scale Box Test Materials Characterization}




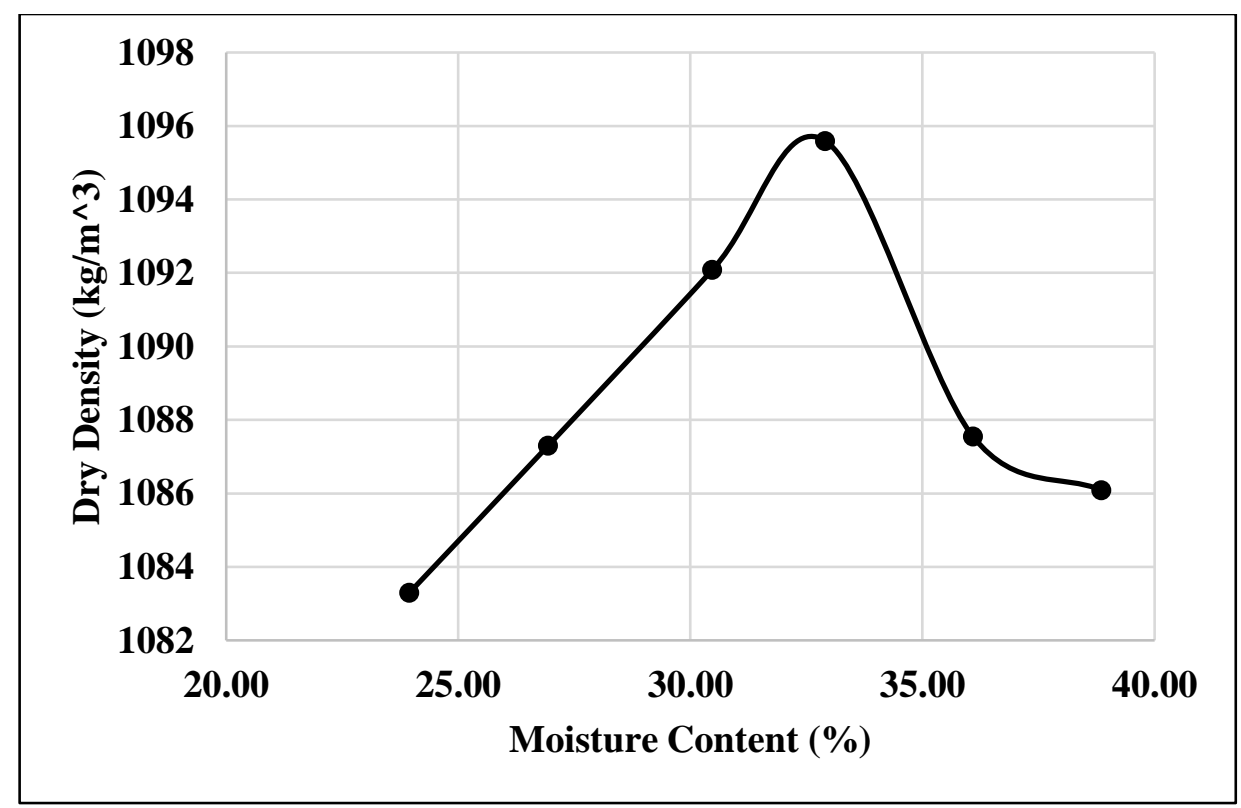

Figure B-1 Moisture -Density Relationship for ES-1

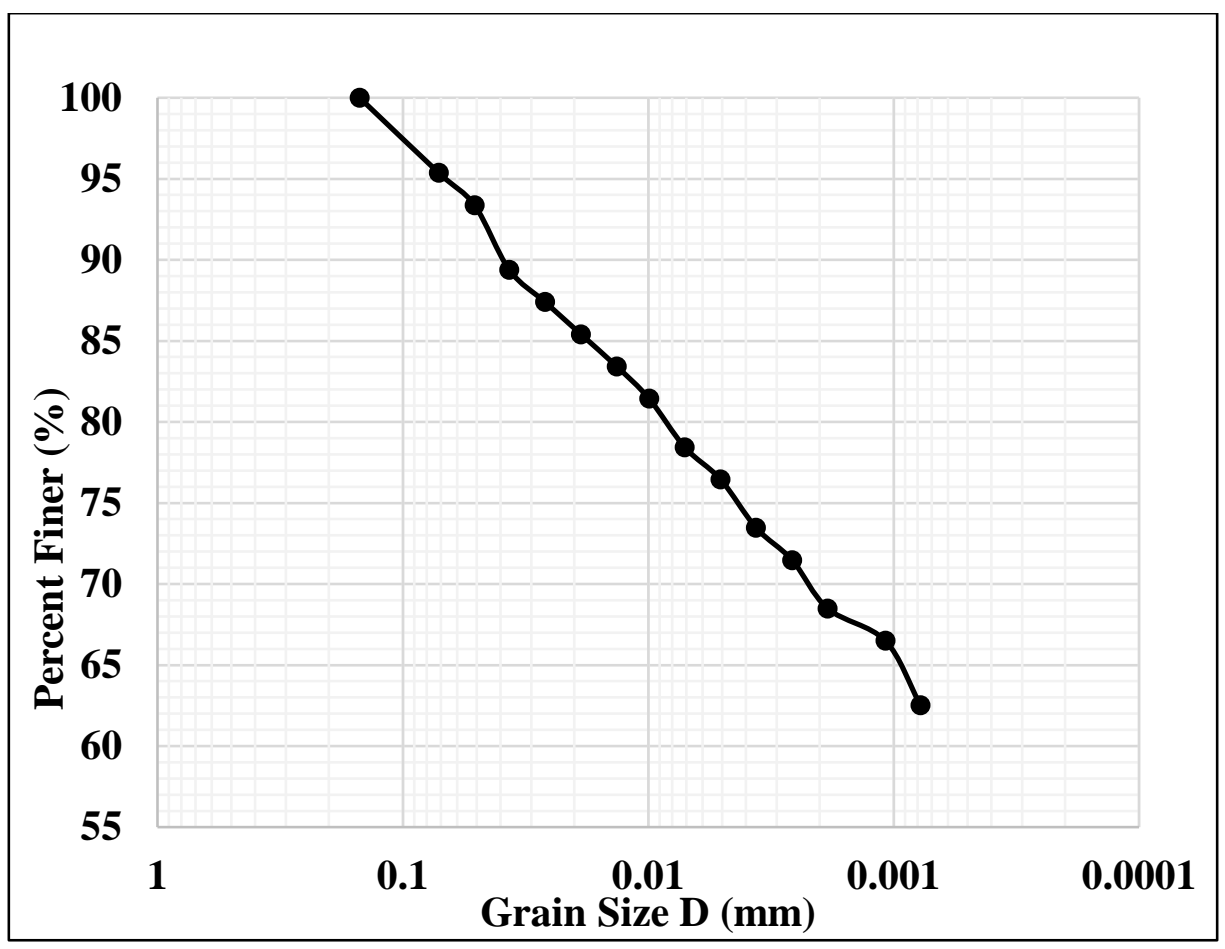

Figure B-2 Hydrometer Analysis Results of ES-1 


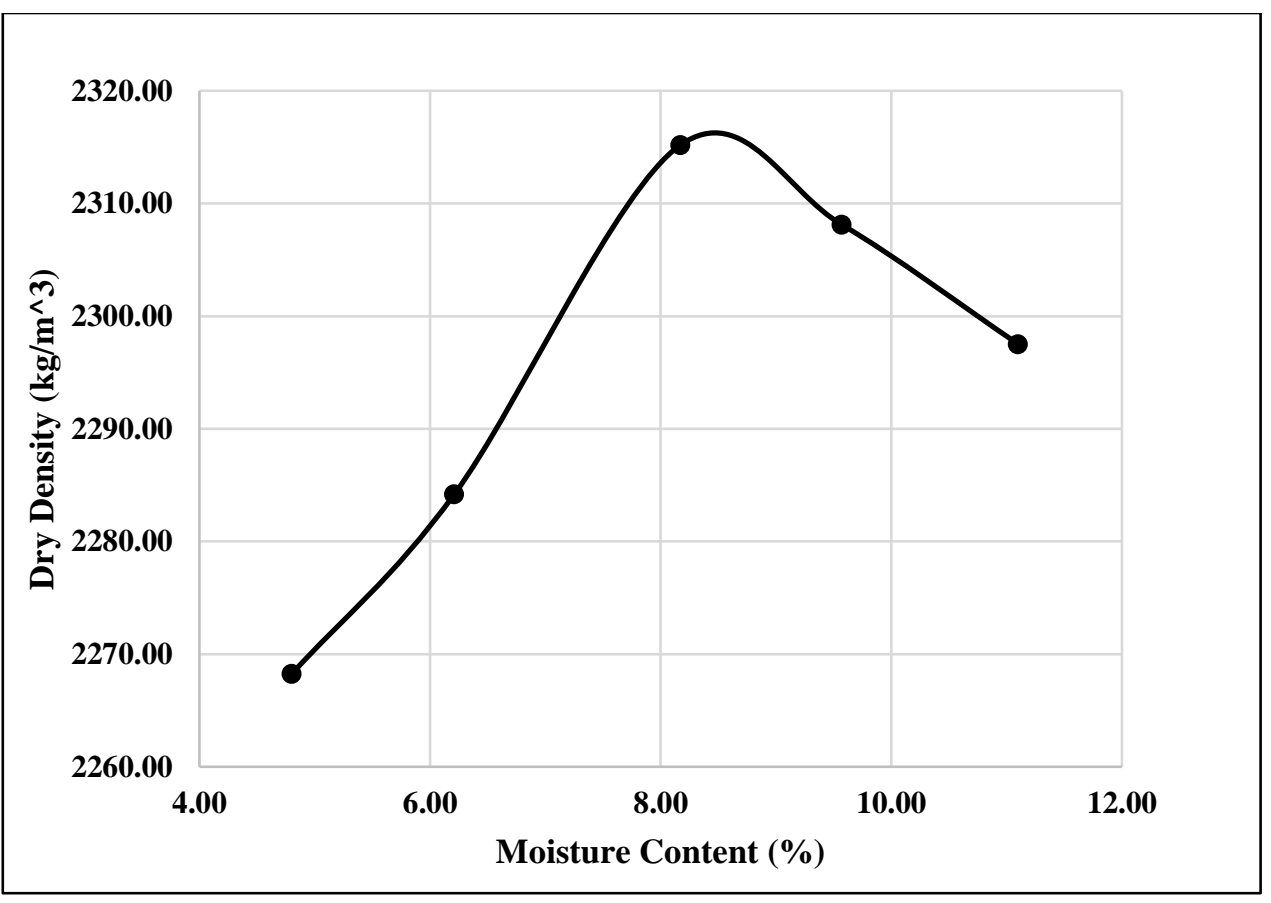

Figure B-3 Moisture-Density Relationship of Base Course Material

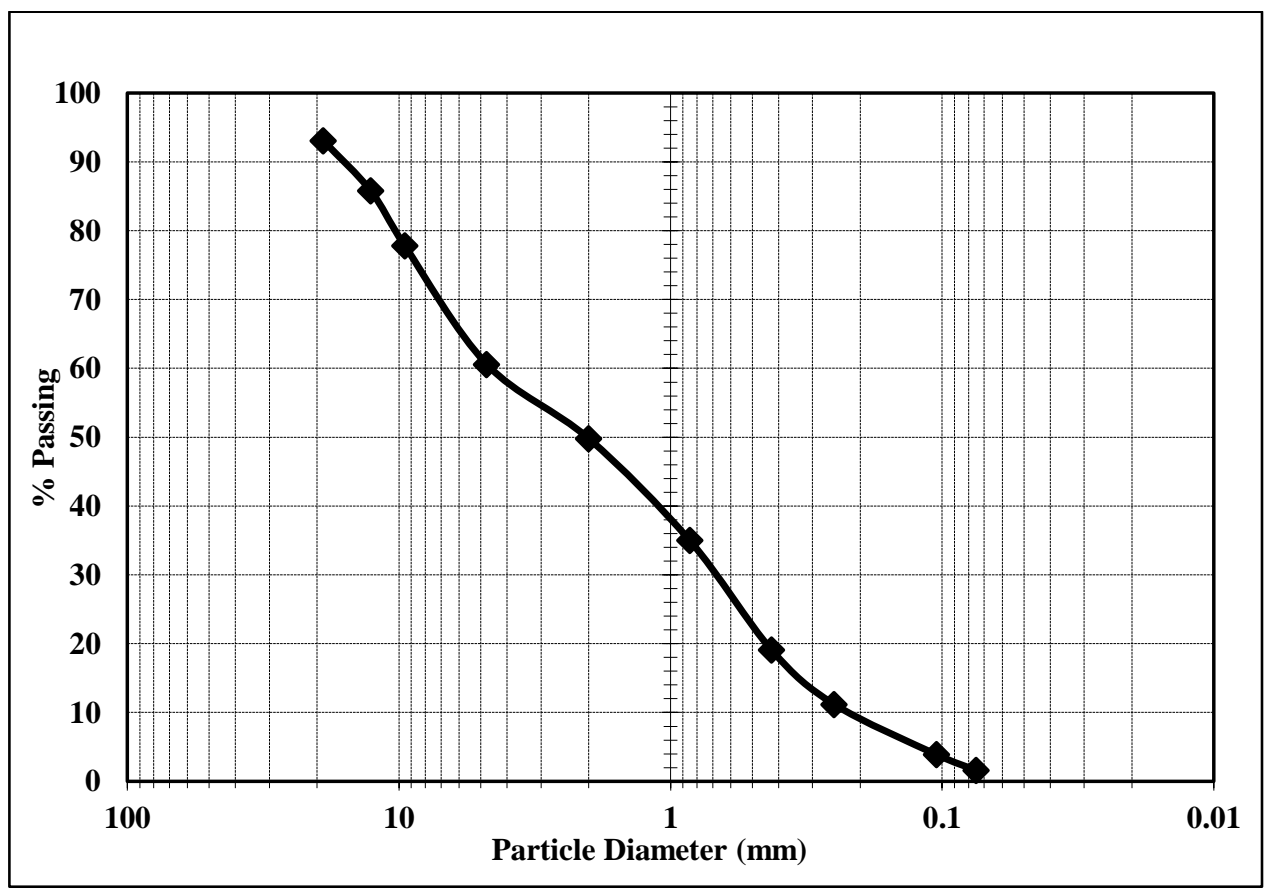

Figure B-4 Gradation Plot for Base Course Material 


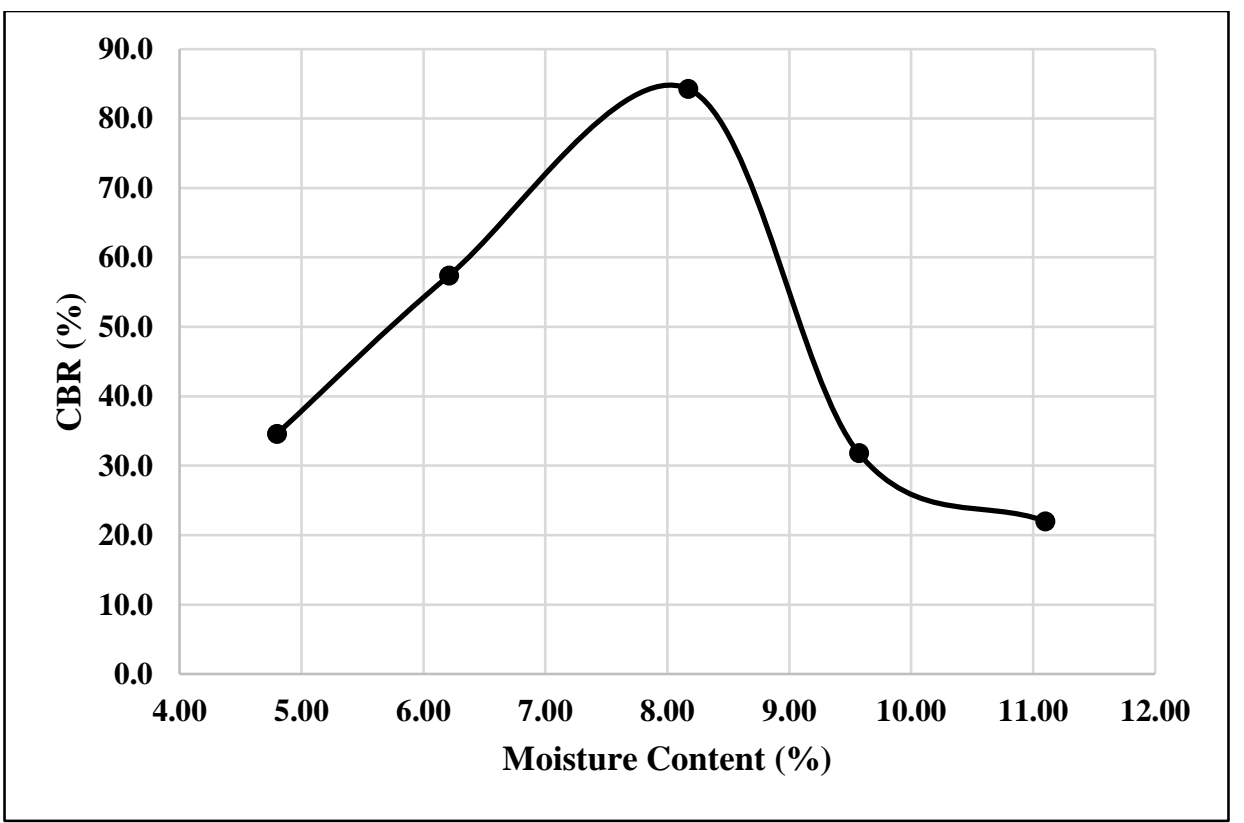

Figure B-5 CBR plot for Base Course Material

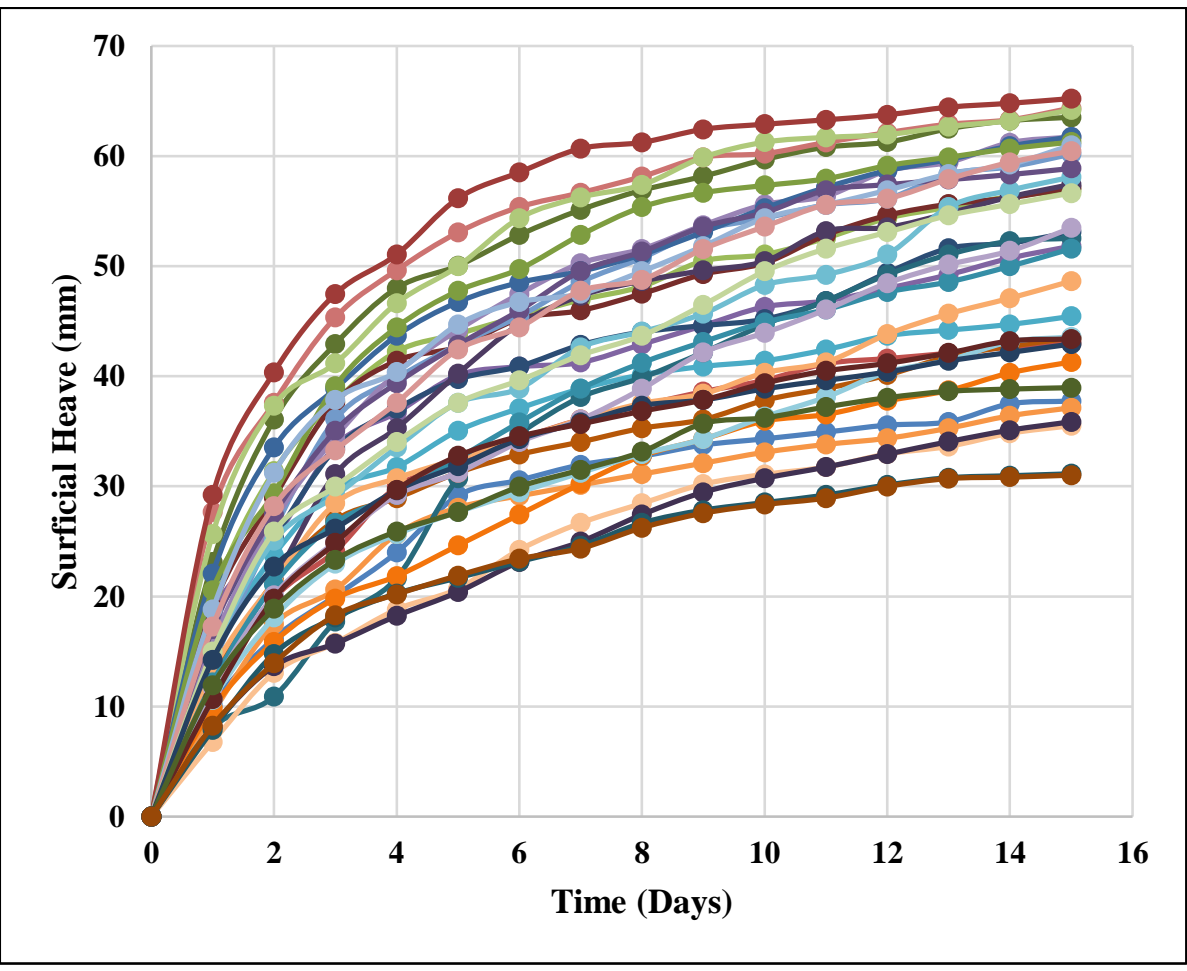

Figure B-5 Swelling data for Control Section (CS) 


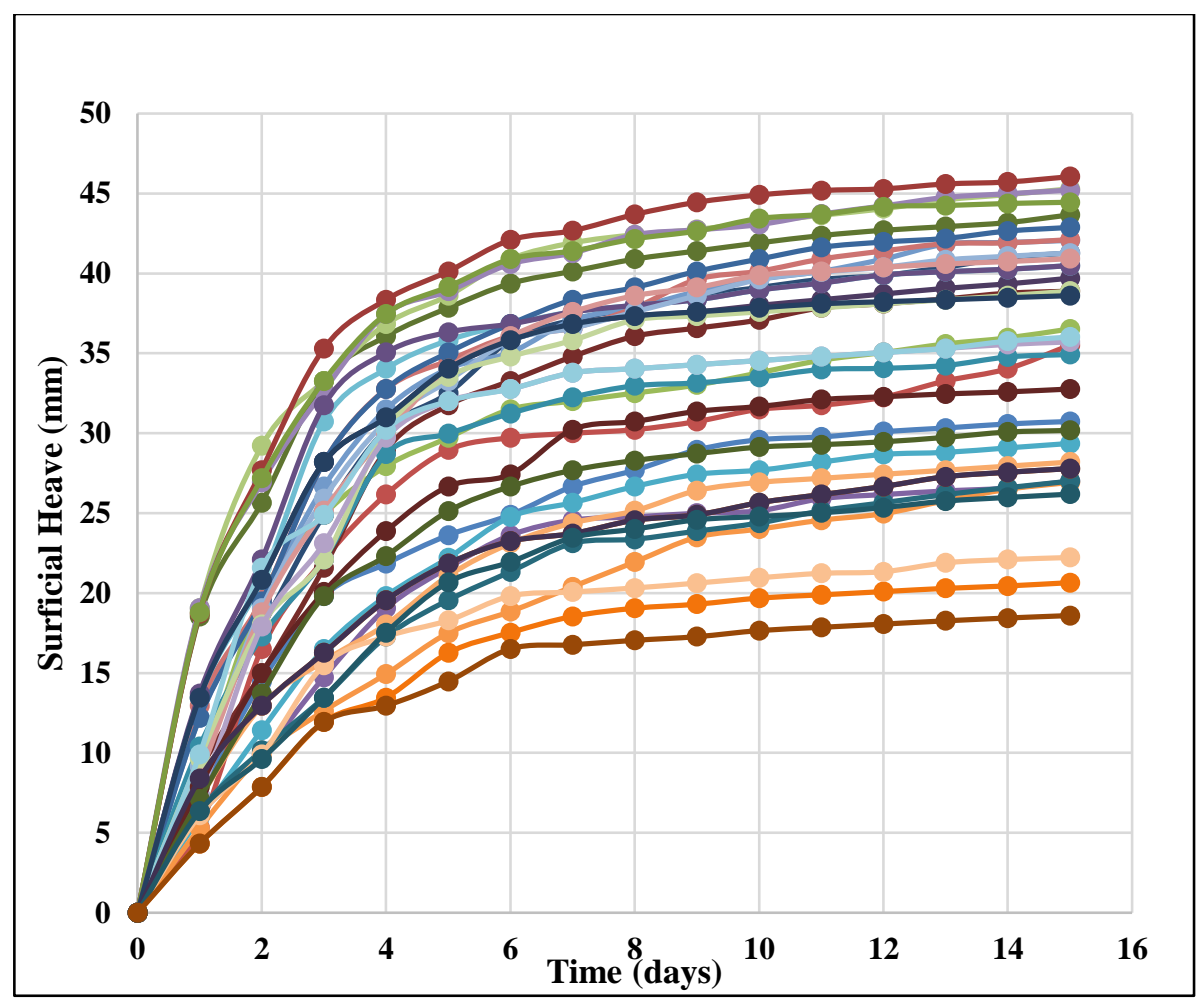

Figure B-6 Swelling data for GC Section

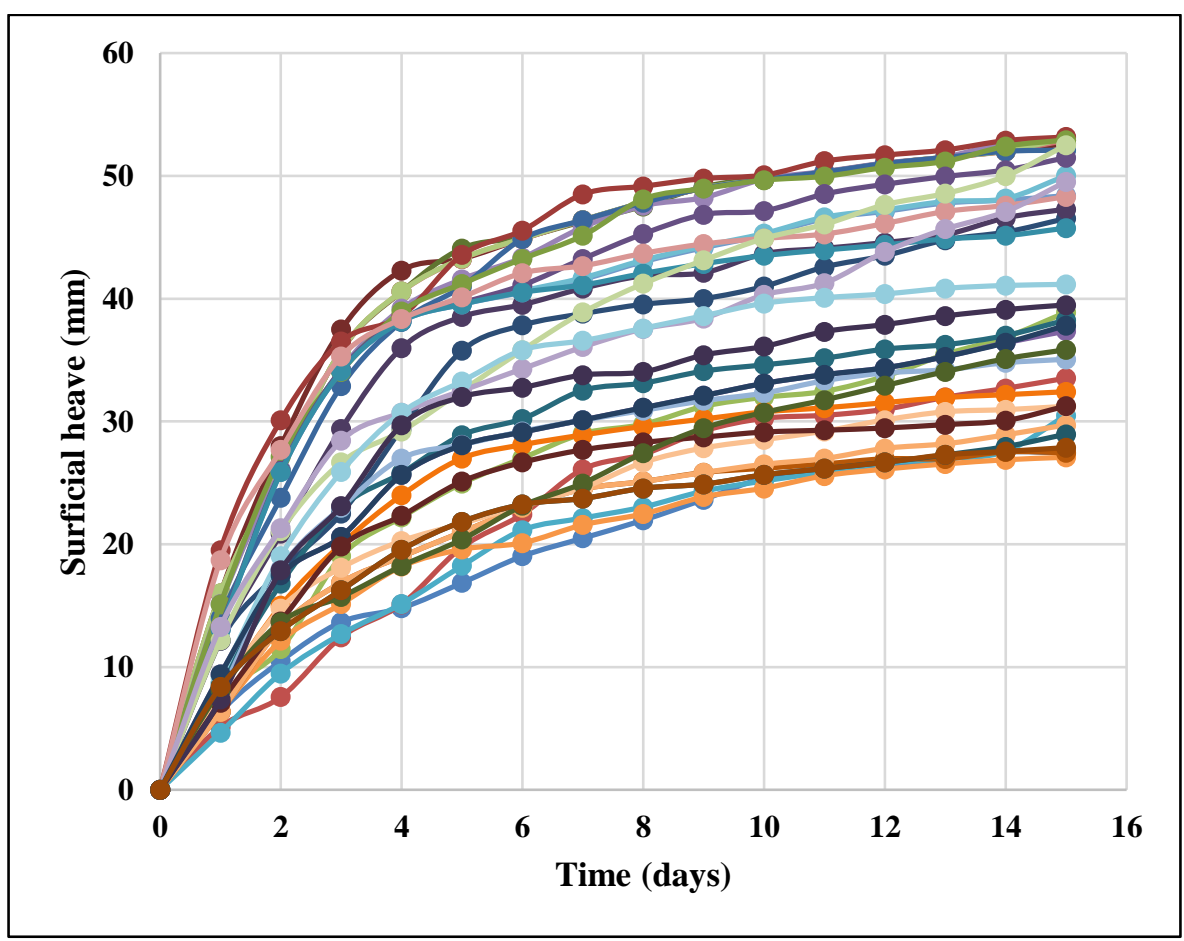

Figure B-7 Swelling data for GG Section 


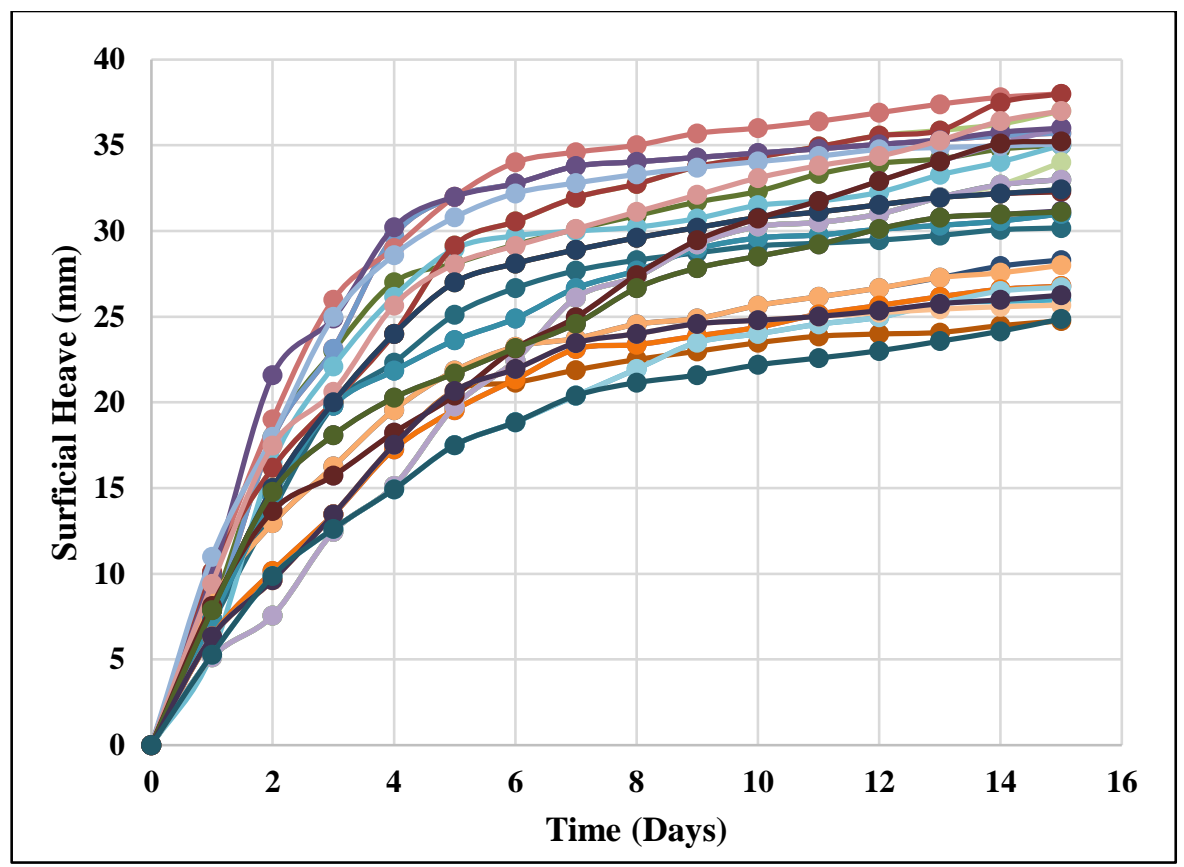

Figure B-8 Swelling data for HGRS Section 